\title{
Le Livre de la Terre \\ À propos du sens de lecture d'une composition funéraire de l'Égypte ramesside
}

Par

\section{Léna Pleuger*}

Université catholique de Louvain

$\mathrm{L}$

e mystère de la course nocturne du soleil et de sa régénération quotidienne a fasciné les anciens Égyptiens. Dès l'Ancien Empire, ils ont cherché à comprendre ce phénomène et à l'expliquer dans des textes à vocation funéraire. Au Nouvel Empire, ceux-ci sont largement illustrés et décrivent le parcours de la barque solaire à travers les espaces géographiques de son trajet nocturne : à la XVIII ${ }^{\mathrm{e}}$ dynastie apparaissent le Livre de l'Amdouat et le Livre des Portes; à la XIX ${ }^{\mathrm{e}}$ dynastie s'ajoutent les compositions que l'égyptologie actuelle désigne comme le Livre des Cavernes et le Livre de la Terre, représentées pour la première fois sur les parois du cénotaphe de Séthi I ${ }^{\text {er }}$ à Abydos et dont l'étude fut initiée par Piankoff.

C'est Piankoff qui identifia le Livre de la Terre, d'abord dans la tombe de Padiaménopé (TT 33), et il le désigna alors comme le «Livre d'Aker ${ }^{1}$. À partir de 1953, s'intéressant à

\footnotetext{
${ }^{*}$ Cet article est issu du mémoire de master intitulé «Le Livre de la Terre. Étude des scènes majeures et de leurs textes », présenté à l'Université catholique de Louvain en août 2019.

${ }^{1}$ PIANKoff 1946.
} 
l'exemplaire de la tombe de Ramsès VI (KV 9), il préféra l'appellation «Création du disque solaire $»^{2}$. Quant au nom «Livre de la Terre », il a été introduit en 1972 par Hornung (« Buch von der Erde $»)^{3}$.

\section{Introduction}

Le Livre de la Terre est principalement attesté dans les tombes royales de la Vallée des Rois, aux $\mathrm{XIX}^{\mathrm{e}}$ et $\mathrm{XX}^{\mathrm{e}}$ dynasties, ainsi qu'à Tanis, dans la tombe d'Osorkon II, à la XXII ${ }^{\mathrm{e}}$ dynastie. Comme les autres livres funéraires, il sera progressivement employé par les particuliers : plusieurs versions de son corpus de scènes ont été identifiées dans des tombes privées de la région thébaine ${ }^{4}$, ainsi qu'à Saqqara ${ }^{5}$. Le Livre de la Terre sera également figuré sur du mobilier funéraire (sarcophages royaux ou privés), ainsi que sur des papyrus. La thèse de Roberson, publiée en 2012, qui offre le premier catalogue complet des exemplaires, des scènes et des textes du Livre de la Terre, distingue 78 ou 79 scènes au total ${ }^{6}$.

\section{a. La localisation du Livre de la Terre dans les chambres funéraires royales ramessides}

Dans les tombes royales de la XVIII ${ }^{\mathrm{e}}$ dynastie, c'est le Livre de l'Amdouat qui ornait les parois des chambres funéraires ${ }^{7}$. Un ciel étoilé recouvrait le plafond plat, comme c'est le cas chez Touthmôsis III, et le plan des tombes était complexe avec un ou plusieurs changements de direction. À la XIX ${ }^{\mathrm{e}}$ dynastie, la structure interne de la tombe évolue au profit d'un plan axial, composé d'une succession de couloirs en enfilade qui mènent à la chambre funéraire. Les chambres funéraires ramessides ont généralement des plafonds voûtés ornés de figurations de la déesse Nout.

Pour Roberson ${ }^{8}$, l'architecture de ces dernières représente symboliquement l'horizon-akhet à travers lequel le soleil se lève chaque matin. Son hypothèse repose sur les arguments suivants : le haut des murs courbés par la voûte évoque la forme des deux collines du signe akhet; la présence presque systématique de la représentation du ciel au plafond crée un microcosme terre-ciel; la figure de Nout suggère une orientation dictée par le modèle biologique. À l'époque ramesside, le corps du roi est disposé au centre d'une dépression au milieu de la chambre funéraire ; il prend la place du soleil renaissant, entre la terre représentée par les murs et le ciel représenté par le plafond, orienté par la présence de Nout au plafond. Ce schéma s'intègre parfaitement dans la symbolique de renaissance solaire telle que la pensée

\footnotetext{
2 PIANKOFF 1953a.

${ }^{3}$ HORNUNG 1972, p. 427-480.

${ }^{4}$ Notamment dans la tombe de Padiaménopé (TT 33) : cfr TRAUnECKER 2009, p. 15-48; TRAUNECKER, REGEN, 2016, p. 52-83 ; TRAUNECKER, RÉGEN 2018, p. 60-63.

${ }^{5}$ Il s'agit de la tombe d'Horirâa (Lepsius 23 : cfr LEPSIUS 1897, p. 175-177), dont ROBERSON 2012, p. 54, identifia certaines scènes comme appartenant au corpus du Livre de la Terre.

${ }^{6}$ ROBERSON 2012. Son corpus primaire se compose des scènes et textes présents sur les parois des chambres funéraires des tombes royales, accompagnés par la représentation du ciel au plafond. Le corpus secondaire se compose des scènes des tombes royales ne correspondant pas au corpus primaire, ainsi que celles issues des tombes privées, et des scènes présentes sur le mobilier funéraire.

${ }^{7}$ ReEves, Wilkinson 2005, p. 91-111 ; CAUVILle 2014, p. 15.

${ }^{8}$ ROBERSON 2012, p. 55-59.
} 
égyptienne la conçoit. La très grande fréquence de la symbolique du signe $a k h e t^{9}$ dans l'iconographie permet d'envisager sa présence dans l'architecture même de la chambre funéraire. Fort de cette argumentation, Roberson propose une orientation symbolique des deux murs selon un axe ouest-est avec l'est marqué par les pieds de la déesse.

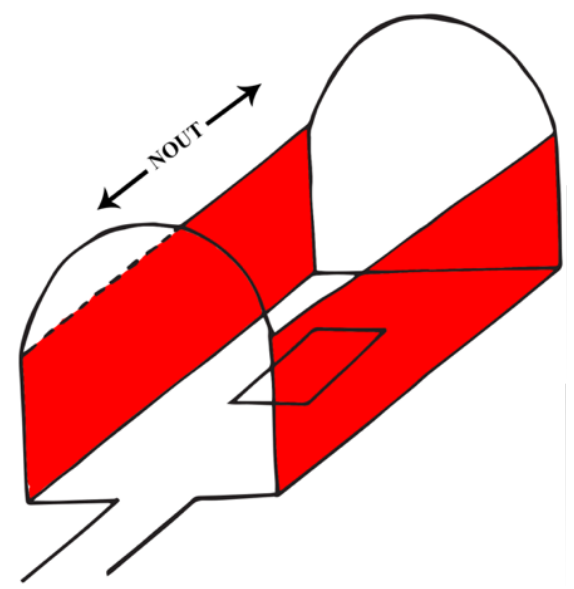

Fig. 1. Modèle 1

(Osiréion, Ramsès IV, Ramsès VII, Ramsès IX)

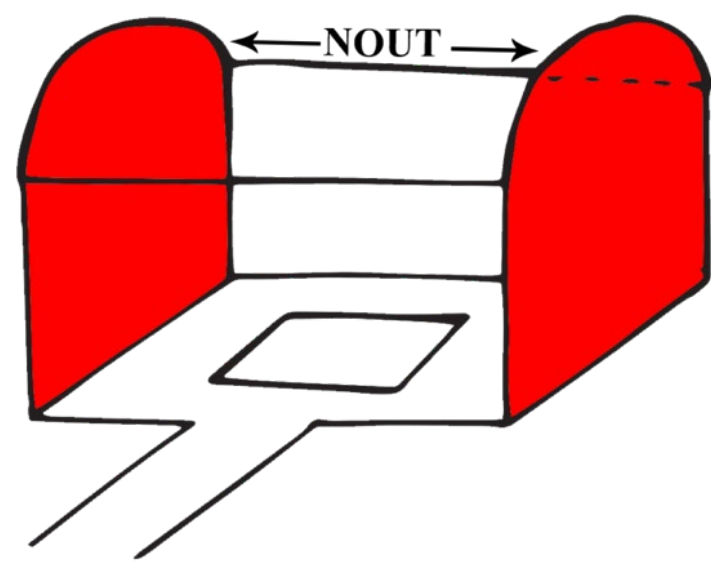

Fig. 2. Modèle 2

(Mérenptah, Taousert, Ramsès III, Ramsès VI)

Bien que Nout soit presque systématiquement présente dans les tombes où le Livre de la Terre est attesté, on remarque toutefois que l'orientation de la déesse n'y est pas fixe. En effet, dans l'Osiréion d'Abydos ${ }^{10}$ (notre modèle 1), la déesse Nout se trouve dans l'axe du couloir du sarcophage, alors que les scènes du Livre de la Terre figurent sur une paroi du côté de son flanc. Dans les tombes de Mérenptah ${ }^{11}$, de Taousert et Sethnakht ${ }^{12}$ et de Ramsès III ${ }^{13}$, la disposition des scènes du Livre de la Terre sur les parois par rapport à Nout au plafond correspond au modèle proposé par Roberson (notre modèle 2). Dans la chambre funéraire de Ramsès IV, le plafond est plat et Nout est figurée dans l'axe de la tombe, comme le sarcophage : le Livre de la Terre ne figure pas sur les parois de la chambre, mais sur le sarcophage. Dans la tombe de Ramsès VI, la disposition correspond au modèle 2, bien que l'on retrouve aussi des scènes du Livre de la Terre sur la paroi du fond. Dans les tombes de Ramsès VII ${ }^{14}$ et de Ramsès IX ${ }^{15}$, les scènes sont disposées comme dans la tombe de Ramsès IV $^{16}$ avec Nout et le sarcophage dans l'axe de la tombe, mais avec le Livre de la Terre sur les murs latéraux

\footnotetext{
${ }^{9}$ Les pylônes des temples représentent l'horizon avec le soleil qui s'y levait à un moment précis de l'année. Les deux parties du corps d'Aker composées de protomes de lion font également référence à la double colline. Ce symbole revêt une grande importance et sera employé pour exprimer la renaissance solaire d'une multitude de façon.

${ }^{10}$ FRANKFORT 1933.

${ }^{11}$ BROCK 1992.

12 Altenmüller 1983, 1985, 1992 et 2003.

${ }^{13}$ ABITZ 1986 ; MAURIC-BARBERIO 2004a et 2004 b.

${ }^{14}$ PiAnKofF 1958 ; HoRnung 1984 et 1990.

15 GUILMANT 1907 ; ABITZ 1992.

${ }^{16}$ CARTER, Gardiner 1917 ; Hornung 1990.
} 
(modèle 1). Ces deux tombes, qui offrent un plafond voûté, attestent donc, comme l'Osireion et la tombe de Ramsès IV, un modèle différent de celui de Roberson.

Sur ces modèles, on observe un changement d'orientation de Nout qui va de pair avec la position du sarcophage. La forme et le décor de la chambre funéraire sont donc intimement liés à la position du sarcophage. Ce changement d'orientation n'influe néanmoins pas sur la localisation du Livre de la Terre qui, à l'exception de la tombe de Ramsès IV, figure sur les parois nord et sud. Sur les parois des sarcophages, la scène A 10 se trouve à la tête du défunt, au niveau de la tête de Nout lorsque celle-ci est présente sur la face interne du couvercle. Mais dans la tombe de Ramsès VI, cette scène prend place sur le mur nord, non loin des pieds de Nout.

Les éléments sur lesquels Roberson construit sa théorie de l'orientation du Livre de la Terre semblent inappropriés, car il projette son interprétation des autres livres funéraires égyptiens - dont on connait le début et la fin - sur le Livre de la Terre de Ramsès VI que l'on sait incomplet, en adoptant un sens de lecture des scènes qui est loin d'être certain. Si on s'en tient au modèle de chambre funéraire qu'il propose, deux hypothèses seraient à envisager : soit plusieurs chambres funéraires ramessides seraient mal orientées et n'auraient dès lors pas été bien conçues, soit les deux murs où le Livre de la Terre est placé n'évoquent pas l'est et l'ouest, mais autre chose qui reste à déterminer. Le lien que Roberson établit entre la chambre funéraire et l'horizon-akhet mérite toutefois d'être retenu, même s'il ne paraît pas déterminer l'emplacement et l'orientation du Livre de la Terre.

Si le Livre de la Terre a fait l'objet de plusieurs études depuis celle de Piankoff en 1946, il conserve encore de nos jours sa part de mystère, tant pour l'ordre de lecture des sections qui le composent que pour son interprétation globale, même si certaines scènes semblent avoir été correctement interprétées. L'exemplaire présent dans la chambre funéraire de Ramsès VI en constitue la version la plus développée, si bien qu'il est généralement considéré comme le modèle de référence servant de point de départ pour toute réflexion sur le sujet. Toutefois, il serait illusoire de traiter cet exemplaire comme une sorte de version «canonique »: d'une part, il est incomplet ${ }^{17}$, d'autre part, est-il certain qu'une telle version canonique ait jamais existé?

\section{b. Le début de la composition}

En prenant comme référence la chambre funéraire de la tombe de Ramsès VI (fig. 3-4), les chercheurs ont développé deux théories différentes : commencer la lecture soit par le mur nord (fig. 1 et fig. 2), soit par le mur sud (fig. 3 et fig. 4). C'est Piankoff qui mit au point en 1953 la numérotation des scènes encore employée aujourd'hui : A pour le mur nord, B pour la partie nord de la paroi du fond (mur ouest), C pour la partie sud du mur du fond (mur ouest) et D pour le mur sud.

\footnotetext{
${ }^{17}$ BARTA 1987, p. 7-9, souligne une absence de tableau final dans la tombe de Ramsès VI, mais il en identifie une dans la tombe de Ramsès VII. MANASSA 2007, p. 57-58, met en évidence l'existence de légendes présentes sur certains sarcophages, mais absentes dans la version de la tombe de Ramsès VI.
} 


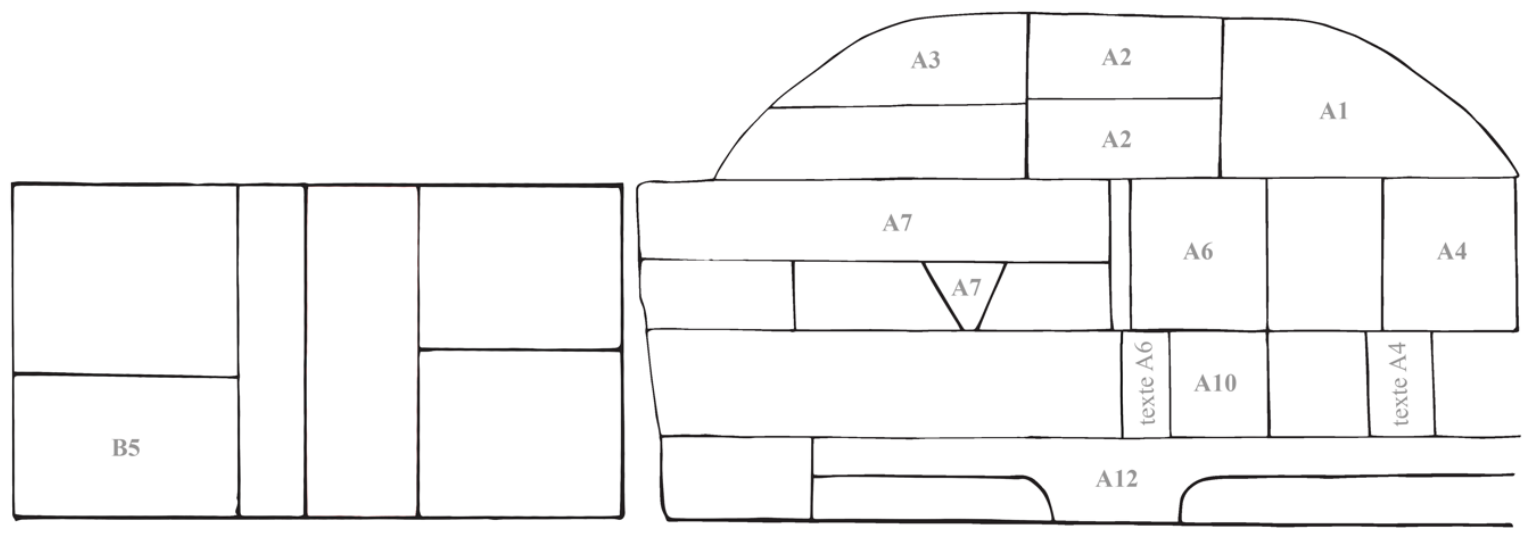

Fig. 3. Schéma général, mur nord (A) et partie nord du mur ouest (B)

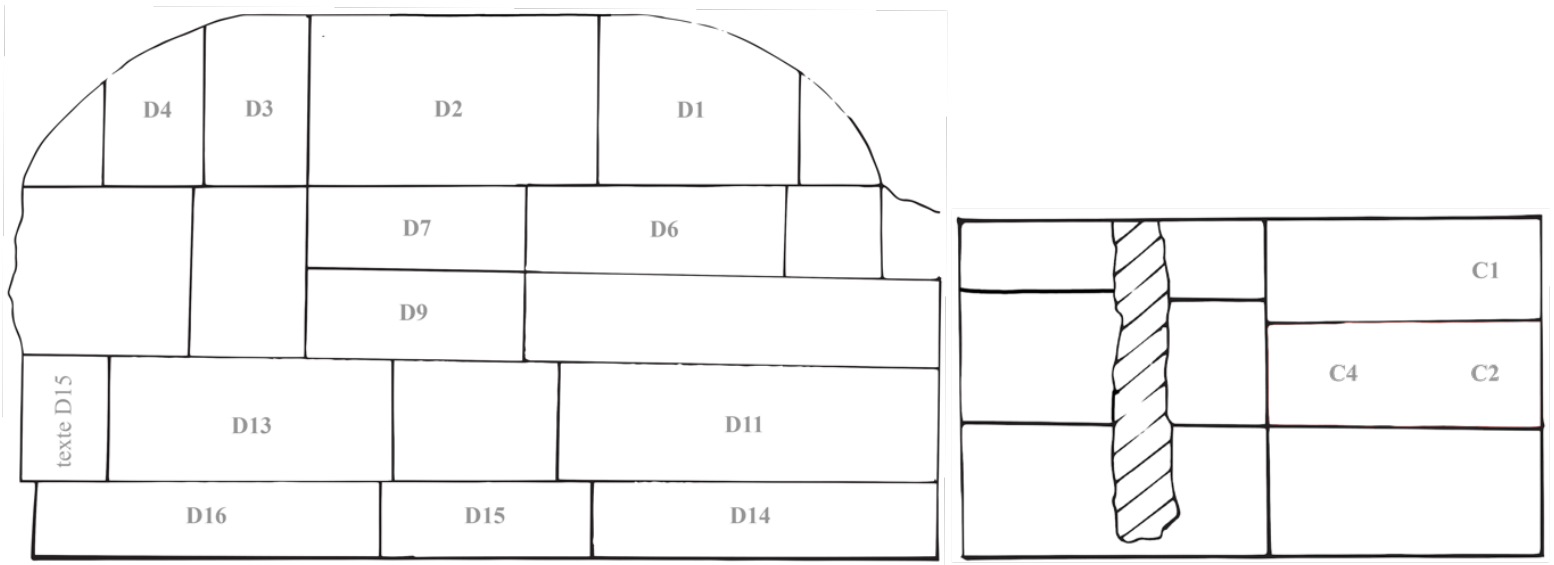

Fig. 4. Schéma général, mur sud (D) et partie sud du mur ouest (C)

Piankoff, Hornung, Barguet et, plus récemment, Cauville débutent par le mur nord. Piankoff propose de commencer la lecture en haut à droite du mur nord (scène A 1) et de poursuivre en lisant les scènes du haut vers le bas et de la droite vers la gauche ${ }^{18}$. Adoptant le sens de lecture proposé par Piankoff, Hornung estime que toutes les scènes forment un ensemble cohérent constituant une composition funéraire à part entière et il propose une association entre les parois latérales (A et D) et les portions du mur du fond qui leur sont directement attenantes $(\mathrm{B} \text { et } \mathrm{C})^{19}$. Barguet divise le mur nord comme suit ${ }^{20}$ : la moitié gauche serait consacrée à l'écoulement du temps, tandis que la moitié droite exprimerait la descente du soleil dans le monde souterrain. Quant à Cauville, elle préfère commencer la lecture du mur nord par le bas (scène $\mathrm{A} 12$ ) et non par la scène $\mathrm{A} 1^{21}$.

À l'inverse, Stricker, Abitz, Roberson et Mauric-Barberio, de même que Hornung qui se rallia à cet avis à partir de 1999, placent le début de la composition du côté sud de la chambre funéraire de Ramsès VI, mais l'identification de la scène de départ varie d'un auteur à l'autre. Stricker privilégie la scène D 1 représentant la chapelle d'Osiris entourée d'ennemis ${ }^{22}$. Abitz

\footnotetext{
${ }^{18}$ PiANKOFF 1953a, p. 5-7.

${ }^{19}$ HoRnUNG 1972, p. 427-480. Il changera d'avis en 1999 et affinera sa réflexion en 2007.

${ }^{20}$ BARGUET 1978, p. 51-56.

${ }^{21}$ CAUViLle, IBRAHim 2014, p. 151-169.

22 STRICKER 1994, p. 96.
} 
choisit la figuration du roi en adoration dans les triangles jouxtant à l'extérieur les scènes D 1 et D 4, arguant qu'il s'agit d'un motif fréquent pour marquer le début d'une composition ${ }^{23}$. Hornung reprend l'idée de Stricker et débute sa lecture par la scène D $1^{24}$. Se basant sur ces derniers et sur la thèse de Roberson, encore inédite à l'époque, Mauric-Barberio ne fixe pas de scène précise du mur sud comme le début de la composition, estimant que la signification du Livre de la Terre échappe encore à la compréhension ${ }^{25}$. Enfin, Roberson choisit comme point de départ l'ensemble placé à gauche de la scène $\mathrm{D} 3$, soit la scène $\mathrm{D} 4$ et la figuration du roi en adoration ${ }^{26}$. En réalité, son étude porte peu sur l'agencement des scènes, car il considère le Livre de la Terre comme un ensemble modulable ${ }^{27}$.

\section{c. Le tableau final}

Piankoff choisit comme scène finale celle qui est située en bas à gauche du mur sud (D 16), en suivant simplement le sens de lecture qu'il a mis en place ${ }^{28}$. Cette idée sera reprise par Hornung en $1972^{29}$. Barguet, quant à lui, propose de terminer par le registre inférieur de cette paroi sud mais sans fixer de scène en particulier, se focalisant sur la symbolique globale de la paroi $^{30}$. Cauville voit en la scène D 2, par laquelle elle choisit de terminer sa lecture, le moment de la renaissance du soleil ${ }^{31}$.

Stricker ne traite pas la question d'un tableau final éventuel, se concentrant sur les mécanismes de naissance du soleil évoqués selon lui sur la paroi sud. Abitz n'en propose pas non plus, car il n'y a pour lui aucune évocation du coucher ou du lever du soleil dans cette composition $^{32}$. Hornung (à partir de 2007) désigne la scène A 12 comme le tableau final du Livre de la Terre ${ }^{33}$, idée reprise par Roberson, qui se base aussi sur l'observation de certains papyrus privés ${ }^{34}$. Mauric-Barberio ne propose pas de tableau final, car l'objet de son étude est principalement de proposer de nouvelles associations de texte et d'image, et de comparer la structure du Livre des Cavernes à celle du Livre de la Terre ${ }^{35}$.

\footnotetext{
${ }^{23}$ ABITZ 1995, p. 165.

${ }^{24}$ HORNUNG 1999, p. 97, après avoir changé d'avis. quelles la décoration débute généralement par le mur gauche.

${ }^{26}$ ROBERSON 2007a, p. 93-112 ; ROBERSON 2007b ; ROBERSON 2012, p. 132.

${ }^{27}$ RoBERSON 2012, p. 20.

${ }^{28}$ PIANKOFF 1953a, p. 60-61.

${ }^{29}$ HORNUNG 1972, p. 479-480.

${ }^{30}$ BARGUET 1978, p. 55-56.

${ }^{31}$ CAuville, IBRAhim 2014, p. 169.

32 ABITZ 1995, p. 135-173.

${ }^{33}$ HORNUNG 2007, p. 132.

${ }^{34}$ ROBERSON 2012, p. 295-299.

${ }^{35}$ MAURIC-BARBERIO 2010, p. 175-220.
}

${ }^{25}$ MAURIC-BARBerio 2010, p. 181-183, qui rejette le sens de lecture proposé par Piankoff, pour le motif qu'il va à l'encontre de l'organisation des chambres funéraires royales des $\mathrm{XIX}^{\mathrm{e}}$ et $\mathrm{XX}^{\mathrm{e}}$ dynasties, dans les- 
Enfin, Barta ne se positionne pas réellement dans ce débat car il n'y a, selon lui, dans la tombe de Ramsès VI, aucun tableau qui indiquerait clairement la fin de la composition $^{36}$.

\section{d. Le sens de lecture des scènes}

Si le début et la fin du Livre de la Terre font encore débat, qu'en est-il pour le sens de lecture de ses scènes ? Commençant par le mur nord, en haut à droite (A 1), Piankoff lit les deux parois principales du haut vers le bas et de la droite vers la gauche, suivant l'orientation des signes. S'il commence par le mur sud (scène D 1), Stricker adopte le même sens de lecture du haut vers le bas. Il en va de même pour l'ensemble des autres chercheurs, à l'exception de Cauville, qui préconise un sens de lecture du bas vers le haut des parois, suivant la norme en usage pour la lecture des scènes organisées en registres. Ce sens de lecture, bien qu'il repose sur peu d'arguments, semble le plus plausible.

L'objet de cet article est de reprendre la question du sens de lecture des scènes de la chambre funéraire de Ramsès VI, en relevant les arguments textuels et iconographiques livrés par certaines scènes et en mettant en évidence l'intérêt des données similaires présentes dans d'autres compositions funéraires, dont l'agencement et la signification sont mieux connus. En effet, ces grandes compositions cosmographiques du Nouvel Empire sont issues d'un même substrat théologique très ancien et sont donc à même d'offrir autant de clés de compréhension, notamment sur la raison du bipartisme des parois qui semble être la norme. Au terme de cette étude, il s'avère possible d'argumenter en faveur de la proposition de Cauville, qui commence la lecture des scènes par le bas de la paroi nord.

\section{Le mur nord}

Nous examinons les registres du bas vers le haut, soit dans l'ordre inverse de la numérotation de Piankoff.

\section{a. Scène A 12}

La scène A 12 représente les deux moitiés du dieu Aker, à travers lequel la barque du soleil navigue (fig. 5). Considérée parfois comme la scène finale du Livre de la Terre ${ }^{37}$, elle présente plusieurs éléments qui permettent, au contraire, de songer à elle comme un possible début de la composition. Si on suit le sens de lecture imposé par la direction de la barque et le regard des figures animées, la scène A 12 débute à l'extrémité droite de la paroi. La corde

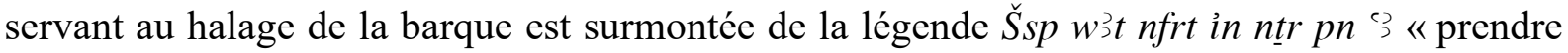
la route parfaite par ce grand dieu». L'utilisation de l'expression $\varsigma_{s p} w^{3} t$ est un élément intéressant, qui véhicule la notion de commencement d'une action ${ }^{38}$. Sous la barque est figuré un personnage momiforme couché sur un tertre qui contient un œil larmoyant et quatre bouts de chair. La première division du Livre des Cavernes offre une scène comparable (fig. 6) : un tertre y contient également des bouts de chair, lesquels évoquent clairement la totalité du

\footnotetext{
${ }^{36}$ BARTA 1987, p. 7-9. Le tableau final du Livre de la Terre est, à son avis, une scène de la tombe de Ramsès VII relevée pour la première fois dans PIANKOFF 1953b, p. 154.

${ }^{37}$ HornUNG 2007 ; RoBERSON 2012, p. 137-138 ; MAURIC-BARBERIO 2010, p. 211.

${ }^{38} \mathrm{~Wb}$. IV, 533.5
} 
corps d'Osiris dans le Livre des Cavernes ${ }^{39}$, dont la première division concerne le mystère de la sécrétion d'Osiris, de sa putrescence et de son essence. Ce cadavre putrescent gît au fond de la Douat, au fond de la terre, et incarne, par l'écoulement de ses humeurs, les potentialités fécondes du monde de l'au-delà et de la terre elle-même ${ }^{40}$. Les deux figures placées à gauche du tertre de la scène A 12 sont nommées ḩ̉yt. Selon Roberson, ce terme désigne des personnages en lamentation devant la dépouille d'Osiris ${ }^{41}$. Cependant, ce terme peut aussi signifier «l'endroit inondé », ainsi que « la vase » et «le limon ${ }^{42}$ », ce qui est très cohérent au vu du parallèle établi avec le Livre des Cavernes. On aurait un jeu de mots permettant d'évoquer deux réalités liées à la mort d'Osiris : les lamentations et la tristesse suscitées par le corps d'Osiris défunt, mais également la fertilité issue de l'écoulement des humeurs de ce même corps. Ce motif des deux figures féminines qui encadrent un personnage masculin rappelle la disposition de la scène directement à côté du tertre dans le Livre des Cavernes, où les deux figures féminines en adoration sont identifiées à Isis et Nephthys, qui protègent la putrescence d'Osiris. Cette scène est également comparable à une vignette de la sixième heure du Livre de l'Amdouat, où le cadavre de Rê, dispersé dans trois tombes, est accompagné d'un cadavre couché avec trois morceaux de chair à ses pieds et entouré d'un serpent ${ }^{43}$. Toutefois, comme le Livre de l'Amdouat est issu d'une tradition solaire, le corps y est identifié au cadavre de Khépri.

Selon Roberson, ce tableau est très proche des tableaux finaux du Livre de l'Amdouat, du Livre des Portes et du Livre des Cavernes ${ }^{44}$. En réalité, le tableau final du Livre de l'Amdouat et celui du Livre des Cavernes sont visuellement très différents de la scène A 12. Seule une ressemblance avec celui du Livre des Portes est clairement observable. En effet, ce tableau final présente Noun, bras tendus, soulevant la barque solaire d'où émerge Khépri, figuré comme un scarabée, poussant le globe solaire devant lui ${ }^{45}$. L'exemplaire de ce tableau du Livre des Portes dans la chambre funéraire de Ramsès VI, au fond de la niche du mur ouest, évoque la renaissance du soleil à cet endroit.

La scène A 12 s'apparente davantage à la cinquième heure du Livre de l'Amdouat (fig. 7) qu'à son tableau final. Elle évoque le passage de la barque solaire dans le domaine de Sokar, région inhospitalière et obscure qui est une étape fondamentale dans le processus de régénération du soleil. La caverne de Sokar, qui surmonte des étendues d'eau, est gardée par le dieu Aker, sous les traits d'un double sphinx à tête humaines. Au-dessus de cette scène, Isis et Nephthys, sous forme d'hirondelles, gardent un monticule associé à la tombe d'Osiris ${ }^{46}$. La scène A 12 du Livre de la Terre et la cinquième heure du Livre de l'Amdouat sont donc assez proches. Il en résulte qu'Aker n'est pas seulement une divinité gardienne de l'entrée et de la

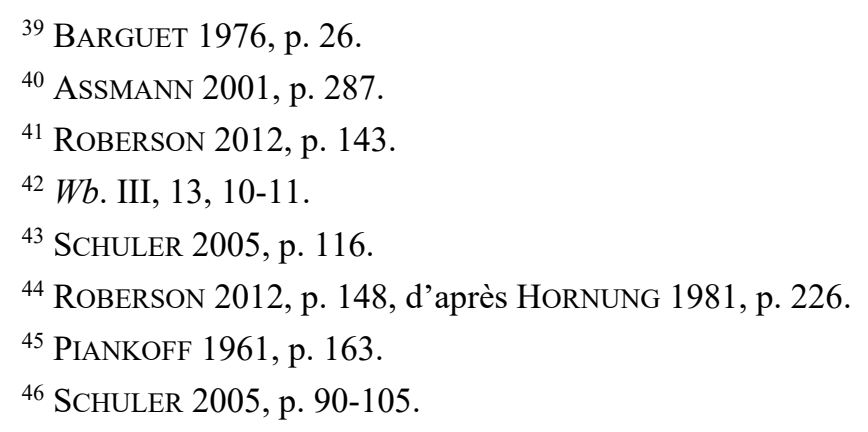


sortie de la Douat, il assure également ce rôle protecteur au plus profond de celle-ci. Sa présence ne peut donc pas être utilisée pour indiquer une sortie du soleil hors de la Douat.

Contrairement à l'idée de Roberson, qui reprend Piankoff ${ }^{47}$, la scène A 12 n'est pas une synthèse de la course du soleil positionnée à la fin du récit, mais plutôt l'entrée de la barque solaire au plus profond de la Douat à travers Aker, divinité chtonienne liée au domaine de Sokar et associée à la notion de cadavre d'Osiris. Cette scène se présenterait donc comme une première évocation du mystère essentiel du domaine funéraire : le processus pour passer de l'état de cadavre à celui d'une entité capable de renaître. La barque qui ressort de l'autre côté d'Aker (vers la gauche) ne concernerait pas la renaissance du soleil, mais indiquerait plutôt qu'une fois les différents mystères effectués au fond de la Douat, il quitte cette zone. L'emplacement des cartouches de Ramsès VI n'est pas le fruit du hasard. Ils sont positionnés au plus proche de la barque solaire, juste au-dessus du tertre abritant le cadavre d'Osiris, comme pour l'associer aux deux traditions.

\section{b. Scènes $A 10$ et $A 7$}

Située juste au-dessus de la scène A 12, la scène A 10 (fig. 8) est celle qui fut le plus souvent reproduite à l'époque pharaonique ${ }^{48}$. Comme l'indique Mauric-Barberio ${ }^{49}$, ces nombreuses versions permettent de dissocier cette scène du texte situé à sa gauche dans la tombe de Ramsès VI, afin de l'associer à la légende présente sur les sarcophages, qui évoque plusieurs notions complexes. Sur le sarcophage de Ramsès IV, la figure centrale est identifiée à Osiris, pénétré par les rayons de Rê. Le concept évoqué, l'union d'Osiris et de Rê, est attesté également aux chapitres $15^{50}$ et $17^{51}$ du Livre des Morts, le second étant représenté dans différentes tombes, notamment celles de Néfertari (QV 66) et de Nakhtamon (TT 355) ${ }^{52}$. Cette union explique le mystère le plus insondable de la religion égyptienne : comment le soleil passe d'un état de corps mort à celui d'un corps en pleine capacité de renaissance. Dans les différentes compositions funéraires du Nouvel Empire, ce processus se produit généralement à mi-parcours, en l'occurrence aux cinquième et sixième heures du Livre de l'Amdouat, à la sixième heure du Livre des Portes ${ }^{53}$, et à la troisième division du Livre des Cavernes. Le cadavre d'Osiris, gisant au fond de la Douat, devient le corps de Rê et Rê devient le $b a$ d'Osiris : l'union de ces deux unités enclenche le processus de renaissance. Dans les attestations de cette scène sur les sarcophages, le rôle de Rê, qui est le $b a$ réanimant le cadavre par l'action vivifiante de son rayonnement, est marqué par un rayon qui relie l'astre solaire au centre de la composition. L'association de Rê au $b a$ d'Osiris, dont l'origine est ancienne, s'inspire de l'idée que le soleil éclaire la terre, à l'intérieur de laquelle Osiris est inhumé. Le

\footnotetext{
${ }^{47}$ PIANKOFF 1953, p. 23-24.

${ }^{48}$ Elle figure dans la tombe de Ramsès VI, mais aussi dans celle de Ramsès III et celle d'Osorkon II, ainsi que sur le sarcophage de Ramsès IV. De nombreux exemplaires sont également attestés sur des sarcophages privés, de la Troisième Période Intermédiaire à l'Époque Ptolémaïque.

${ }^{49}$ MAURIC-BARBERIO 2010, p. 187-195.

${ }^{50}$ ASSMAN, 2001, p. 285.

${ }^{51}$ BARGUET 1967, p. 57.

52 Servajean 2017, p. 253-255.

${ }^{53}$ HORNUNG 1999, p. 62.
} 
soir venu, le soleil, Rê, descend sous terre pour s'unir à son cadavre dans le plus grand des secrets $^{54}$. Osiris incarne le limon fertile apporté par la crue du Nil, et Rê offre l'énergie qui permet aux plantes de pousser ${ }^{55}$. L'un ne peut fonctionner sans l'autre. La légende associée à cette scène mentionne deux termes particulièrement intéressants dans ce contexte : $\underline{d} t$ et $n h h^{56}$, traduits traditionnellement par « pour toujours et à jamais ${ }^{57}$ ", induisant qu'ils recouvrent tous deux la notion d'éternité. Toutefois, selon Servajean, ces deux mots correspondent à des concepts bien distincts. Ainsi, nhhh est à comprendre comme " le temps », vecteur de changements conditionnant la finitude des êtres et des choses. Le concept d'éternité $\underline{d} t$, qui permet de remédier à cette fin irrévocable et définitive, est omniprésent dans la vie égyptienne : il traduit notamment l'idée que le temps se déploie en une succession infinie de cycles. Ainsi, la pensée de l'éternité $\underline{d} t$ est concrète : le temps $n h \underline{h}$ est cyclique et ces cycles sont éternels. La mort est donc un passage obligatoire pour le renouvellement du cycle ${ }^{58}$. Cette notion se reflète également dans le concept d'union d'Osiris et de Rê. Rê évoque cette idée de temps cyclique rendu éternel de par son union avec Osiris, qui évoque une éternité transcendant le temps et indissociable de celui-ci. L'union de ces deux entités permet donc d'insuffler de l'éternité dans le temps et d'assurer ainsi le renouvellement des cycles ${ }^{59}$.

La seconde thématique abordée dans cette scène A 10 est la disparition des heures. La figure centrale de la composition, Osiris, est également identifiée comme htm(w) wnw(wt) «Celui-qui-détruit-les-heures ${ }^{60}$ » dans la tombe de Ramsès VI. La légende des sarcophages indique qu'Osiris n'est pas seulement pénétré par les rayons du soleil, mais aussi par les heures comme le confirme la présence régulière d'une étoile au sommet de la figure centrale. Les heures sont conçues comme des entités solaires : le mot wnwt est déterminé par le globe solaire ${ }^{61}$. Elles sont donc créées par le cycle du soleil et procèdent de lui. L'apparition d'une heure induit la disparition de l'heure précédente qui, comme le soleil, doit « mourir » pour pouvoir renaître. Dans ce contexte, le terme htm est une destruction nécessaire et préalable à une renaissance ${ }^{62}$. La régénération du soleil induit dès lors la régénération du temps. Osiris, entité confondue avec la Douat, donne naissance, non seulement au soleil, mais aussi aux heures. La scène A 10 illustre la thématique de la destruction des heures, tandis que celle de la naissance des heures le sera dans la scène A 7 (fig. 9), via l'identification de la figure centrale à $i m n(w) w n w w t ~ « C e l u i-q u i-c a c h e-l e s-h e u r e s{ }^{63}$, et la présence de douze femmes tenant un

\footnotetext{
${ }^{54}$ ASSMANN 2001, p. 146-149.

${ }^{55}$ Cauville 2014, p. 5.

${ }^{56}$ 'I r rty.fy s33.sn sw r $\underline{d} t$ nhh ; «Les deux uraeus le protègent pour l'éternité et à jamais ». Il s'agit de la fin de la légende présente sur les sarcophages attestant de la scène A 10, suivant l'édition de MANASSA 2007, p. 58.

57 SERVAJEAN 2007, p. 1.

58 SERVAJEAN 2007, p. 105.

${ }^{59}$ SERVAJEAN 2007, p. 27-28 et p. 57-58.

${ }^{60}$ On retrouve également la légende $w n w(w) t{ }^{c} p k k w y$ hr tbt ; « Les heures qui ont traversé l'obscurité sous la sandale », qui évoque cette thématique.

${ }^{61}$ MAURiC-BARBerio 2012, p. 193 ; MANASSA 2007, p. 60-62 ; HorNUnG 1978, p. 269-307.

62 MANASSA 2007, p. 61 ; MAURIC-BARBERIO 2012, p. 194.

${ }^{63}$ L'identification de ce personnage est possible grâce à l'examen des légendes de la scène A 7 de la tombe de Ramsès IX.
} 
petit astre solaire ${ }^{64}$. La scène A 7 présente en son centre un personnage ithyphallique inscrit dans une forme d'entonnoir soulignée par un immense serpent. Selon Barguet, cette forme évoque celle d'une clepsydre, instrument permettant la mesure de l'écoulement du temps ${ }^{65}$. Cette idée de disparition et d'apparition des heures est bien marquée à la cinquième heure du Livre des Portes $^{66}$, où une divinité momiforme se tient debout devant douze personnages masculins qui tiennent une double corde sortant de la bouche de cette divinité : la corde doit être tirée hors de la bouche d'Aker afin de faire naître de lui les heures, tandis qu'Aker continue d'avaler la corde ${ }^{67}$. Cette idée est également illustrée dans la quatrième heure du Livre des Portes : il y est dit qu'un serpent est à l'origine de la création des heures, qui sont ensuite avalées, et qui renaissent derechef de lui ${ }^{68}$. Dans ces exemples, on constate que la destruction ou la disparition des heures n'est que très temporaire ${ }^{69}$.

La scène A 7 présente une forme inversée par rapport à la scène A 10 marquant visuellement que ces deux scènes correspondent à deux étapes d'un même processus, à savoir la renaissance des heures consécutive à leur destruction dans la scène A 10. La proposition de Barguet de voir à la scène A 7 la forme d'une clepsydre permet d'apporter un regard nouveau sur la scène A 10. En effet, sur les versions des sarcophages, on observe des personnages versant de l'eau. La scène A 7 symboliserait donc la naissance des heures qui remplissent ainsi la clepsydre. L'eau qui s'écoule de manière régulière évoque le temps qui passe mais qui ne peut continuer à s'écouler qu'à la condition que les heures soient sans cesse créées.

\section{c. Scène A 4}

La scène A 4 (fig. 10) présente le dieu memphite Taténen, personnification de la terre initiale qui émerge du Noun lors de la création du monde. Comme Geb et Aker, il s'agit d'un dieu chtonien qui évoque les profondeurs et la richesse de la terre ${ }^{70}$. Parfois considéré comme hermaphrodite $^{71}$, Taténen a un rôle lié à la création et à la naissance. Aussi n'est-il pas étonnant de le voir ici enceint du soleil : à la fois en tant que divinité créatrice, mais aussi en tant qu'incarnation de la terre. Cette idée est également évoquée dans la huitième heure du Livre des Portes où Taténen incarne la Douat à l'intérieur de laquelle se déplace le soleil ${ }^{72}$. Le dieu figure aussi à la cinquième division du Livre des Cavernes, entre Atoum et Khépri. Il y est mentionné comme «créateur de naissance et engendreur ${ }^{73}$. Dans la litanie qui précède la sixième division du Livre des Cavernes, il est décrit comme « le façonneur des dieux après leur avoir donné naissance, Taténen qui crée les naissances, qui engendre ceux qui sortent de

\footnotetext{
${ }^{64}$ Elles sont divisées en deux groupes de six et représenteraient ainsi deux moments bien distincts de la nuit, si elles ne sont pas disposées de la sorte par simple souci de symétrie.

65 BARguet 1978, p. 53.

${ }^{66}$ PIANKOFF 1949, p. 115.

${ }^{67}$ PIANKOFF 1961, p. 61-66.

${ }^{68}$ HoRNUNG 1979, p. 118-121.

${ }^{69}$ MANASSA 2007, p. 61.

${ }^{70}$ Corteggiani 2007, p. 531-532 ; SCHLÖGL 1980, p. 121-125.

${ }^{71}$ WILKINSON 2005, p. 130

72 SCHLÖGL 1980, p. 31, repris par MAURIC-BARBERIO 2010, p. 199.

${ }^{73}$ BARGUET 1976, p. 33.
} 
lui (...), duquel est (issu) Khépri ${ }^{74}$. Dans la troisième heure du Livre de l'Amdouat, il est le rameur qui convoie la barque du soleil ${ }^{75}$. Au chapitre 15 du Livre des Morts, consacré à l'adoration d'Amon-Rê, on lit: " ton père Taténen te soulève, il met ses bras autour de toi, qui t'es transformé et qui es devenu divin au sein de la terre $(\ldots)^{76} »$. Et au chapitre 180 , on trouve : «Faites que Taténen me reçoive et me soulève $(\ldots)^{77}$ ». Cette fonction de Taténen est évoquée dans la scène A 12 du Livre de la Terre : « Ce que Rê dit à l'endroit de la destruction lorsqu'il sort et qu'il traverse le gardien de l'Occident : ô Noun qui est à l'intérieur, puisse-t-il traverser Taténen $»^{78}$.

Pour Darnell, les qualificatifs $h r y(t)$ et $h r(y) t$ attestés dans les légendes de cette scène, font clairement référence à la Douat Supérieure et à la Douat Inférieure ${ }^{79}$. Si l'on y associe la notion de traverser le corps de Taténen, présente dans la scène $\mathrm{A} 4$ et dans la scène $\mathrm{A} 12$, cela donne l'idée du mouvement du soleil à travers le corps du dieu. Taténen doit donc être considéré ici dans tous les différents aspects évoqués plus haut. Il est la terre à travers laquelle le soleil se déplace pendant la nuit. Une terre qui est traversée par le soleil, et qui, de par la fonction créatrice de Taténen, donne naissance à l'astre le matin. Toutefois, Rê reste le démiurge qui a créé Taténen lors de la création du monde ${ }^{80}$, ce qui explique la phrase «ô cadavre, duquel je suis advenu de lui, après avoir enfanté comme enfant Rê lui-même ensuite $^{81}$ ». Rê et Taténen sont donc, dans cette vision des choses, chacun le créateur de l'autre. La scène A 4 rappelle en outre une scène de la paroi droite de la deuxième chapelle de Toutânkhamon (fig. 11). Une divinité momiforme y est représentée debout, la tête et les pieds entourés du serpent Mehen formant donc deux cercles, tandis qu'un oiseau criocéphale, évoquant l'union d'Osiris et Rê, est placé dans le corps de celui-ci ${ }^{82}$. On retrouve dans cette scène les mentions de Taténen et de l' « endroit de destruction » $(h t m y t)^{83}$, notion abordée plus particulièrement à la scène A 6 .

\section{d. Scène A 6}

La scène A 6 (fig. 12) représente la déesse Htmyt qui est, selon la légende, celle qui détruit le soleil, mais également celle qui le soulève pour lui permettre d'être vu en entier. Manassa associe Htmyt au verbe htm, qui rend la notion de destruction nécessaire, car il faut détruire la forme vieillie du soleil pour qu'elle puisse se régénérer et renaître le lendemain matin ${ }^{84}$.

\footnotetext{
${ }^{74}$ PIANKOFF 1943, p. 9.

75 SCHULER 2005, p. 75.

${ }^{76}$ BARGUET 1967, p. 51.

${ }^{77}$ BARGUET 1967, p. 265.

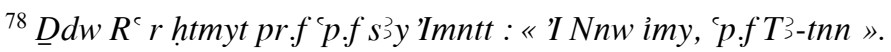

${ }^{79}$ DARNELL 2004, p. 376, déduit cette association par la comparaison de plusieurs légendes où les bras et la tête sont dits être dans la région supérieure, ou Douat Supérieure, tandis que les pieds sont placés soit dans la région inférieure, ou Douat Inférieure, soit dans l'endroit de destruction.

${ }^{80}$ POSENER 1998, p. 67.

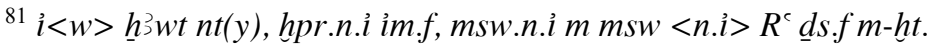

82 DARNELl 2004, p. 384.

${ }^{83}$ PIANKOFF 1949, p. 113-114.

${ }^{84}$ MANASSA 2007, p. 61.
} 
Darnell associe la Douat Inférieure (hrryt) à la notion de htmyt qui est le lieu où se produit la destruction $\mathrm{htm}^{85}$. L'association des idées de Darnell et de Manassa donne du sens à cette scène. La déesse du lieu de la destruction, la Douat Inférieure, détruit la forme vieillie du soleil et lui offre la possibilité d'atteindre un état où il est capable de se régénérer. Après quoi, elle contribue à son élévation. Sur le plan visuel, la forme de la scène A 6 est inversée par rapport à celle de la scène $\mathrm{A} 10$, comme c'était le cas de la scène $\mathrm{A} 10$ par rapport à la scène A 7, qui se trouvent directement en dessous dans la tombe de Ramsès IV. Il conviendra dès lors, ici aussi, d'envisager ces deux scènes comme deux étapes d'un même processus. La scène A 10 évoque le processus d'union entre Osiris et Rê et la scène A 6 la destruction de la forme vieillie du soleil suivie de sa renaissance.

\section{e. Scène A 1}

La scène A 1 (fig. 13) présente en son centre un personnage surmonté du soleil qui semble émerger d'une butte dans laquelle différents personnages sont enfermés, évoquant pour la première fois l'idée que le soleil quitte une zone en particulier afin d'en rejoindre une autre. Le texte indique qu'après le départ du soleil, ces personnages sont plongés dans l'obscurité ${ }^{86}$. La scène A 1 fonctionne en symétrie avec la scène A 2 qui la jouxte. En effet, ces deux scènes sont coupées horizontalement en leur milieu et associées à l'idée d'une élévation du soleil.

\section{f. Scène A 2}

La scène A 2 (fig. 14) est très proche d'une scène de la troisième division du Livre des Cavernes (fig. 15), qui représente un personnage ithyphallique couché et surmonté d'un globe solaire ; Aker se tient juste au-dessus de lui, sous la forme d'un double sphinx à têtes humaines surmonté lui aussi d'un globe solaire. Mauric-Barberio assimile cette scène du Livre des Cavernes à la scène A 12 du Livre de la Terre, pourtant fort différente ${ }^{87}$. Cette scène du Livre des Cavernes est accompagnée de la légende associant clairement le cadavre en érection avec Osiris et mentionnant sa putrescence. Selon Barguet, l'entièreté de la troisième division du Livre des Cavernes est dédiée, d'une part à la recherche et à l'identification des différents membres d'Osiris, d'autre part à ce que les différents morceaux du corps d'Osiris soient maintenus ensemble par Néhaher ${ }^{88}$. Barguet identifie ce moment du Livre des Cavernes à celui de la cinquième heure du Livre de l'Amdouat ${ }^{89}$. La troisième et la quatrième division du Livre des Cavernes sont séparées par un immense serpent accompagné de la légende : "ô ce grand, le serpent Hérychetef, qui unit les deux Douat (et) les deux Occidents (...)». Ces légendes permettent de comprendre que, dans le Livre des Cavernes, Aker a une fonction

\footnotetext{
${ }^{85}$ DARNELL 2004, p. 376-378.

${ }^{86}$ PIANKOFF 1953, p. 6, mentionne l'expression ḩ’h.hr st kkwy empruntée au Livre des Cavernes, où le soleil se déplace dans une multitude de cavernes qui retombent, après son passage, dans l'obscurité. Le verbe $h h^{3} p$ signifie « (être, devenir) caché, mystérieux, secret» (cfr FAULKNER 1962, p. 163), mais aussi « voiler, recouvrir, couvrir » (cfr $W b$. III, 30, 6-19), avec le déterminatif S 28 de la pièce d'étoffe. L'emploi de ce verbe rend donc très visuelle l'idée de l'obscurité qui vient recouvrir un lieu comme une pièce d'étoffe que l'on poserait dessus.

${ }^{87}$ MAURIC-BARBERIO 2010, p. 211.

${ }^{88}$ Corteggiani 2007, p. 360-361.

${ }^{89}$ BARGUET 1976, p. 29-31.
} 
«d'horizon souterrain », de gardien du passage entre la Douat Inférieure et la Douat Supérieure. Cette idée peut être transposée à la scène A 2 du Livre de la Terre. En effet, la notion de Douat Supérieure et de Douat Inférieure a déjà été abordée, puisqu'elle est au centre de la scène A 4 représentant le dieu Taténen. Le cadavre couché, surmonté de l'astre solaire, est nommé ḩ̉ imy $R^{c}$ " le cadavre dans lequel est Rê » dans le Livre de la Terre, c'est-à-dire le cadavre d'Osiris. L'union d'Osiris et de Rê est donc effective : Rê a, par la force de ses rayons, régénéré la forme défunte d'Osiris et ils sont aptes à passer dans la Douat Supérieure, sous la forme d'une entité capable de renaître.

Cette représentation serait celle d'une première renaissance solaire, depuis la région la plus profonde et mystérieuse de la Douat, la région htmyt, l'Inférieure évoquée à la scène A 4. Barguet décrit ces deux zones comme « la Douat de la mort ou du corps mort ancien » et « la Douat du corps nouveau ", mettant en opposition un lieu statique et un lieu dynamique ${ }^{90}$. Une fois le grand mystère de l'union d'Osiris et Rê effectué, après être passé dans l'état d'un être capable de renaître, le soleil traverse une première fois l'horizon : la barque du soleil est maintenant représentée au-dessus d'Aker. La légende indique que le soleil « se met à naviguer dans la Douat» (šsp.f $\left.n^{`} t m d w^{\jmath} t\right)$, utilisant le verbe $\check{s} s p$ déjà présent dans la légende de la scène $\mathrm{A} 12$, qui définit ainsi un deuxième endroit stratégique de la paroi nord de la tombe de Ramsès VI.

Les attestations de la scène A 2 dans les tombes de Mérenptah (fig. 16 et 17), de Taousert et Sethnakht (fig. 18 et 19) et de Ramsès III (fig. 20), dont les chambres funéraires présentent un décor très semblable, voire quasi identique, mettent en évidence le caractère bipartite de cette scène. La partie supérieure de la scène, à savoir le dieu Aker surmonté de la barque solaire, se trouve au registre inférieur du mur nord, tandis que sa partie inférieure, à savoir le personnage momiforme couché et surmonté de globes solaires, se trouve au registre supérieur du mur sud, au-dessus de la scène A 7, inversant ainsi les parois nord et sud par rapport à la version de Ramsès VI. Cette répartition de la scène $\mathrm{A} 2$ entre les deux parois pourrait très bien illustrer l'idée d'un passage entre deux états ou zones. Cette observation peut aussi éclairer la dynamique de lecture, un argument supplémentaire en faveur d'une lecture du bas vers le haut des parois. Ainsi, la division de la cette A 2 dans ces trois tombes implique un mouvement ascendant sur le mur sud (correspondant, au niveau des scènes, au mur nord de la version de Ramsès VI), ainsi qu'un passage vers le bas de la paroi nord (correspondant, par déduction, au côté sud de la version de Ramsès VI)

Au registre médian du mur nord des tombes de Mérenptah, Taousert et Sethnakht et Ramsès III, un immense oiseau criocéphale, placé au-dessus de la partie supérieure de la scène A 2, étend ses ailes sur toute la longueur du registre. Cet oiseau est absent dans les tombes de Ramsès VI, Ramsès VII et Ramsès IX. Dans la tombe de Ramsès III et dans celle de Mérenptah, l'oiseau criocéphale est identifié à Osiris, lui-même identifié au roi, tout comme le personnage momiforme couché. Après la mort, le cadavre du roi devient Osiris, tandis que son $b a$ s'assimile à $\mathrm{Re}^{91}$. Si cet oiseau est lié au roi et s'il est en outre associé à la représentation de Rê en tant que $b a$ d'Osiris, il ne manque plus qu'un élément pour évoquer l'union d'Osiris et de Rê dans son ensemble, à savoir, le corps d'Osiris. Le corps du roi, situé

\footnotetext{
${ }^{90}$ BARguet 1976, p. 31.

${ }^{91}$ Cauville, Ibrahim 2014, p. 4.
} 
dans le sarcophage placé devant l'oiseau, serait l'incarnation du corps d'Osiris, surmonté de son $b a$ sur la paroi. Cette scène évoquerait soit l'union d'Osiris et de Rê à venir, soit cette union déjà effective puisque les deux éléments sont rassemblés au même endroit. Le registre supérieur, au-dessus de cet oiseau, est occupé par une version légèrement modifiée du tableau final du Livre des Cavernes. En effet, dans sa version originale, ce tableau est beaucoup plus étroit, peut-être parce qu'il est n'est pas destiné à être représenté verticalement ou sur toute la largeur d'une paroi. Cette opposition entre tableau final du Livre des Cavernes sur une paroi, et les scènes A 7 et A 2 sur 1'autre mur, semble être un argument supplémentaire en faveur du sens de lecture proposé. Sur les sarcophages de Djedhor (Louvre D 8) (fig. 21), de Djedhor (Louvre D 9) et de Tjahorpata (Caire CG 29306), l'oiseau solaire surmonte la scène A 2 qui représente la barque solaire sur le dos d'Aker (fig. 22 et 23). Il y figure à l'intérieur d'un astre solaire. Isis et Nephthys sont représentées sous forme d'oiseau, de part et d'autre d'Aker, comme elles le sont auprès d'Osiris. Figurée de cette façon au-dessus de la scène qui, dans le Livre de la Terre et dans le Livre des Cavernes, évoque l'union d'Osiris et Rê, cette scène semble évoquer l'union effective du $b a$ et du cadavre. De plus, le corps de Tjahorpata est nommé « le cadavre dans lequel est Rê » ( $h^{3}$ t imy $R^{`}$ ), comme la figure momifiée couchée dans la tombe de Ramsès VI.

\section{Le mur sud}

Nous examinons ici également les registres du bas vers le haut, soit dans l'ordre inverse de la numérotation de Piankoff.

\section{a. Scène D 14}

La scène D 14 (fig. 24) évoque différentes divinités qui, au moyen de flammes sortant de leur bouche, attisent des chaudrons qui contiennent des têtes et des morceaux de chair, dans le but de provoquer la terreur chez les rebelles ${ }^{92}$. Cette thématique est également évoquée à la cinquième division du Livre des Cavernes (fig. 25) ${ }^{93}$, ainsi qu'à la septième heure du Livre de l'Amdouat, où il est question de «rôtir» les ennemis d'Osiris ${ }^{94}$. À la onzième heure de l'Amdouat, cinq déesses armées de couteaux crachent des langues de feu sur des buttes contenant des ennemis ${ }^{95}$. À la huitième heure du Livre des Portes, les ennemis sont attachés devant un serpent qui crache du feu ${ }^{96}$.

\section{b. Scène D 15}

La scène D 15 (fig. 26) figure au milieu du registre inférieur du mur sud. Selon Hornung, le texte situé à l'extrémité gauche du registre supérieur y fait référence et aurait été placé là

\footnotetext{
${ }^{92}$ La scène D 14 est, par ces évocations de la punition des ennemis d'Osiris, plus dynamique que celles que l'on retrouvait sur le mur nord.

${ }^{93}$ PIANKOFF 1943, p. 14.

94 SCHULER 2005, p. 123.

95 SCHULER 2005, p. 175.

96 PiANKOFF 1962, p. 171.
} 
par manque de place à proximité de la scène ${ }^{97}$. Un personnage féminin momiforme de grande

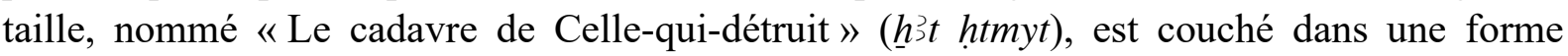
identique à celle d'un sarcophage ${ }^{98}$. Différents protagonistes émergent de ce sarcophage, dont la Mystérieuse ( $\left.\check{s}^{3} 3 y t\right)$, qui est une figure essentielle de cette paroi sud. Il s'agit de la plus grande représentation d'une figure individuelle dans le Livre de la Terre de la tombe de Ramsès VI ${ }^{99}$, ce qui lui confère un caractère cosmique. Sa disposition assez proche de celle de la scène A 12, qui s'étend également en bas d'une paroi, a incité Roberson à proposer une association entre ces deux scènes ${ }^{100}$. La scène D 15 renvoie à la déesse Htmyt présente à la scène A 6. Si l'on admet que le mur nord représente la Douat Inférieure, alors il est logique de trouver, en bas de la paroi sud, une représentation du cadavre de Htmyt qui, prisonnière d'un sarcophage, n'appartient pas à la Douat Supérieure.

\section{c. Scène D 16}

La scène D 16 (fig. 27) présente, comme la scène D 15, divers protagonistes émergeant. Le personnage central, Osiris qui préside à l'Occident (Wsir hnty 'Imnt), est représenté entièrement rouge, un choix de couleur qui n'est pas anodin car il correspond à tous les soleils représentés dans la version de Ramsès VI. Les pieds d'Osiris sont encore emprisonnés dans le sol, mais il est déjà plus élevé que Geb et Taténen qui l'encadrent. Ces deux divinités, qui représentent la terre, ne peuvent pas s'élever et sortir de la Douat. Les trois divinités sont entourées d'un grand serpent, Apophis, un couteau fiché dans sa tête ${ }^{101}$. Une scène relativement similaire est représentée à la sixième division du Livre des Cavernes (fig. 28). Le dieu solaire émerge d'une butte qui emprisonne un serpent identifié grâce aux épithètes le désignant comme Apophis ${ }^{102}$. À côté de cette butte, le dieu Taténen est aussi représenté émergeant du sol, mais encore en partie enfoncé dans celui-ci. Cette scène du Livre des Cavernes intervient dans le récit au moment où figurent de nombreuses images du dieu solaire qui entame son processus de renaissance. Dans la chambre funéraire de Ramsès VII, la scène D 16 est sur la même paroi que celle identifiée par Barta comme la scène finale du Livre de la Terre ${ }^{103}$ (fig. 29). Les noms du roi, peu attestés dans les légendes du Livre de la Terre, apparaissent dans la légende de la scène D 16. Leur présence dans cette scène semble indiquer qu'elle revêt une symbolique importante, un moment stratégique de la régénération du soleil auquel le roi souhaite être associé.

\footnotetext{
${ }^{97}$ Hornung 1972, p. 478-479, qui reprend l'idée de PIANKOFF 1953, p. 60, et PiAnKOFF 1954, p. 375. Voir aussi ROBERSON 2012, p. 277.

${ }^{98}$ RoBERSON, 2012, p. 278.

${ }^{99}$ STRICKER 1989, p. 286 ; DARNELL 2004, p. 374-424.

${ }^{100}$ ROBERSON 2012, p. 279.

${ }^{101}$ Les livres funéraires regorgent de figurations d'Apophis vaincu. Par exemple, à la septième heure du Livre de l'Amdouat, Apophis est tenu en laisse par la déesse Serqet, six couteaux fichés dans son corps, cfr SCHULER 2005, p. 122. À la douzième heure du Livre des Portes, il est maintenu enchaîné à cinq piquets plantés dans le sol: cfr PIANKOFF 1962, p. 118. Au chapitre 17 du Livre des Morts, Apophis est décapité par le chat d'Héliopolis : cfr BARGUET 1967, p. 57-64.

102 LEITZ 2002, 7, p. 120.

${ }^{103}$ BARTA 1987, p. 7-9.
} 


\section{d. Scène D 13}

La scène D 13 (fig. 30) évoque, dans le même esprit que la scène D 14, le châtiment des ennemis, avec Rê jouant un rôle plus dynamique. Il se déplace dans l'au-delà, dispense sa lumière et punit les ennemis qui seront condamnés à ne pas voir sa lumière et, par conséquent, à être définitivement plongés dans l'obscurité ${ }^{104}$. Cette thématique de la punition des ennemis du soleil est omniprésente à la fin du Livre de l'Amdouat.

\section{e. Scènes D 11 et D 9}

Situées au registre médian, les scènes D 11 (fig. 31) et D 9 (fig. 32) représentent Rê sous la forme du scarabée Khépri. Désignées «la naissance de Khépri » par Roberson, ces scènes illustrent une thématique également présente dans la scène $\mathrm{C} 1$, dans laquelle le scarabée ailé qui émerge d'un astre solaire est également visible. Elles expriment de façon claire une idée de renaissance solaire.

\section{f. Scène D 6}

La scène D 6 (fig. 33) présente deux divinités féminines, identifiées comme « le cadavre de

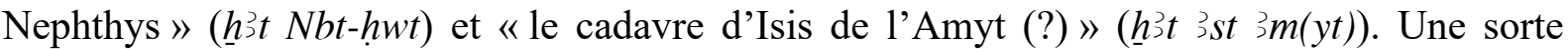
d'ovale contient Osiris, représenté couché sur le dos, son corps décrivant une forme concave. Une divinité hiéracocéphale, nommée « le cadavre d'Horus » $\left(\underline{h} 3 t H r^{105}\right)$, se tient debout au niveau du bassin d'Osiris. La légende de cette scène est particulièrement éclairante :

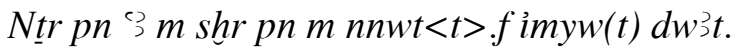

Bhdty pr.f $m$ hỉ it it.f.

Hknw.f n pn wtt sw,

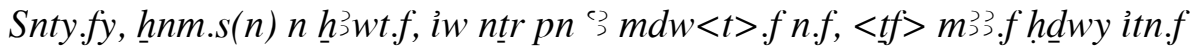

«Ce grand dieu en cette forme (est) dans son œuf ${ }^{106}$ qui est dans la Douat.

Celui de Béhédet (?) sort (hors) du cadavre de son père.

Sa louange (est adressée) à celui qui l'a engendré.

Ses deux sœurs s'unissent à son cadavre, tandis que ce grand dieu lui parle et qu'il voit la lumière de son astre solaire. »

Selon Cambefort, cette scène représente un Osiris sous forme de larve de scarabée enfermée dans sa «boulette-œuf». À l'intérieur de cette « enveloppe », réceptacle lors de la ponte, appelée $n n w t$, le scarabée en devenir va effectuer ses transformations, afin d'en sortir adulte $^{107}$. La forme du corps d'Osiris rappelle également le signe akhet à travers lequel le

${ }^{104} N n$ ntrw $m$ shr $<p w>p n,<s n>(m) r . s n \underline{h} 3$ wt hft $(y) w . s n$ dỉ.t $(w)<s n>s \underline{d} w t$ im.sn, ỉw ntr pn 3 wd.f $\underline{d} w w t . s n$

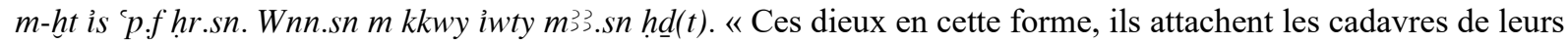
ennemis afin que les flammes soient placées en eux, tandis que ce grand dieu prescrit leurs maux après avoir voyagé au-dessus d'eux. Alors ils seront dans l'obscurité sans voir la lumière ».

105 DARNELL 2004, p. 603. Le signe I 14 peut avoir une valeur cryptographique de « $\mathrm{r} »$.

106 PiANKOFF 1953, p. 48. Il traduit ce terme par «œuf»; toutefois, nnt indique également le «ciel inférieur », cfr FAULKNER 1962, p. 134. Dans ce contexte, il est plus logique de traduire par « œuf », dans le sens de matrice qui précède la naissance ; CAMBEFORT 1987, p. 21 : nnwt désigne la boule de fumier du scarabée.

${ }^{107}$ CAMBEFORT 1987, p. 21-26. 
soleil se lève. Il s'agit d'une nouvelle manière d'expliquer le mystère de la renaissance du soleil et de ses métamorphoses pendant la nuit. Une scène assez similaire se voit à la quatrième division du Livre des Cavernes (fig. 34). Le corps d'Osiris y est représenté dans la même position avec un soleil au-dessus de son ventre. Il ne figure pas à l'intérieur d'un réceptacle, mais il est encadré par Isis et Nephthys qui le soulèvent et recomposent son corps. Comme on l'observe dans les chambres funéraires et sur les sarcophages, Nephthys se trouve à la tête d'Osiris et Isis à ses pieds.

\section{g. Scène D 7}

La scène D 7 (fig. 35) est juste au-dessus de la scène D 9. Pour Roberson, il s'agirait de la représentation de Rê entre les deux collines de l'horizon ${ }^{108}$. D'après Stricker, l'élévation du $b a$ d'Osiris, mentionné et figuré dans la scène, correspond à l'élévation du corps du dieu nouveau-né ${ }^{109}$. Mauric-Barberio précise que l'élévation du ba d'Osiris par deux divinités équivaut à l'élévation de $\mathrm{Re}^{110}$. La notion d'élévation est clairement indiquée dans la légende :

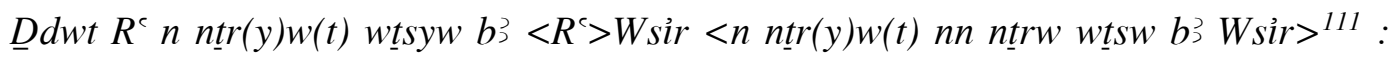

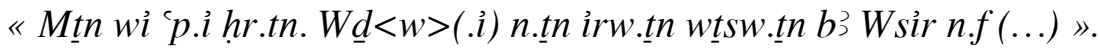

«Ce que Rê dit aux déesses qui élèvent le $b a$ d'Osiris ${ }^{112}:$ "Voyez moi, je traverse au-dessus de vous. J'ordonne à vous et à vos formes que vous souleviez le $b a$ d'Osiris pour lui $(\ldots) »$.

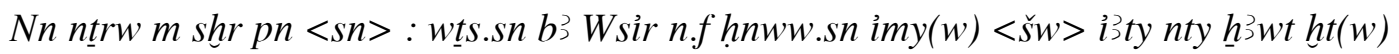
$R^{\circ}$ im.s, iw ntr pn $3 m d w<t>$.f $n$ nn ntrw.

«Ces dieux en cette forme : ils soulèvent le $b a$ d'Osiris pour lui, ils louent ceux qui sont dans les deux buttes où le cadavre de Rê se retire, tandis que ce grand dieu parle à ces dieux. »"

Comme précédemment, la présence de la titulature royale de Ramsès VI dans cette scène permet d'associer le roi à l'élévation du ba d'Osiris.

\section{h. Scène D 2}

La scène D 2 (fig. 36) présente deux grandes paires de bras rouges émergeant du sol, d'où surgit un grand soleil rouge. Cette scène évoque pour la première fois le lever du soleil de façon concrète. La scène, qui occupe le centre du registre supérieur de la paroi, montre le soleil dans toute sa splendeur et est associée au texte suivant, on ne peut plus explicite : Wnn

\footnotetext{
${ }^{108}$ ROBERSON 2012, p. 267.

109 STRICKER 1989, p. 231.

${ }^{110}$ MAURIC-BARBERIO 2010, p. 207.

${ }^{111}$ Il s'agit probablement d'une dittographie.

112 PIANKOFF 1953 p. 48, propose de voir ici une inversion entre $b a$ de Rê et $b a$ d'Osiris, lequel est clairement mentionné à la ligne suivante (qui est probablement issue d'une dittographie).
} 


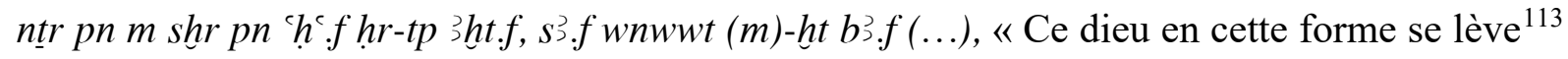
au-dessus de son horizon en gardant les heures (qui sont à) la suite de son $b a(\ldots) »$.

Un élément intéressant est offert par la légende suivante : 'p.hr ntr pn ${ }^{`} m$-hnt wnwwt.f, htw.sn ir.sn ihyw.sn " Alors ce grand dieu traversera à la suite de ses heures, ils se retournent pour faire leurs devoirs ${ }^{114}$. » Cet extrait fait référence aux uraei placés sur le globe solaire. Le texte introduit le fait que ces derniers effectuent leurs tâches dans le processus de régénération solaire avant de retourner à leur place initiale. C'est un concept qui se retrouve à fin du Livre de l'Amdouat ${ }^{115}$. Ces différentes entités, que ce soit dans le Livre de la Terre ou dans le Livre de l'Amdouat, ont un rôle à jouer dans l'au-delà et ne peuvent donc pas se lever avec le soleil car elles doivent effectuer leurs tâches nuit après nuit. Leur destinée est donc de résider dans la Douat.

\section{i. Scène D 3}

La scène D 3 (fig. 37) présente une grande figure féminine nommée la Mystérieuse ( $\breve{S} t 3 y t$ ). La légende explicite des notions qui méritent d'être soulignées et qui sont également attestées à la scène A 4 :

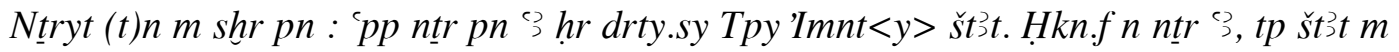

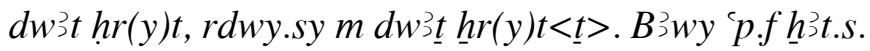

«(...) Il se réjouit pour ce grand dieu, la tête de la Mystérieuse (est) dans la Douat Supérieure, ses deux pieds (sont) dans la Douat Inférieure. Les deux $b a^{116}$, il(s) traverse(nt) son cadavre. »

Le motif de la Mystérieuse apparaît également à la cinquième division du Livre des Cavernes (fig. 38) qui évoque le mystère de la formation d'un nouvel être. Elle fait face à un dieu ithyphallique de même taille coiffé d'un oiseau en lequel Piankoff reconnait Nout et Geb. Cette scène du Livre des Cavernes lui permet d'identifier, par comparaison, la divinité féminine du Livre de la Terre à la déesse Nout ${ }^{117}$. Toutefois, selon Barguet, il ne s'agit pas de la représentation de Geb, mais bien de celle d'Osiris surmonté de son $b a^{118}$. Par déduction, Barguet identifie la Mystérieuse à Isis et reproduit ainsi le schéma de la légende osirienne ${ }^{119}$. Notons cependant que les noms de Nout et d'Isis ne sont à aucun moment mentionnés dans le Livre des Cavernes ni dans le Livre de la Terre.

\footnotetext{
113 OBSOMER 2009, p. 190. La forme wnn.f + prédicat adverbial se traduit en moyen égyptien par un futur mais peut être traduite ici par un présent pour tenir compte de l'influence du néo-égyptien. L'emploi du futur ou du présent reste cohérent par rapport à la symbolique de la scène.

114 HORNUNG 1972, p. 463, propose de traduire par le terme « devoir », toutefois sans certitude.

115 HORNUNG 1972, p. 190-194 ; SCHULER 2005, p.193 ; CARriER 2009, p. 162.

${ }^{116}$ DARNELl 2004, p. 382. MAURIC-BARBERIO 2010, p. 188, estime que les deux ba qui traversent son corps font référence à une autre tradition liée à l'union d'Osiris et de Rê qui serait celle de leur propre $b a$. Selon Mauric-Barberio, le terme $b$ ‘wy correspond au $b a$ d'Osiris et au $b a$ de Rê réunis.

${ }^{117}$ PIANKOFF 1942, p. 44.

118 BARGUET 1976, p. 31-33. En effet, la litanie qui précède la sixième division du Livre des Cavernes permet d'identifier cette figure à Osiris : « Ô Osiris, le grand dieu aux corps cachés, celui avec lequel se trouve $n h$ ’- $h r$ (...), ton $b a$ repose sur ta tête », cfr PIANKOFF 1943, p. 18.

119 BARGUET 1976, p. 37.
} 
Piankoff observe que la Mystérieuse apparaît aussi sur les couvercles de certains sarcophages royaux ${ }^{120}$, ainsi que sur certains sarcophages privés ${ }^{121}$. Toutefois, contrairement à Nout, la Mystérieuse n'est pas représentée à l'intérieur du couvercle des sarcophages, mais à l'extérieur. L'exemple le plus original est celui du sarcophage de Djedhor (Louvre D 9), où la Mystérieuse figure au fond de la cuve ${ }^{122}$. À l'intérieur du couvercle, où figure traditionnellement Nout, un texte fait référence à la Mystérieuse. Son emplacement sur les sarcophages indique qu'il ne s'agit pas de la déesse Nout, mais bien de la Mystérieuse, divinité à part entière. Si elles sont bien distinctes, il reste toutefois à identifier cette dernière. Selon Assmann et Darnel1 ${ }^{123}$, la Mystérieuse correspond au cadavre d'Osiris réunifié à son $b a$, c'està-dire à Rê. Comme le terme ḩ̉t («cadavre») est féminin, le personnifier par une figure féminine semble logique. Dès que l'union entre Osiris et Rê a eu lieu, une confusion s'installe entre la Douat, la terre qui donne naissance au soleil et la personne d'Osiris. Il peut ainsi aider le soleil à renaître car, en tant que père d'Horus, il est celui qui fait naître le solei1 ${ }^{124}$. C'est une notion également présente dans le texte accompagnant la scène D 3 : ${ }^{\mathrm{C}} p t \underline{h}{ }^{3} w t \check{s} t\left({ }^{3} t\right)$ ir $r w$ in

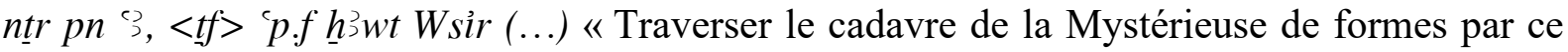
grand dieu, quand il traverse le cadavre d'Osiris (...)». Cette notion permet d'éclairer la scène A 7. Dans la version de Ramsès IX, la figure ithyphallique est « Celui-du-mystère " $\left(p(3)-n(y)\right.$-št $\left.{ }^{3} y t\right)$. Piankoff, Darnell, Mauric-Barberio et Roberson s'accordent à dire que le personnage ithyphallique de la scène A 7 est à l'origine de la renaissance des heures, après les avoir temporairement dissimulées en lui ${ }^{125}$. La dénomination «Celui-du-mystère » permet de l'associer à la figure masculine de la cinquième division du Livre des Cavernes, où il est présenté comme parèdre de la Mystérieuse. Le personnage figuré ici est donc à l'origine de la naissance des heures et de «l'enfant solaire ».

\section{j. Scène D 1}

La scène D 1 (fig. 39), que certains considèrent comme le tableau initial du Livre de la Terre ${ }^{126}$, n'est attesté que dans la tombe de Ramsès VI. Mauric-Barberio estime que cette scène résume les différentes figurations d'Osiris que l'on retrouve dans les deux premières divisons du Livre des Cavernes, ainsi que sur une scène de la troisième division. Les légendes identifient cette scène à la "pièce cachée » ( ${ }^{c} t$ imnt), qui renferme le cadavre d'Osiris ${ }^{127}$. Assmann y voit la même notion dans ce qu'il nomme « le caveau caché » ${ }^{128}$. Selon Roberson, la scène représente le sanctuaire d'Osiris $(k \jmath$ ri $)$, aussi bien par la mention dans le texte que par la forme même de l'édifice représenté. Anubis est placé en protection d'une version réduite de

\footnotetext{
${ }^{120}$ PiANKOFF 1953, p. 44. Notamment ceux de Siptah, Taousert-Sethnakht, Ramsès III et Ramsès IV.

${ }^{121}$ MANASSA 2007, p. 287.

122 MANASSA 2007, pl. 286.

${ }^{123}$ ASSMANN 1983, p. 340-341; DARNELL 2004, p. 80 et p. 382.

124 DARNELl 2004, p. 384 ; MAURIC-BARBERIO 2010, p. 191.

125 PiAnKoff 1949, p. 116 ; DARnell 2004, p. 384 ; MAURIC-BARberio 2010, p. 194 ; Roberson 2012, p. 186-187.

126 STRICKER 1994, p. 96 ; ABITZ 1995, p. 165 ; HORNUNG 1999, p. 97. MAURIC-BARBERIO 2010, p. 181-183, est moins catégorique que ses prédécesseurs.

${ }^{127}$ MAURIC-BARBERIO 2010, p. 204.

${ }^{128}$ ASSMANN 2004, p. 293.
} 
cet édifice, en bas de la scène D $1^{129}$. Abitz voit en cette scène la représentation de la chambre funéraire, de par le parallèle entre la représentation des ennemis décapités à la scène $\mathrm{D} 1$ et ceux représentés sur le pourtour de la chambre funéraire ${ }^{130}$. Pour Hornung, il s'agit de la représentation du royaume d'Osiris dans son intégralité, avec Anubis protégeant le corps d'Osiris placé au centre ${ }^{131}$.

Leitz propose de voir un lien entre les trois scènes du registre supérieur du mur sud de la chambre funéraire de Ramsès VI (D 1, D 2 et D 3) ${ }^{132}$. En effet, ces scènes peuvent être divisées en trois zones : les pieds de la Mystérieuse, les bras de la D 2, et le petit coffret de la D 1 ; la zone médiane (corps et tête de la Mystérieuse, personnage momiforme de la D 2 et la partie haute du sanctuaire d'Osiris); et enfin, le soleil qui domine la paroi. Leitz se réfère ainsi aux légendes accompagnant la scène D 3 pour proposer de voir en la partie inférieure des scènes D 1 et D 2, une représentation de la Douat Inférieure, et en leur partie supérieure, une représentation de la Douat Supérieure ${ }^{133}$. Le personnage central de la scène D 2 est identifié par Cauville comme Osiris ${ }^{134}$, qui appartient donc, par symétrie, à la Douat Inférieure. Le corps d'Osiris (correspondant au mystère $\check{s}^{t}{ }^{3} t$ ) représente, selon Darnell, l'horizon donnant naissance au jeune soleil ${ }^{135}$. La combinaison de ces différentes idées permet de donner du sens à cette scène D 1. Si elle représente le royaume d'Osiris, la Douat, et que le soleil semble s'élever au-dessus de ce lieu, la scène semble indiquer qu'Osiris ne quitte pas la Douat et qu'il y reste durant le jour, après avoir accompli son rôle dans la régénération solaire durant la nuit et permettant ainsi le futur renouvellement du cycle solaire. Cette thématique est clairement exprimée à la douzième heure du Livre de l'Amdouat ${ }^{136}$. Le petit coffret gardé par Anubis est très proche d'une scène de la première division du Livre des Cavernes (fig. 6). Ce parallèle est très cohérent puisque cette zone est associée à la Douat Inférieure, tout comme cette division du Livre des Cavernes.

Concernant le roi défunt, qui souhaite associer son devenir au mystère de la renaissance journalière, son association au corps d'Osiris reste explicable. En effet, selon Assmann, ce mystère revêt deux aspects : l'aspect solaire du renouvellement et l'aspect osirien de la protection, à l'image de la tombe qui doit être lieu de mémoire et lieu de sécurité pour la momie, le roi s'inscrivant ainsi dans ces deux aspects ${ }^{137}$. Les deux figures royales figurant de part et d'autre du mur sud sont placées en adoration du soleil levant, ultime étape du processus de régénération.

\footnotetext{
${ }^{129}$ ROBERSON 2012, p. 282-283.

${ }^{130}$ ABITZ 1989, p. 122-123, repris par MAURIC-BARBÉRIO 2010, p. 204 et par ROBERSON 2012, p. 284.

${ }^{131}$ HORNUNG 1999, p. 97-98.

132 LEITZ 1989, p. 55.

${ }^{133}$ LEITZ 1989, p. 56 (fig. 9) et p. 57.

134 CAUVILle, IBRAHIM 2014, p. 169.

135 DARNELL 2004, p. 384.

${ }^{136}$ HORNUNG 1972, p. 192-193 ; HORNUNG 1999, p. 41.

${ }^{137}$ ASSMANN 2004, p. 283.
} 


\section{k. Les scènes du mur adjacent}

La scène C 4 (fig. 40) est située sur la partie sud du mur du fond de la chambre funéraire de Ramsès VI. Le texte qui l'accompagne évoque «les grands mystères qui sont sortis

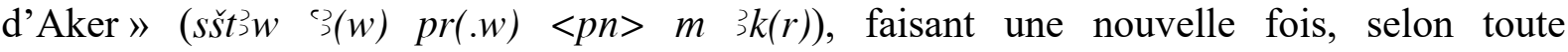
vraisemblance, allusion à l'union d'Osiris et de Rê. Les déesses émergent de buttes et sont placées de façon à évoquer l'horizon-akhet. L'attitude de ces déesses apparaît de façon récurrente dans la sixième division du Livre des Cavernes. La position courbée du personnage central, associée au sceptre ${ }^{138}$ qu'il tient dans sa main, est très similaire à une scène de cette sixième division du Livre des Cavernes, où il est identifié comme Osiris-Orion.

La scène C 2 (fig. 41) présente un globe solaire rouge surmonté d'une tête de faucon. Les légendes associées aux scènes $\mathrm{C} 2$ et $\mathrm{C} 1$ sont inversées dans la tombe de Ramsès $\mathrm{VI}^{139}$. Cette scène que Roberson nomme « la naissance d'Horus » représente la naissance de l'aspect souterrain d'Horus ( $H r-d w 3$ 'ty), et exprime à nouveau cette idée de renaissance, omniprésente sur la paroi sud ${ }^{140}$.

La scène C 1 (fig. 42) montre Khépri émergeant des replis du serpent Apophis dont le mouvement évoque à l'évidence le signe-akhet ${ }^{141}$. Une scène de la sixième division du Livre des Cavernes (fig. 43), visuellement très proche de la scène $\mathrm{C} 1$, montre le scarabée Khépri entre les replis d'un serpent nommé « à la tête malfaisante », épithète du serpent Apophis dont le nom figure dans le texte du Livre de la Terre ${ }^{142}$. Cette scène est placée très proche du tableau final du Livre des Cavernes.

\section{Conclusion}

Le Livre de la Terre est une composition funéraire qui reste difficile à comprendre. Les textes sont fort corrompus et présentent un grand nombre d'erreurs, parfois si récurrentes qu'il est difficile de déterminer si elles sont vraiment des fautes ou si elles procèdent d'une volonté de complexification des textes. Ces erreurs, volontaires ou pas, ne permettent pas toujours de proposer une traduction certaine. De plus, à l'exception des tombes de Mérenptah, de Taousert et de Ramsès III presque identiques, toutes les autres présentent des versions différentes. Mais aucune d'elles ne possède la version complète du Livre de la Terre, si toutefois elle existe. Le corpus est donc assez peu homogène : la version de la tombe de Ramsès VII (fig. 44 et 45) présente un grand nombre de scènes qui ne sont pas attestées dans celle de Ramsès VI, dont un potentiel tableau final dans le coin supérieur droit du mur nord, à côté de l'entrée de la chambre ; sur le mur nord de la tombe de Ramsès IX (fig. 46 et 47) se remarque la scène A 7, tandis que sur la paroi opposée, on retrouve principalement des scènes issues des quatrième et sixième divisions du Livre des Cavernes.

\footnotetext{
${ }^{138}$ Il s'agit du sceptre-djam, ici représenté sans les ondulations qui le caractérisent mais clairement identifié dans le texte.

${ }^{139}$ HORNUNG 1972, p. 452-453. Il constate cette inversion.

140 ROBERSON 2012, p. 174.

${ }^{141}$ ROBERSON 2012, p. 178. La position du serpent Apophis est, selon lui, similaire à celle du serpent Mehen représenté sur la scène $\mathrm{A} 7 \mathrm{du}$ mur nord.

142 BARGUET 1986, p. 36.
} 
La comparaison de la version du Livre de la Terre de la tombe de Ramsès VI avec le Livre des Cavernes permet d'observer, à partir des scènes communes, une certaine logique. Un motif de la scène A 12 figure à la première division du Livre des Cavernes, la scène A 2 est visuellement très proche de la scène de la troisième division qui marque le passage entre les deux Douat. Le mur sud présente davantage de scènes similaires à celles du Livre des Cavernes. La scène D 14 est proche d'une scène de la cinquième division, la scène D 6 évoque la quatrième division, la scène $\mathrm{D} 3$ évoque aussi la cinquième division. Les scènes $\mathrm{C} 4$ et $\mathrm{C} 1$ sont très similaires aux scènes de la sixième division du Livre des Cavernes. Une telle disposition semble indiquer que la lecture de cette paroi s'achève par la partie gauche du mur ouest. Les personnages représentés sur le mur nord sont en grande majorité tournés vers la droite. Comme le sens de lecture se fait en croisant le regard des figures animées, il semblerait que la paroi se lise de droite à gauche. Les personnages du mur sud sont tournés soit vers la gauche, soit vers la droite, ce qui complique la compréhension du sens de lecture des scènes du mur sud.

$\mathrm{Au}$ terme de cette étude, il s'avère possible d'argumenter en faveur de la proposition de Cauville, qui avait pris parti pour une lecture du bas vers le haut des parois, soit une lecture respectant la convention attestée pour les compositions organisées en registres. Nous avons aussi eu l'occasion d'approfondir la symbolique de scènes significatives, en permettant de d'aborder la question du bipartisme qui semble une caractéristique intrinsèque au Livre de la Terre.

L'étude des deux parois latérales de la chambre funéraire de Ramsès VI permet de mettre en opposition deux concepts : sur le mur nord, la notion de htmyt, c'est-à-dire le processus de destruction préalable à la renaissance du soleil $(\mathrm{htm})$, qui incarne par extension l'espace géographique consacré à cet anéantissement provisoire, la Douat Inférieure, et qui se matérialise en la déesse Htmyt; sur le mur sud, la notion de št $3 y t$ qui est l'incarnation du corps réunifié et régénéré d'Osiris, conscient de ses capacités créatrices et confondu avec la terre en tant qu'élément donnant naissance au soleil. La notion de št ${ }^{3} y t$ serait le deuxième espace géographique, la Douat Supérieure où renaît le soleil. Dans le premier de ces espaces se produisent les phénomènes nécessaires à la suppression de l'aspect léthargique du soleil et des heures : processus de destruction et de régénération dont dépend aussi l'écoulement du temps. Dans le second espace se déroulent les différents phénomènes de la renaissance du soleil. Entre ces deux lieux s'effectue l'union d'Osiris et de Rê, qui correspond au mystère qui permet de passer d'un lieu à l'autre, ou plutôt d'un état à l'autre. Les scènes de ces deux parois semblent donc être une multiplication d'explications et d'images concurrentes des mystères de la régénération du soleil pendant la nuit, plutôt qu'un parcours rigoureux et géographique de la barque solaire durant la nuit. En effet, le Livre de la Terre a été conçu à la suite du Livre de l'Amdouat et du Livre des Portes et au même moment que le Livre des Cavernes, avec lequel il est attesté pour la première fois dans l'Osireion d'Abydos. En raison de la proximité temporelle et géographique des attestations de ces deux livres funéraires, il aurait été redondant que le Livre de la Terre soit organisé comme le Livre des Cavernes et décrive, une fois de plus, le parcours nocturne du soleil. Le roi s'associe à l'élévation (fig. 5) et aux processus de régénération du soleil en plaçant ses noms dans une grande colonne à la jonction de l'axe entre la scène $\mathrm{A} 12$ et la scène $\mathrm{A} 2$. 


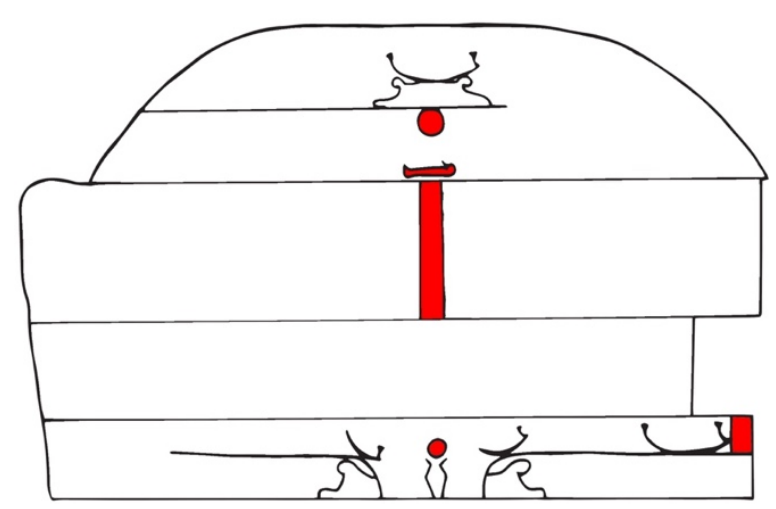

Fig. 5. Élévation du roi, mur nord de la tombe de Ramsès VI. C PLEUGER, 2019.

L'emploi chez Ramsès VI des parois du fond comme prolongement des parois latérales conduit le regard jusqu'au fond de la niche située sur la paroi ouest, dans l'axe de la tombe. Dans cette niche, figure le tableau final du Livre des Portes qui doit probablement faire office de scène finale pour cette version du Livre de la Terre qui n'en possède pas.

Le roi souhaite associer son devenir à celui du soleil et renaître, avec lui, chaque matin. Les scènes qui ornent sa chambre funéraire et son sarcophage sont, à ses yeux, un lieu idéal pour l'expression de cette pensée. À l'époque ramesside, le Livre de la Terre est le recueil de formules funéraires qui illustre le mieux les mystères de la régénération solaire associés à la renaissance osirienne. Le Livre de l'Amdouat, le Livre des Portes et le Livre des Cavernes, qui, à la XIX ${ }^{\mathrm{e}}$ dynastie, sont dorénavant représentés le plus souvent dans les couloirs des tombes, conviennent remarquablement au développement d'un récit linéaire, chronologique et géographique. À l'inverse, le Livre de la Terre, disposé dans les chambres funéraires voûtées, se prête davantage à l'expression visuelle d'élévation aboutissant à la renaissance journalière du soleil. Le Livre des Cavernes et le Livre de la Terre exprimeraient ainsi un récit théologique similaire mais en employant des moyens d'expression différents : le premier en utilisant le moyen du récit ordonné et structuré, le second en privilégiant une expression graphique plus condensée, en adéquation avec l'architecture et la symbolique de la chambre funéraire. 


\section{ILLUSTRATIONS}

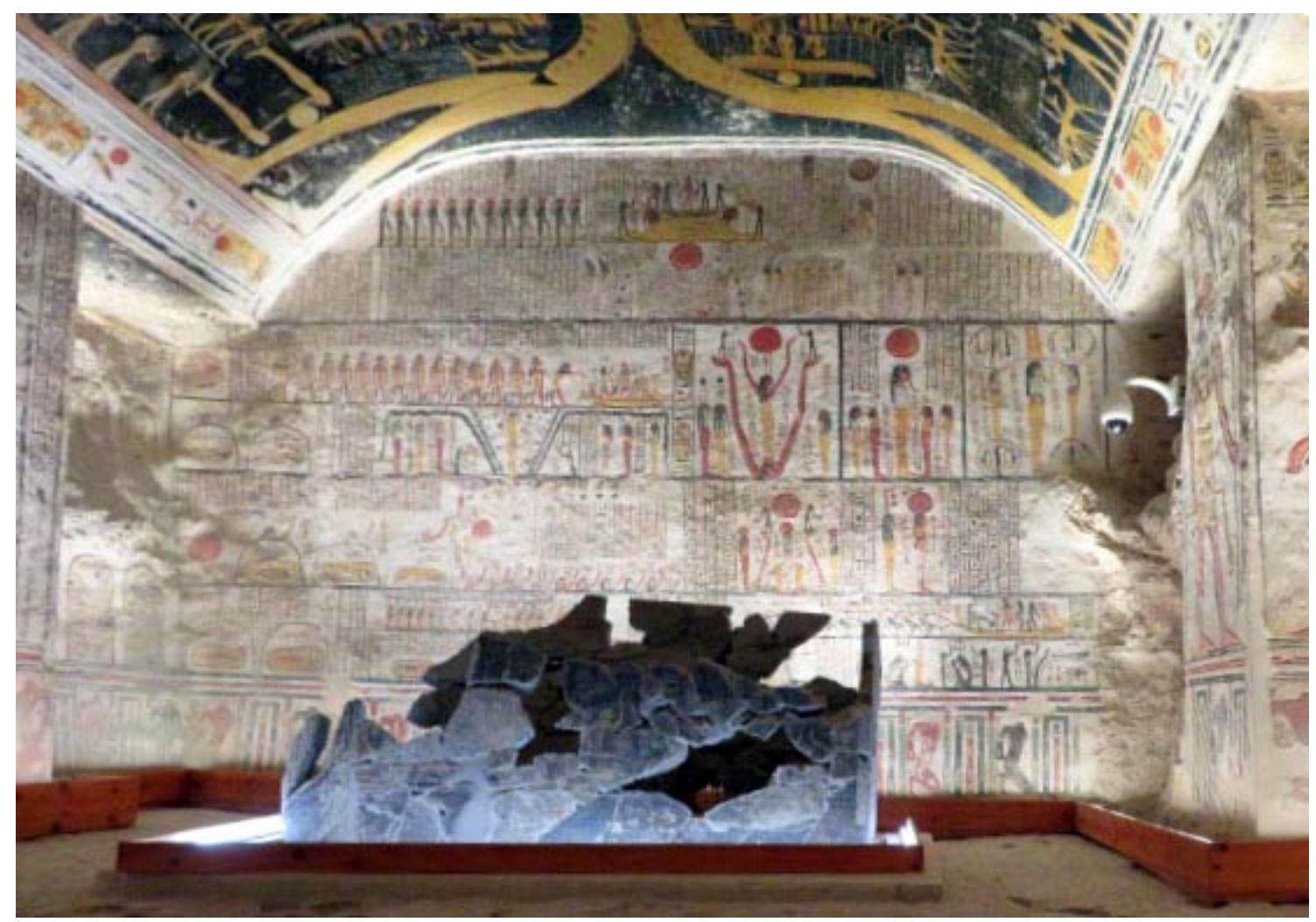

Fig. 1. Mur nord de la chambre funéraire de Ramsès VI (vue d'ensemble). (C PLEUGER, 2020.

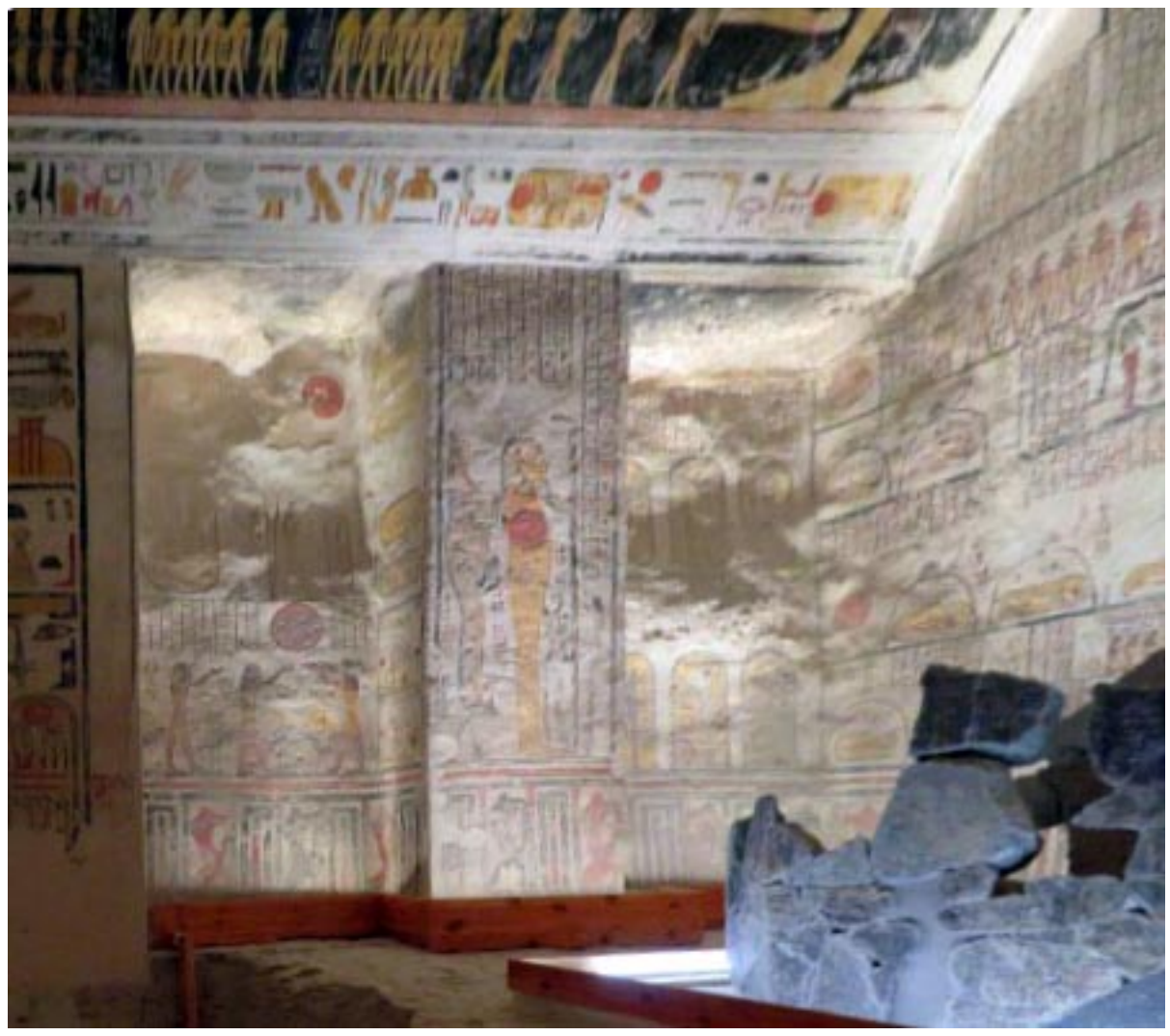

Fig. 2. Mur ouest (partie nord) de la chambre funéraire de Ramsès VI (vue d'ensemble) (C) PLEUGER, 2020. 


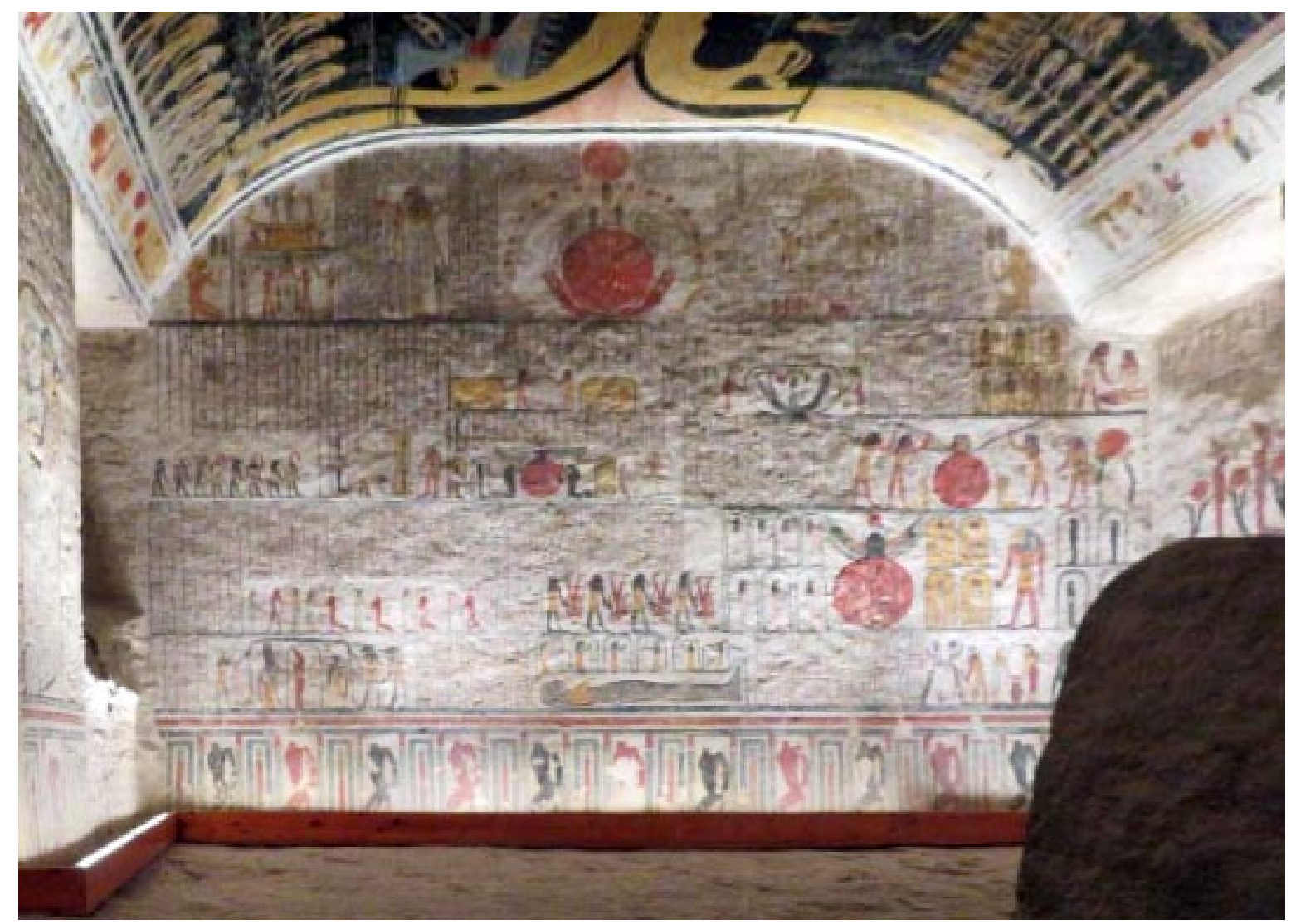

Fig. 3. Mur sud de la chambre funéraire de Ramsès VI (vue d'ensemble). (C) PLEUGER, 2020.

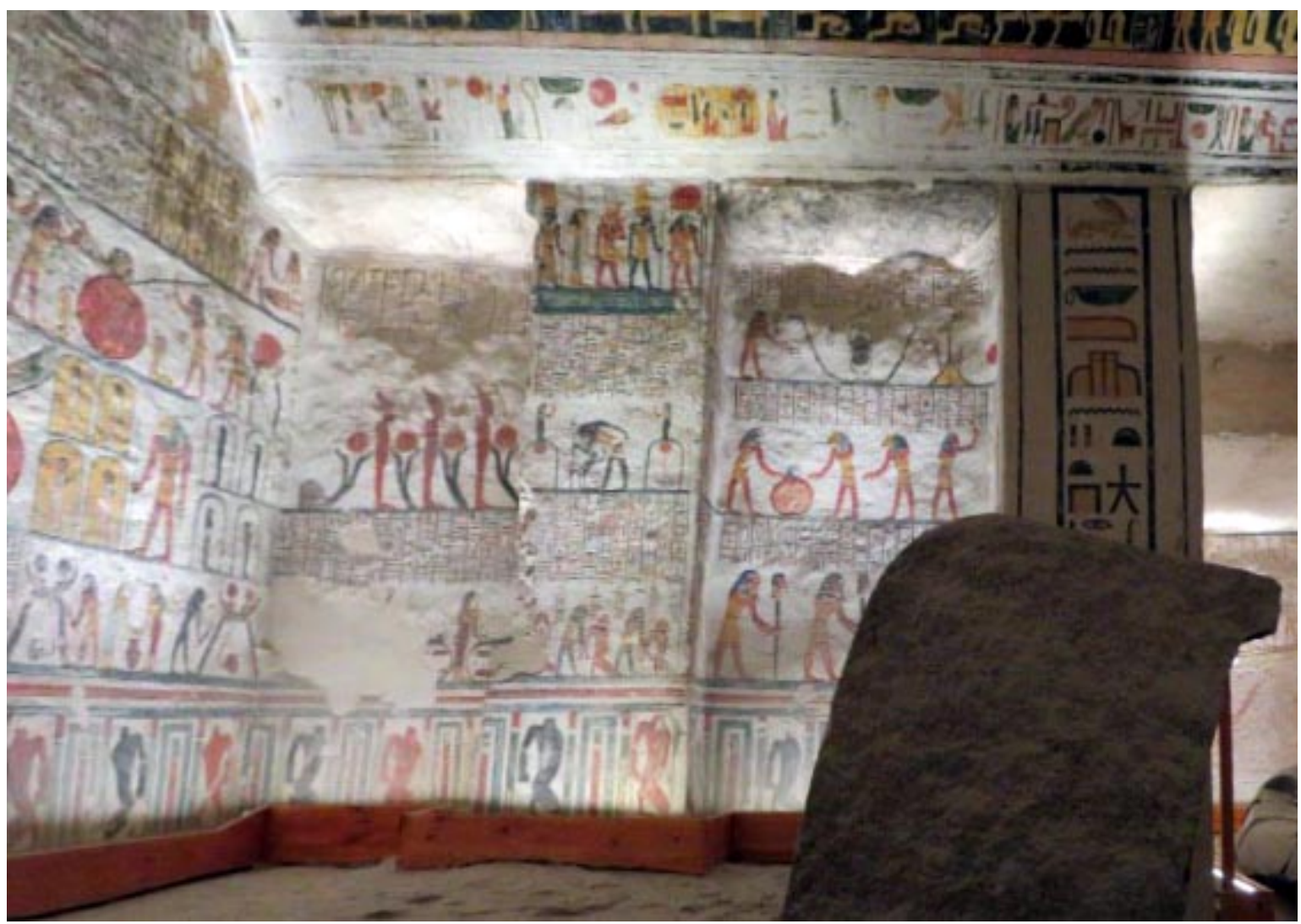

Fig. 4. Mur ouest (partie sud) de la chambre funéraire de Ramsès VI (vue d'ensemble). (C) PLEUGER, 2020. 


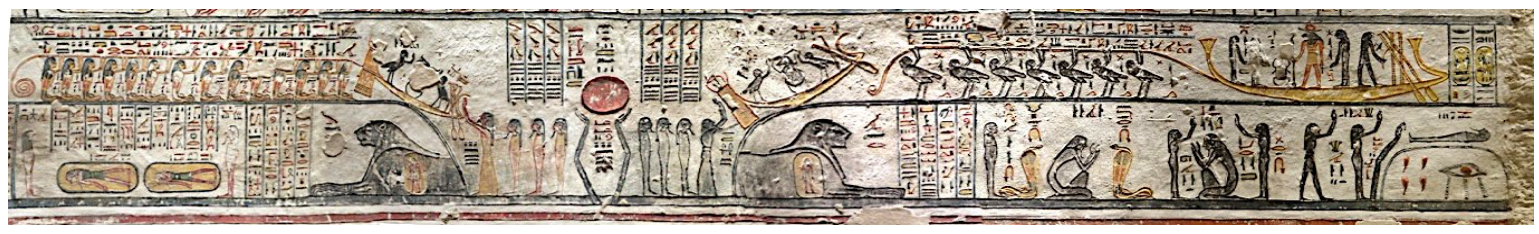

Fig. 5. Scène A 12, détail du mur nord de la tombe de Ramsès VI. (C) PLEUGER, 2020.

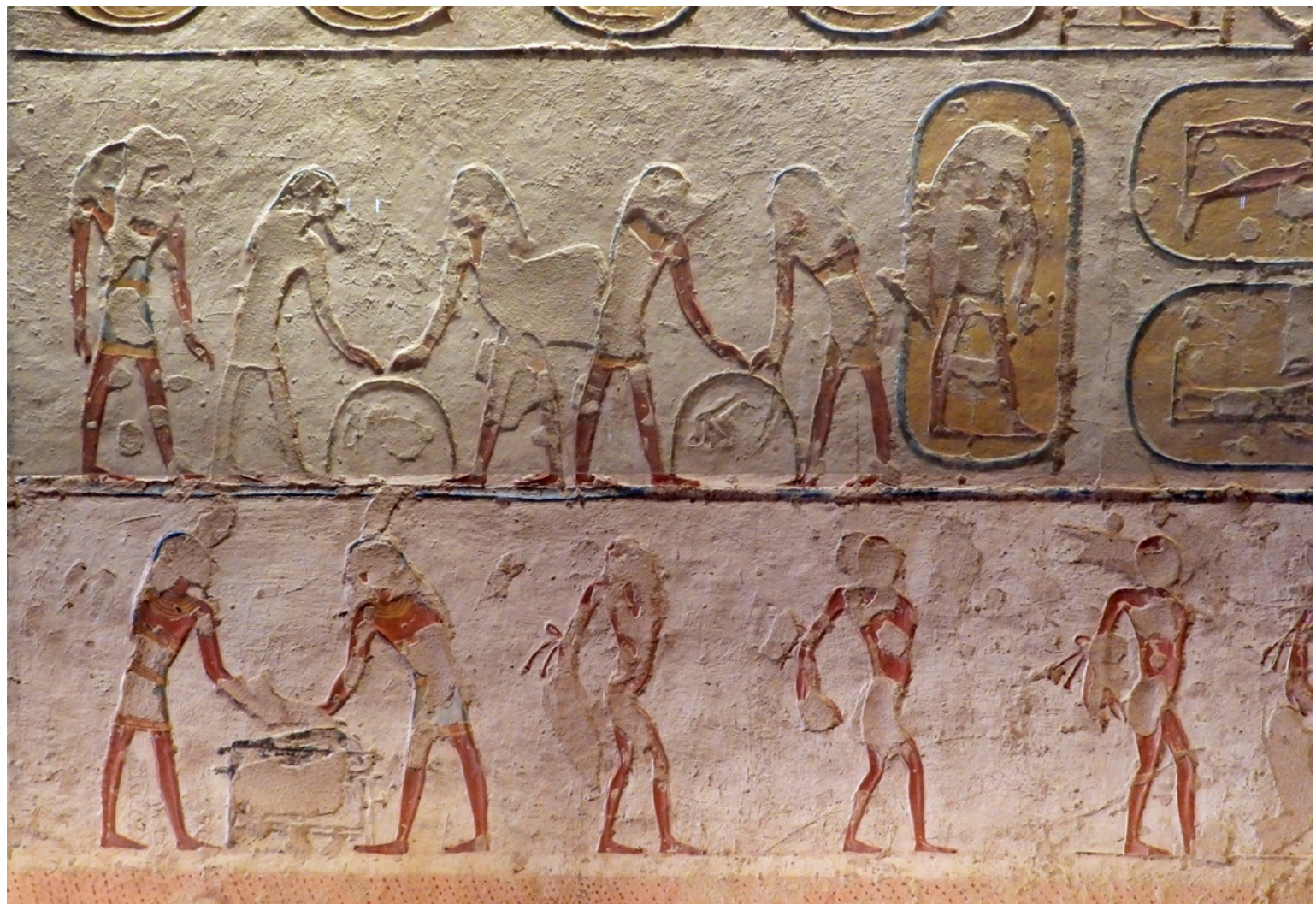

Fig. 6. Détail de la première division du Livre des Cavernes dans la tombe de Ramsès VII. (c) BAILLI, 2020.

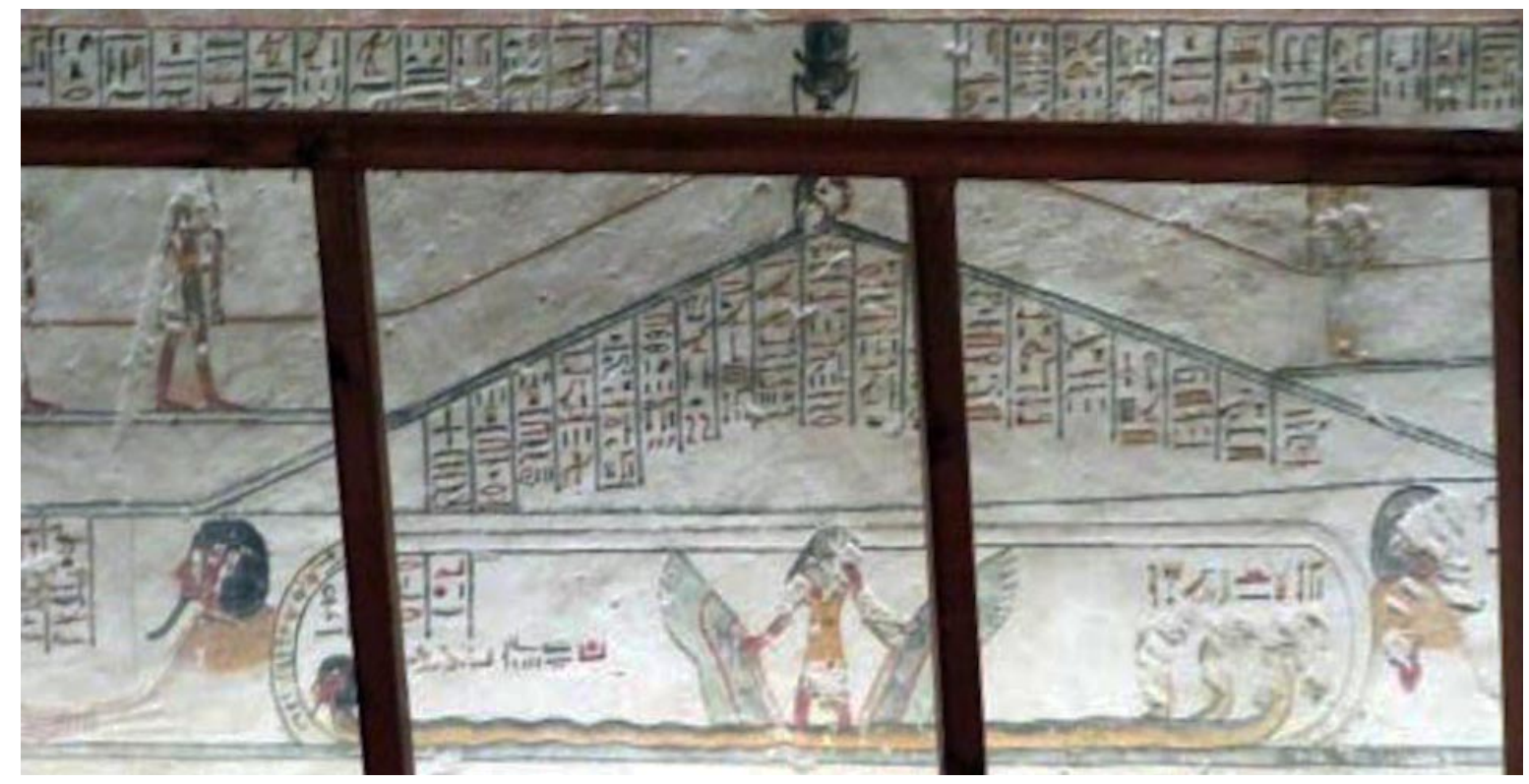

Fig. 7. Détail de la cinquième heure du Livre de l'Amdouat. (C) PLEUGER, 2019. 


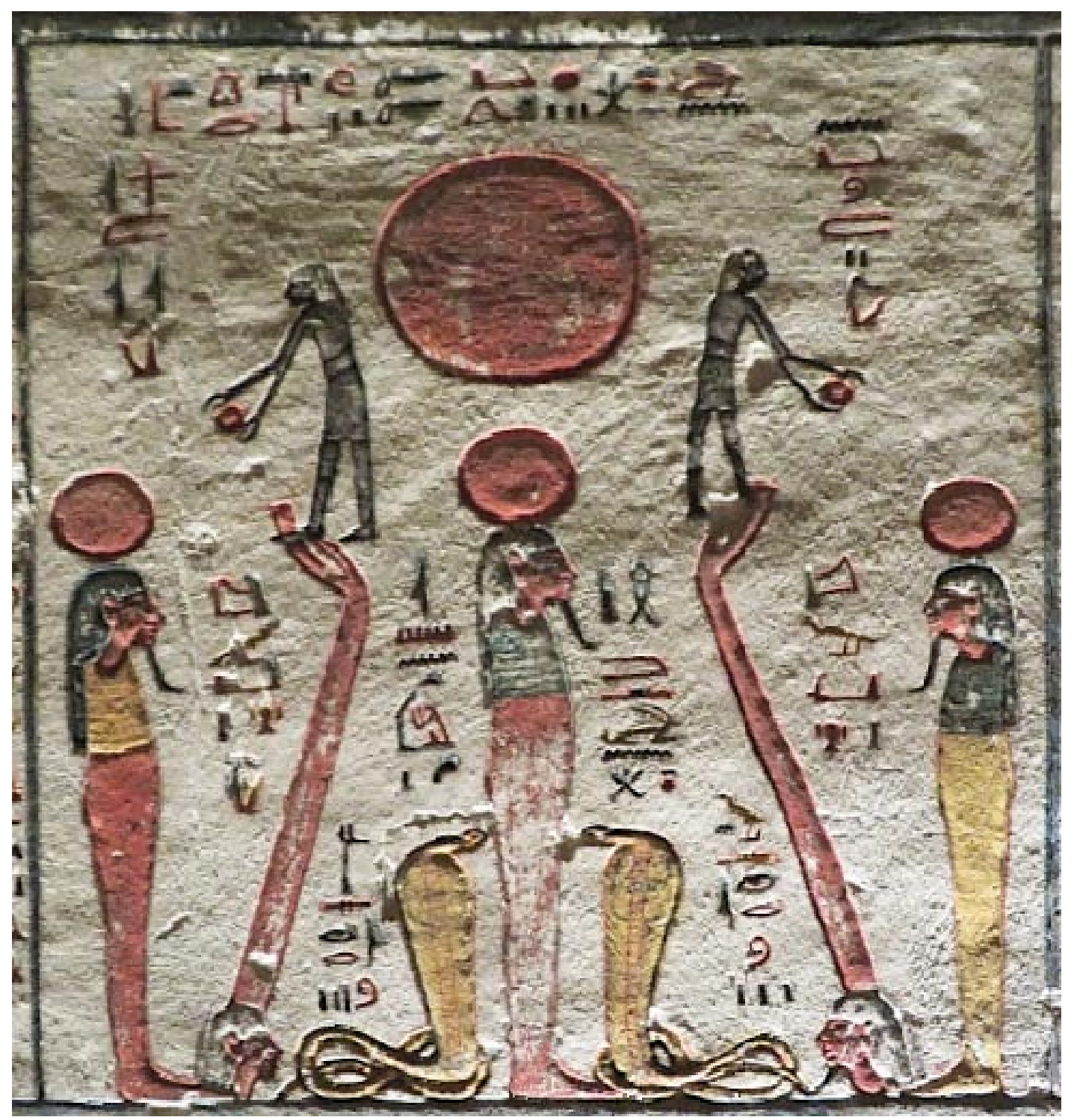

Fig. 8. Scène A 10, détail du mur nord de la tombe de Ramsès VI. C PLEUGER, 2020.

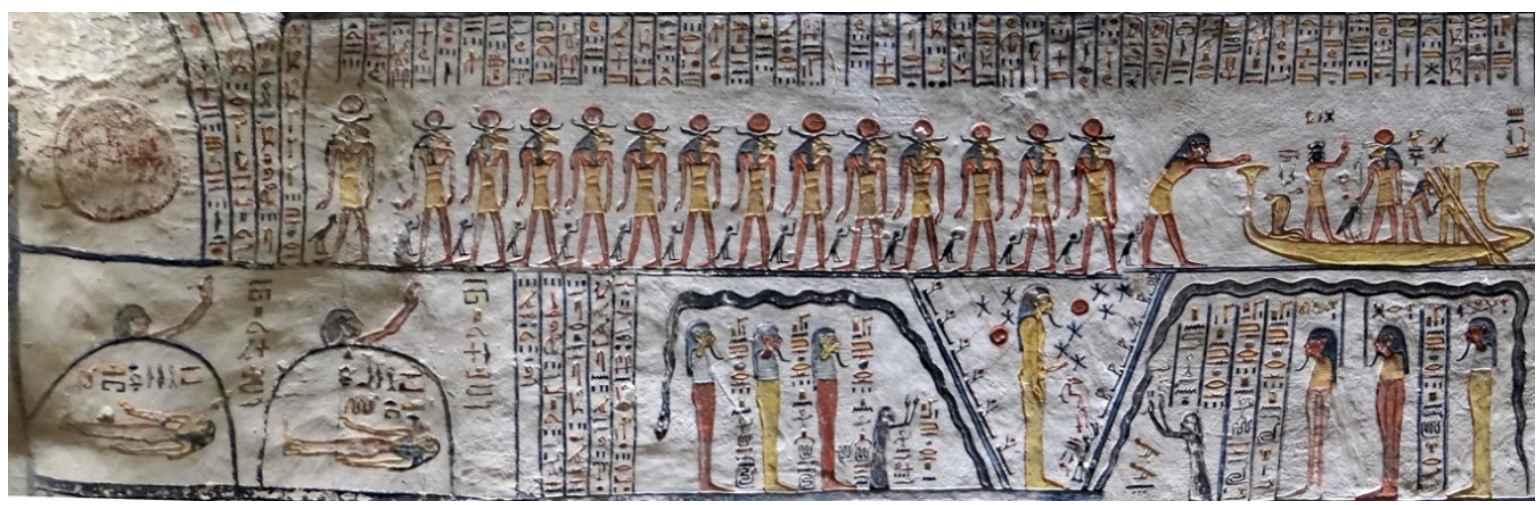

Fig. 9. Scène A 7, détail du mur nord de la chambre funéraire de Ramsès VI. C) PLEUGER, 2018. 


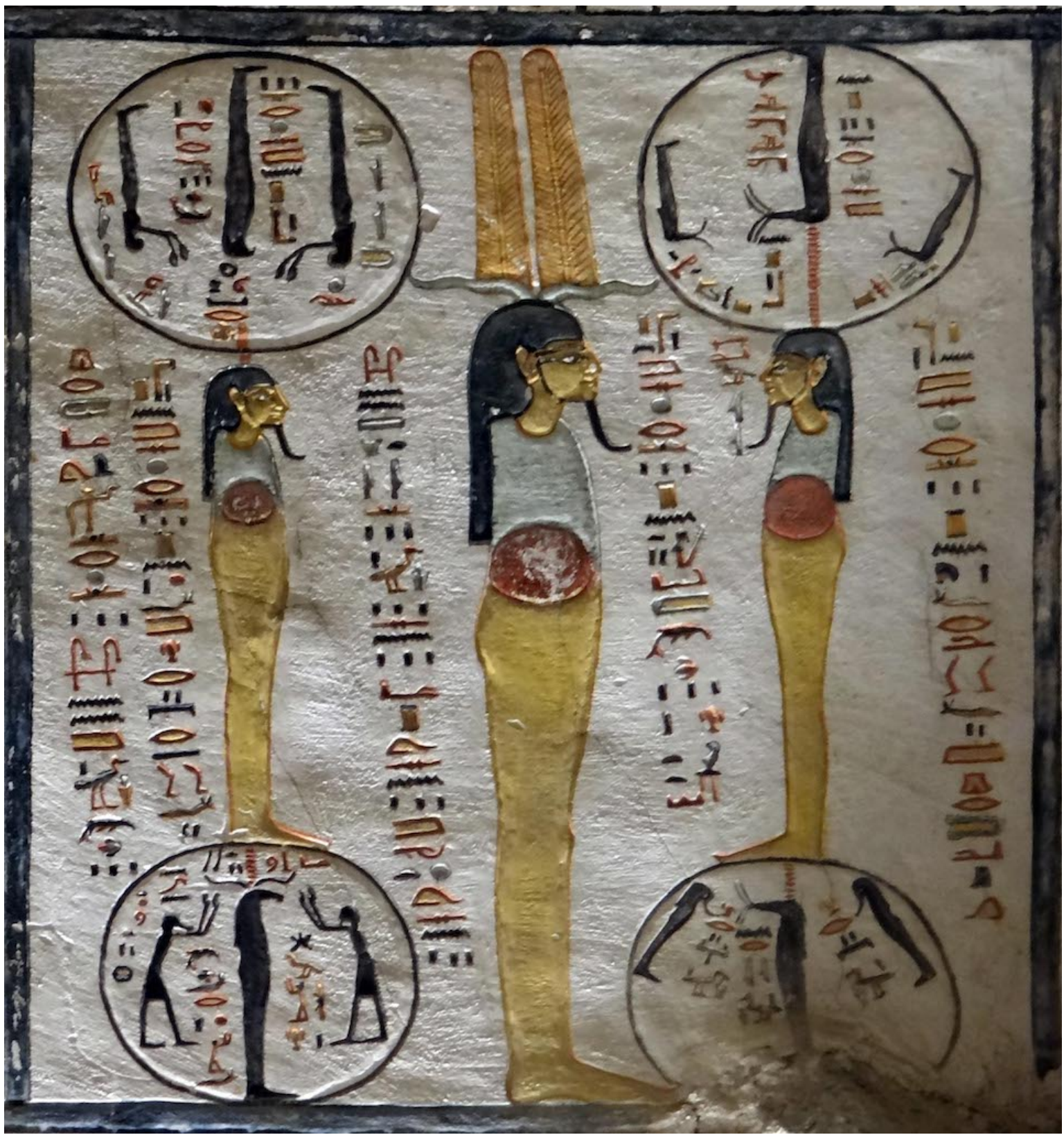

Fig. 10. Scène A 4, détail du mur nord de la chambre funéraire de Ramsès VI. C) PLEUGER, 2018.

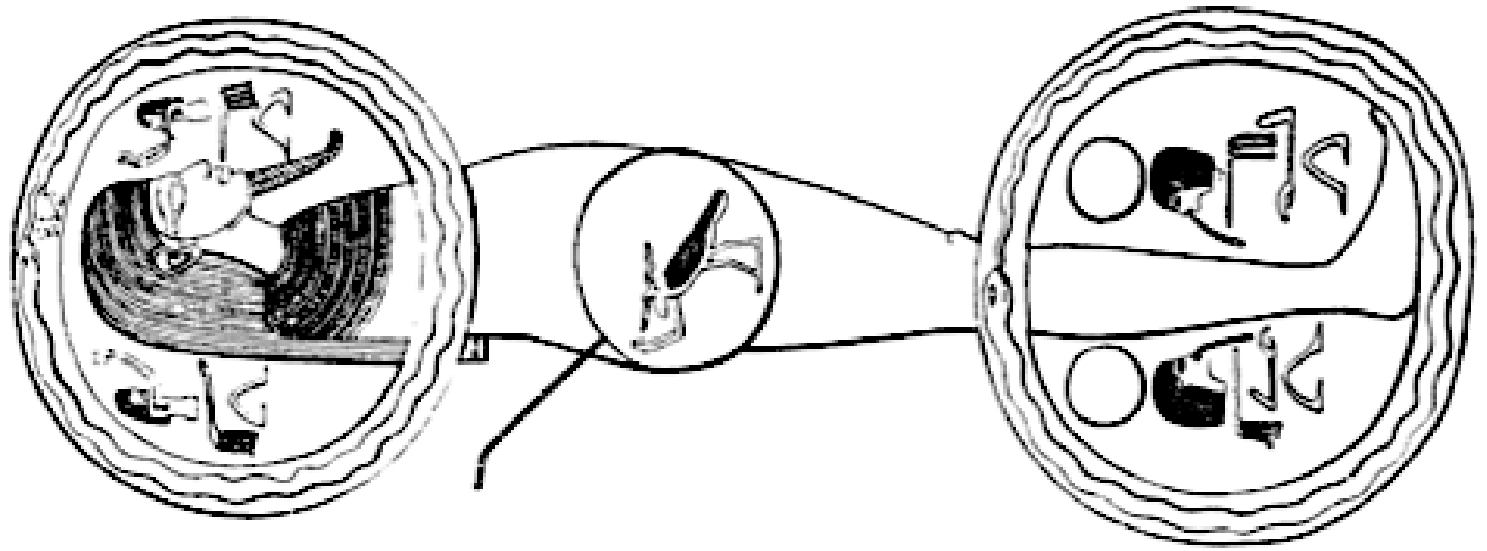

Fig. 11. Deuxième chapelle de Toutankhamon, scène 6. PIANKOFF, 1949, pl. 297, p. 113. 


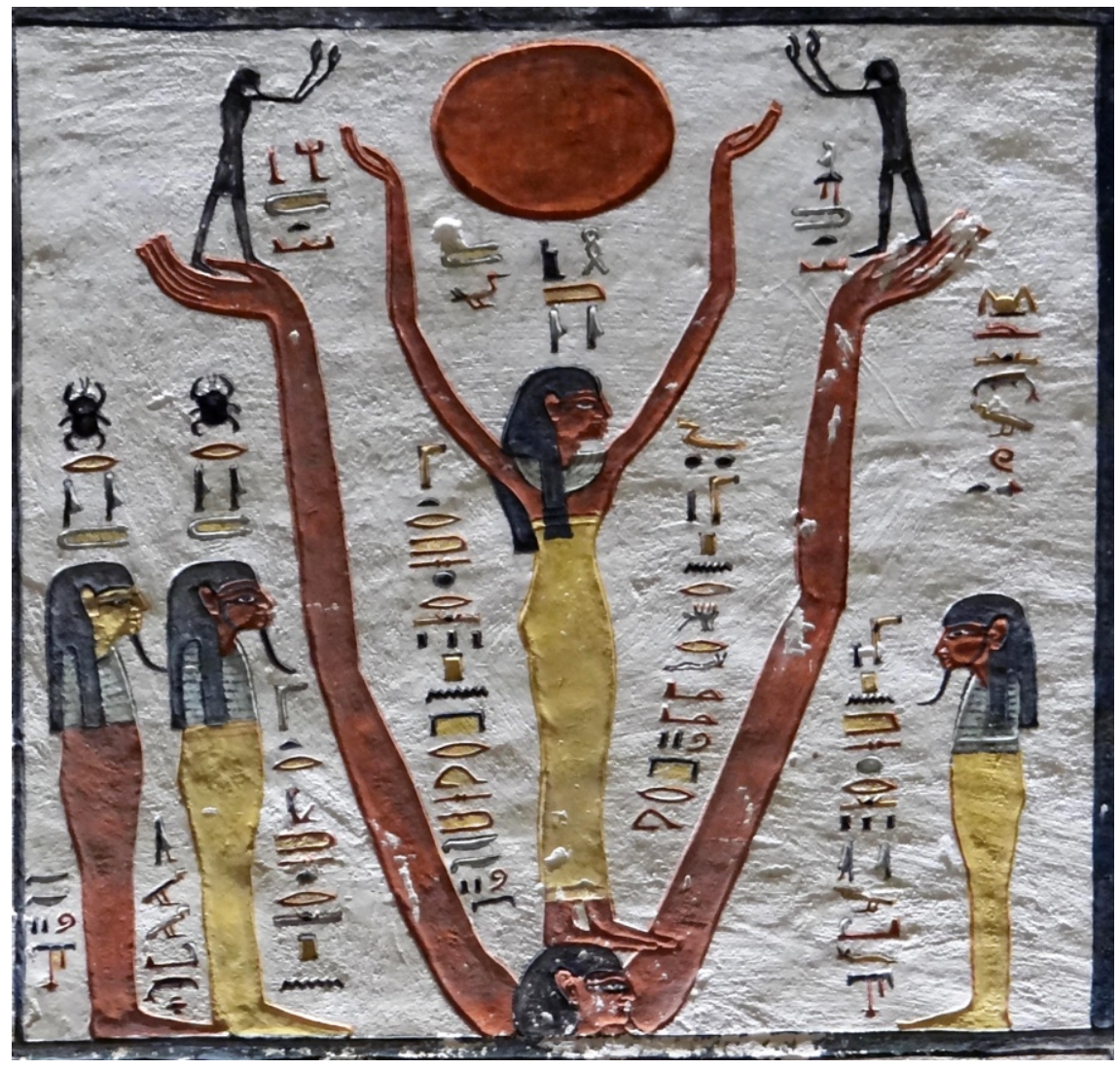

Fig. 12. Scène A 6, détail du mur nord de la tombe de Ramsès VI. C PLEUGER, 2018.

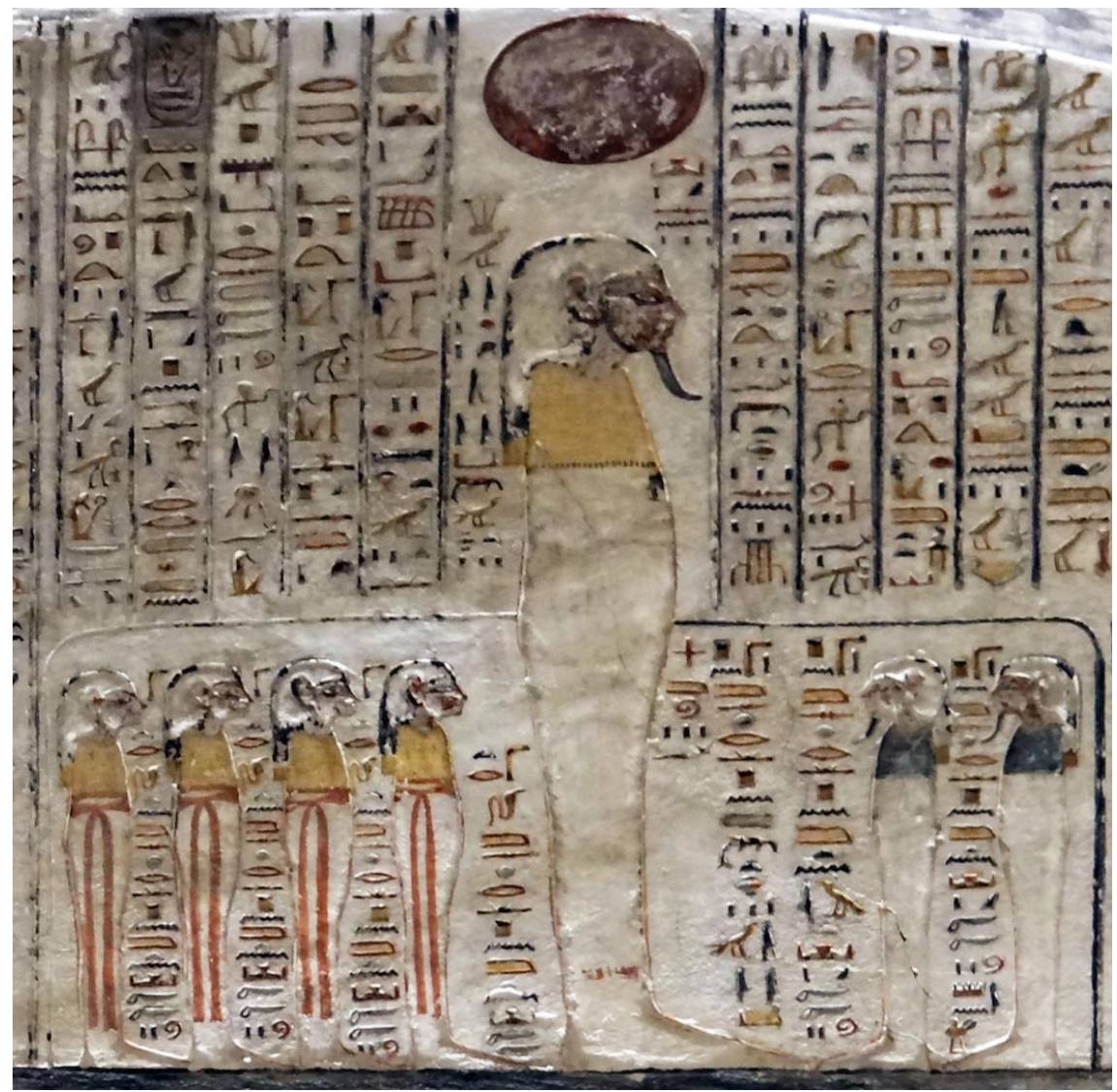

Fig. 13. Scène A 1, détail du mur nord de la chambre funéraire de Ramsès VI. C) PLEUGER, 2018. 


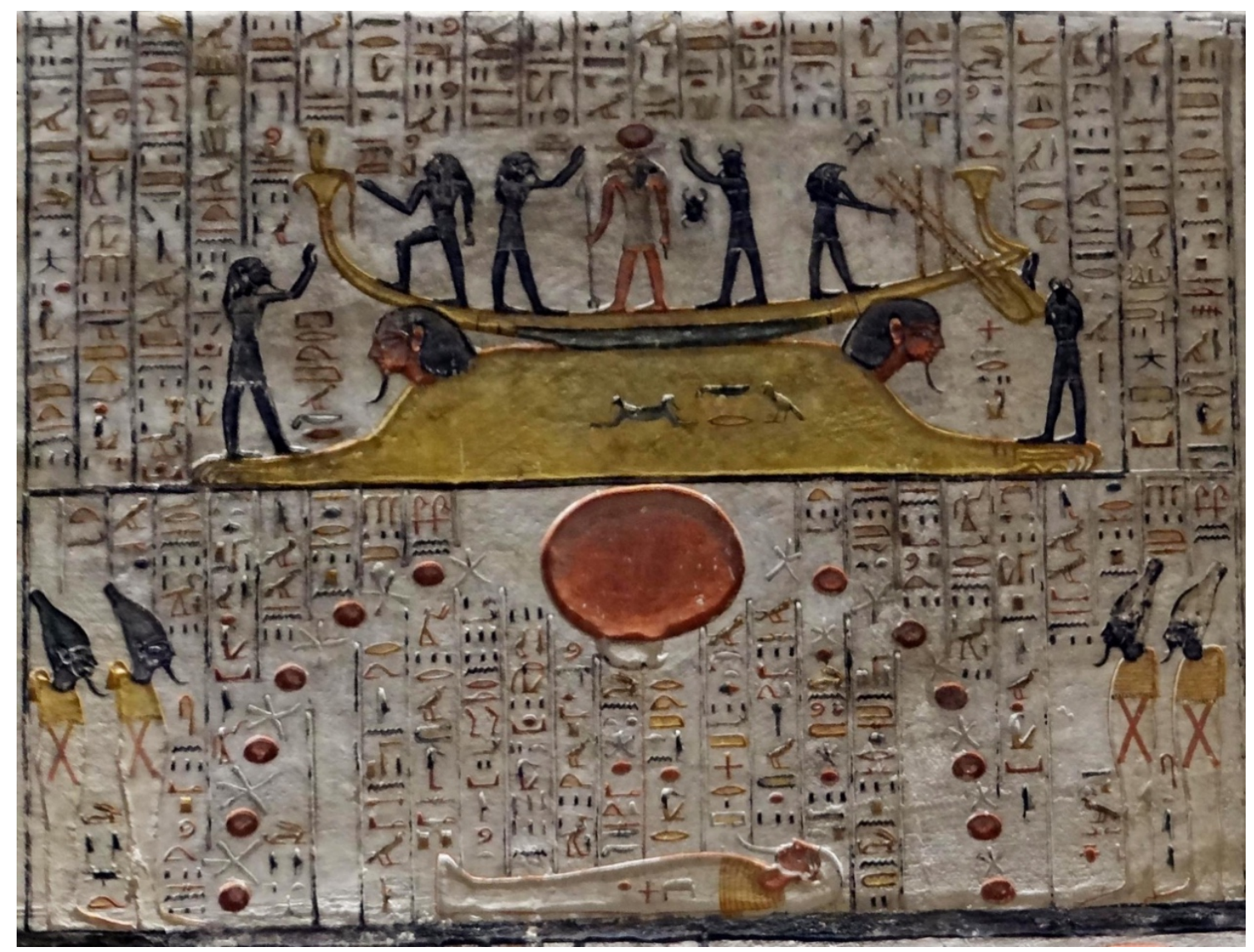

Fig. 14. Scène A 2, détail du mur nord de la chambre funéraire de Ramsès VI. C) PLEUGER, 2018.

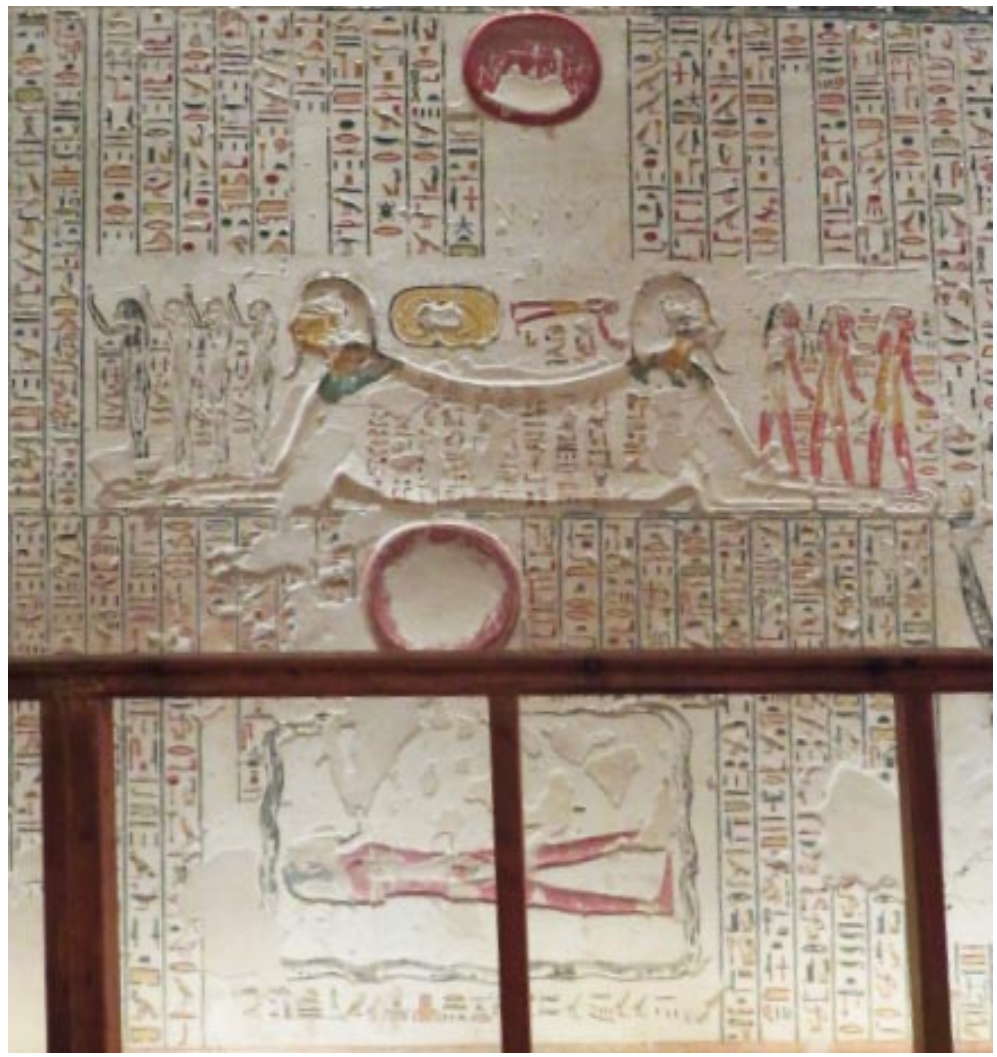

Fig. 15. Détail de la troisième division du Livre des Cavernes dans la tombe de Ramsès VI.

(C) PLEUGER, 2020. 


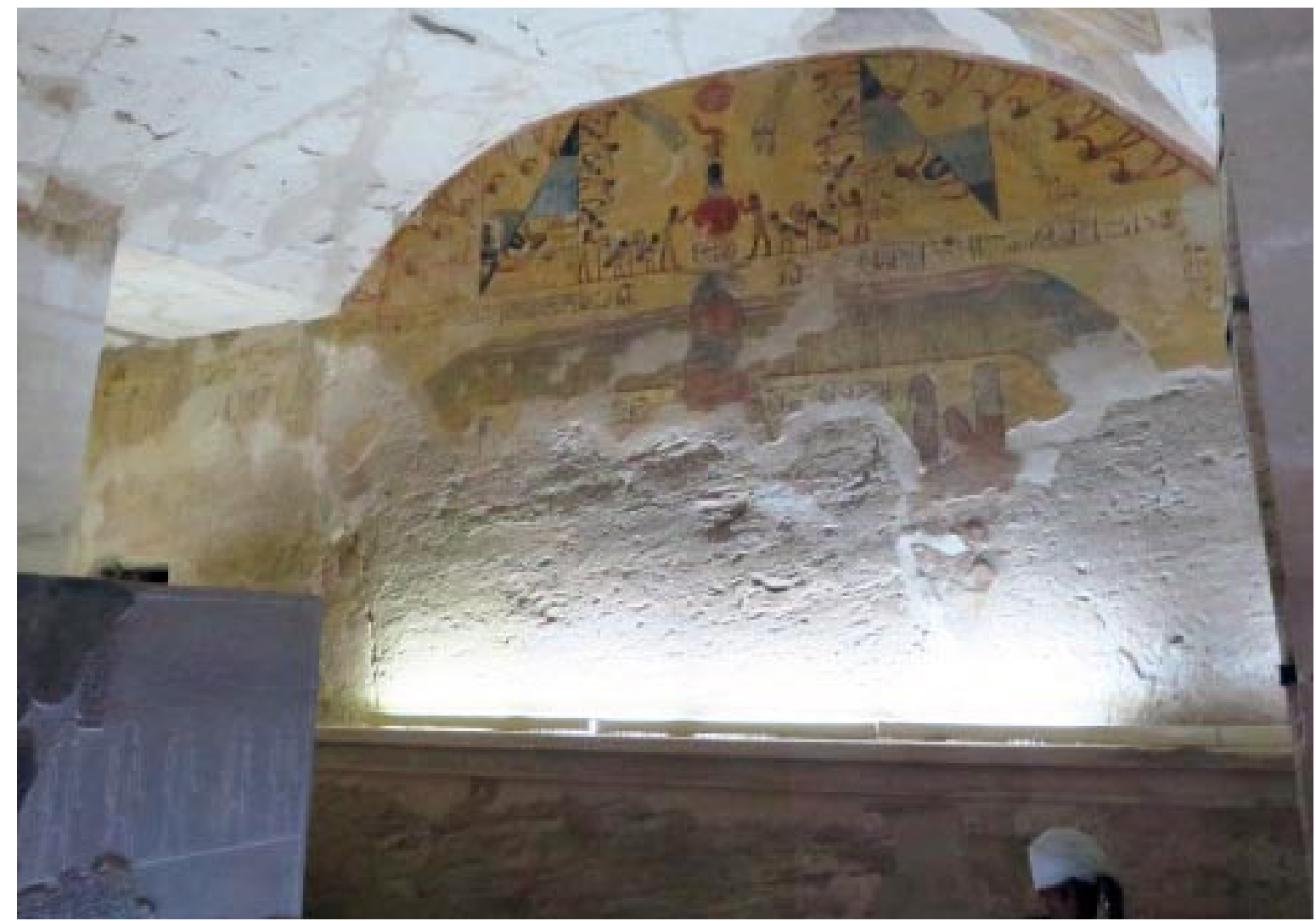

Fig. 16. Mur sud de la chambre funéraire de Mérenptah. (C) PLEUGER, 2018.

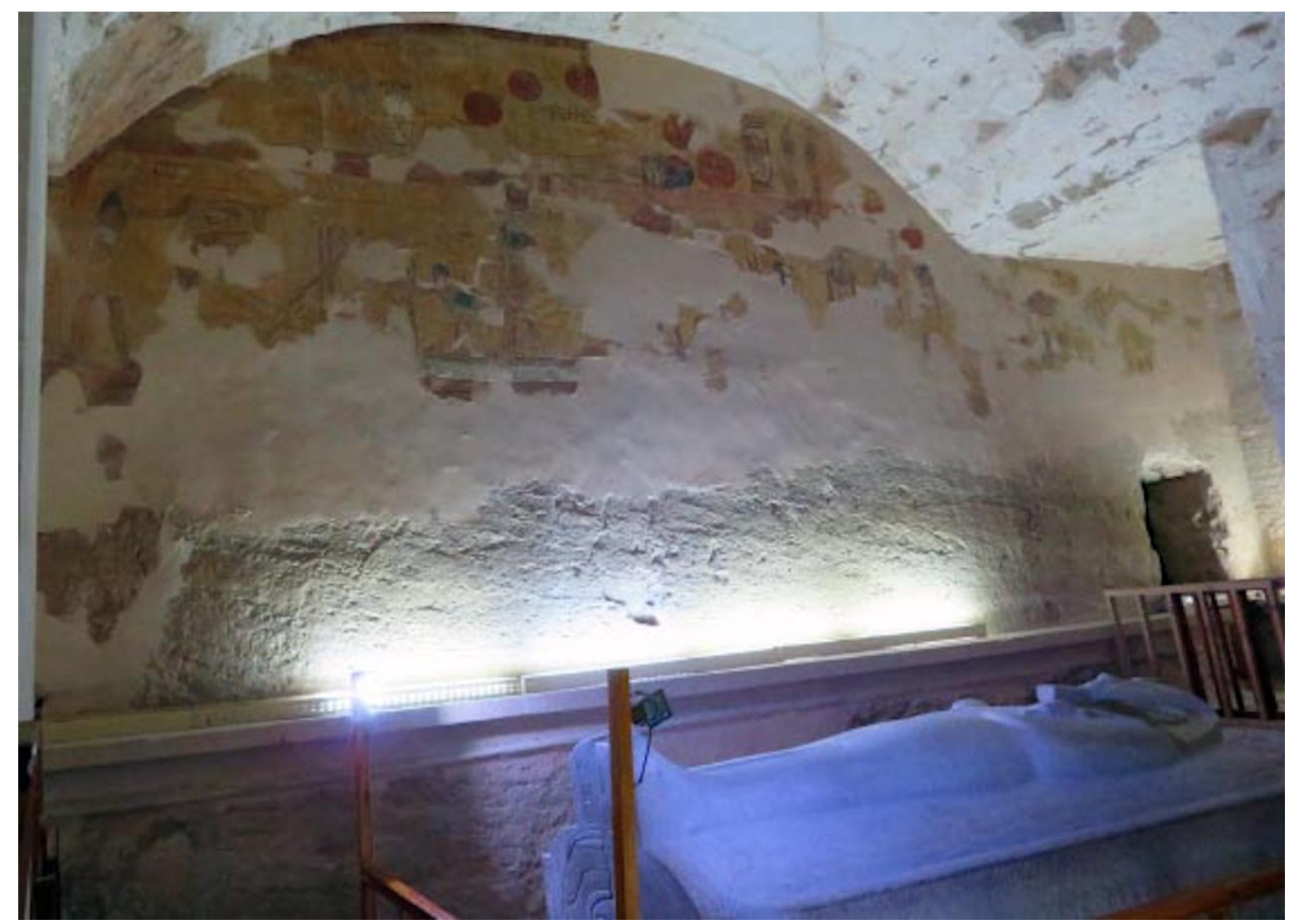

Fig. 17. Mur nord de la chambre funéraire de Mérenptah. (C) PLEUGER, 2018. 


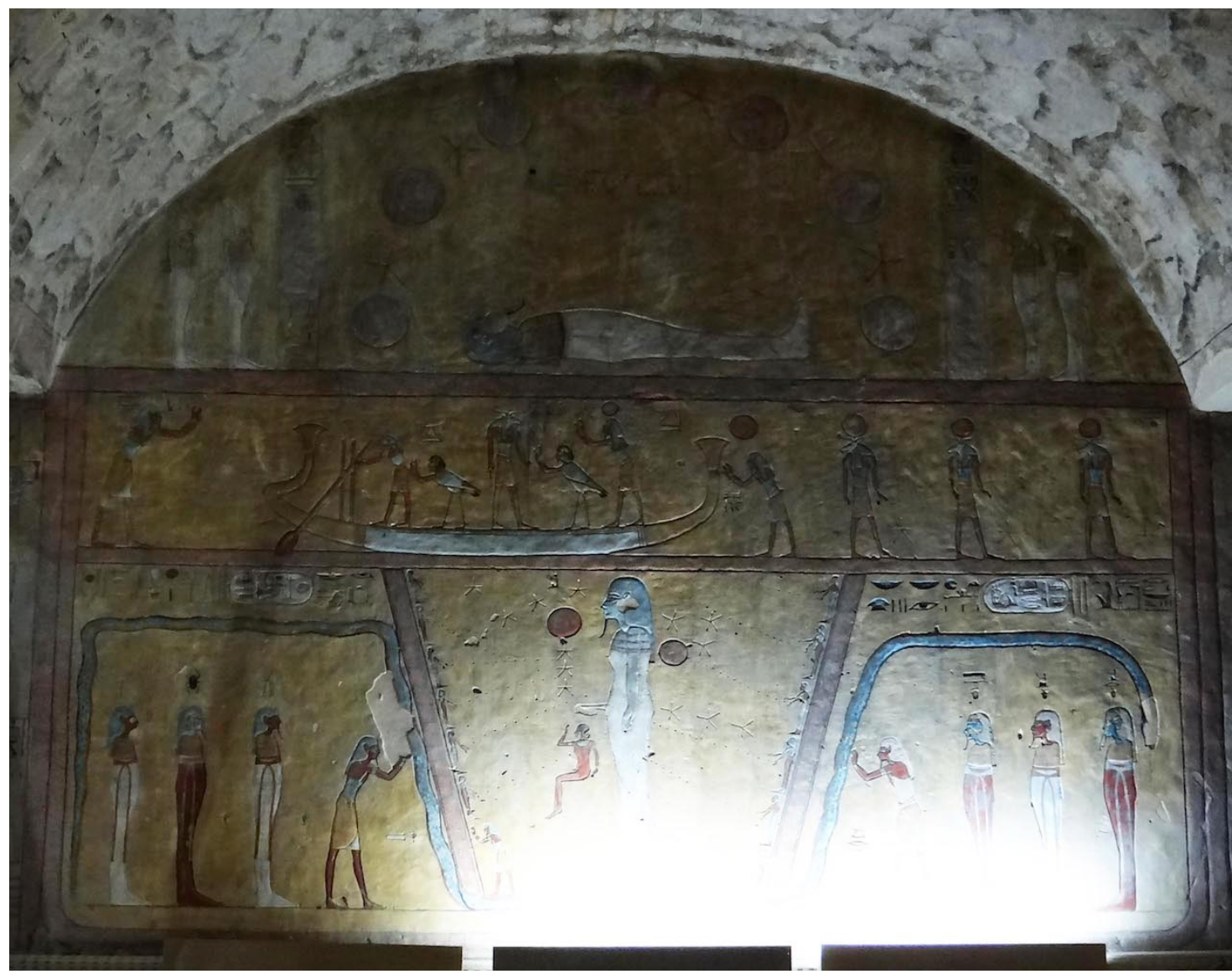

Fig. 18. Mur sud de la chambre funéraire de Taousert et Sethnakht. (C) PLEUGER, 2018.

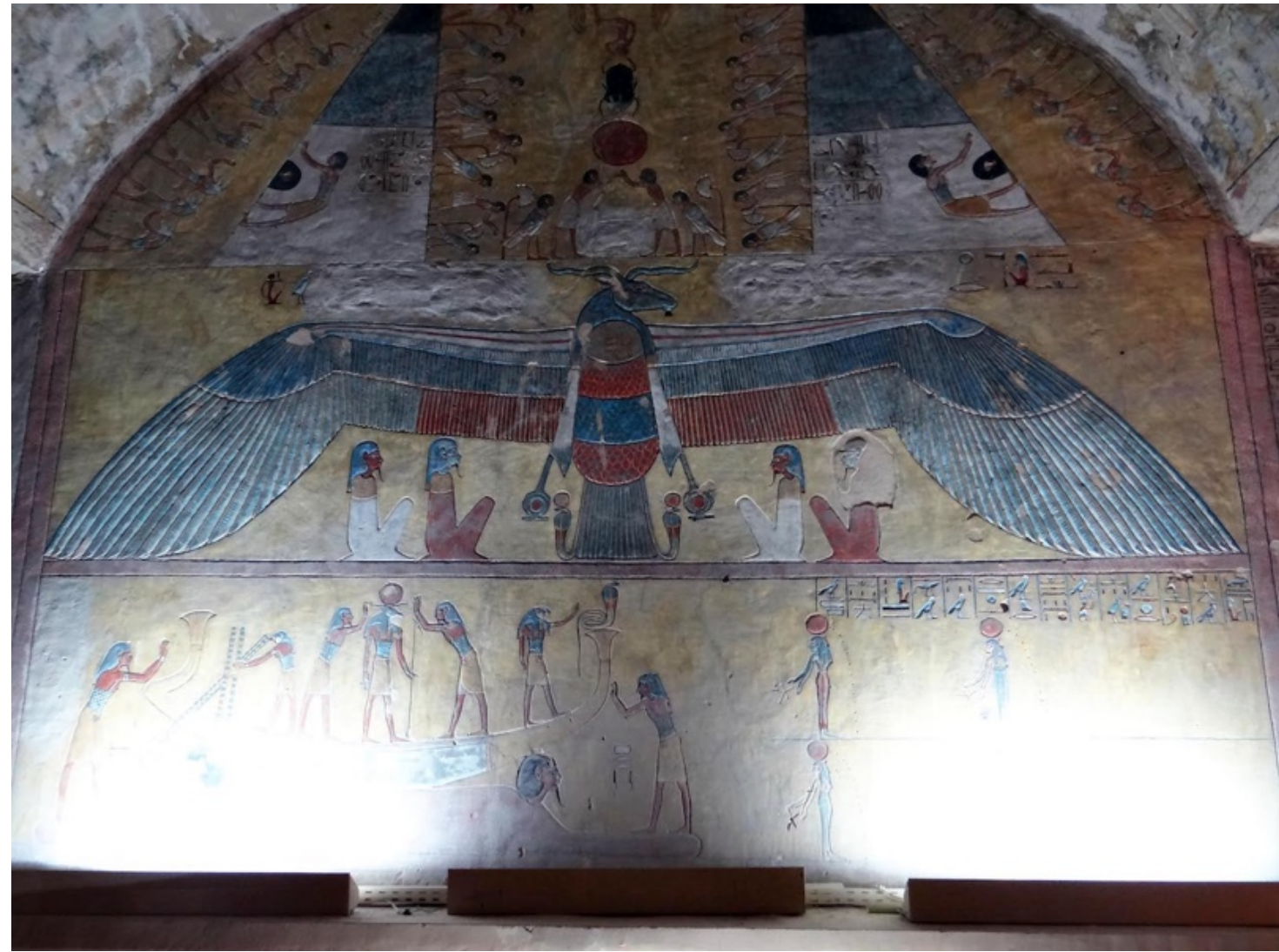

Fig. 19. Mur nord de la chambre funéraire de Taousert et Sethnakht. C PLEUGER, 2018. 


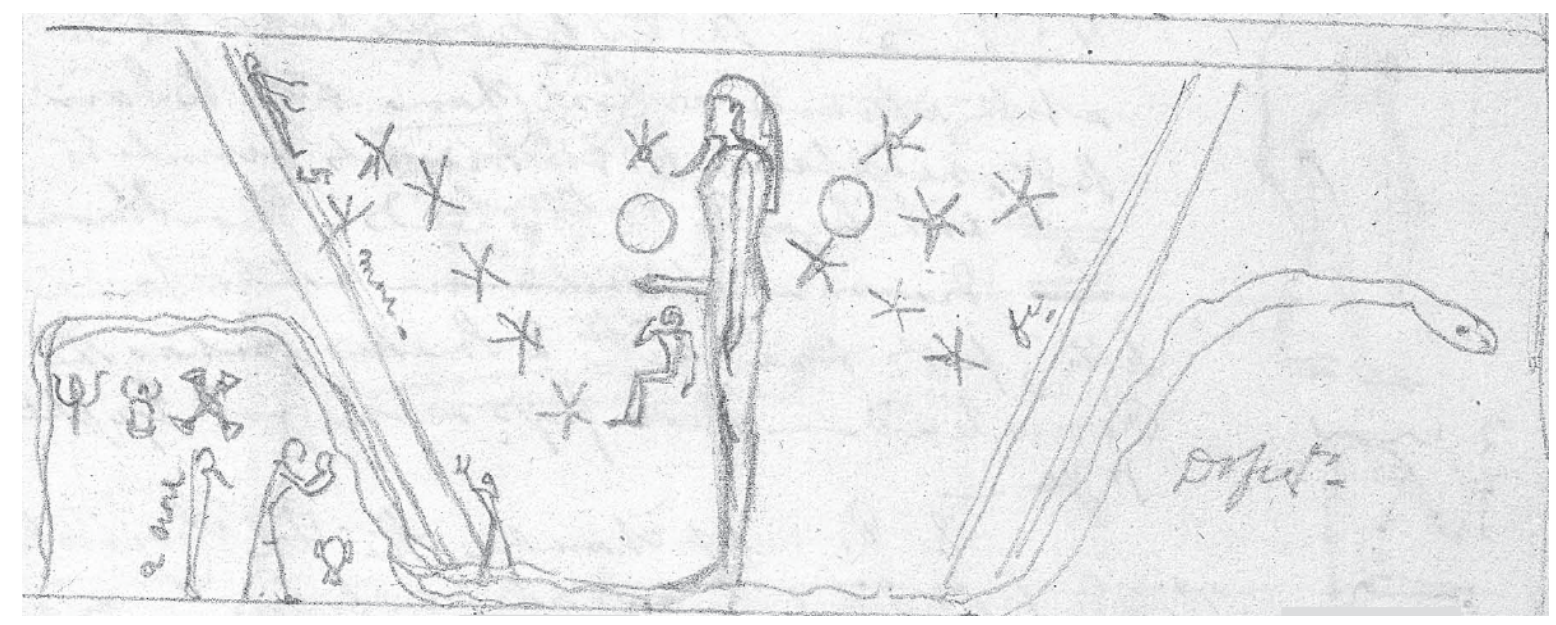

Fig. 20. Scène A 7, mur sud de la chambre funéraire de Ramsès III, dessin de Robert Hay. MAURIC-BARBÉRIO, 2004, p. 415.

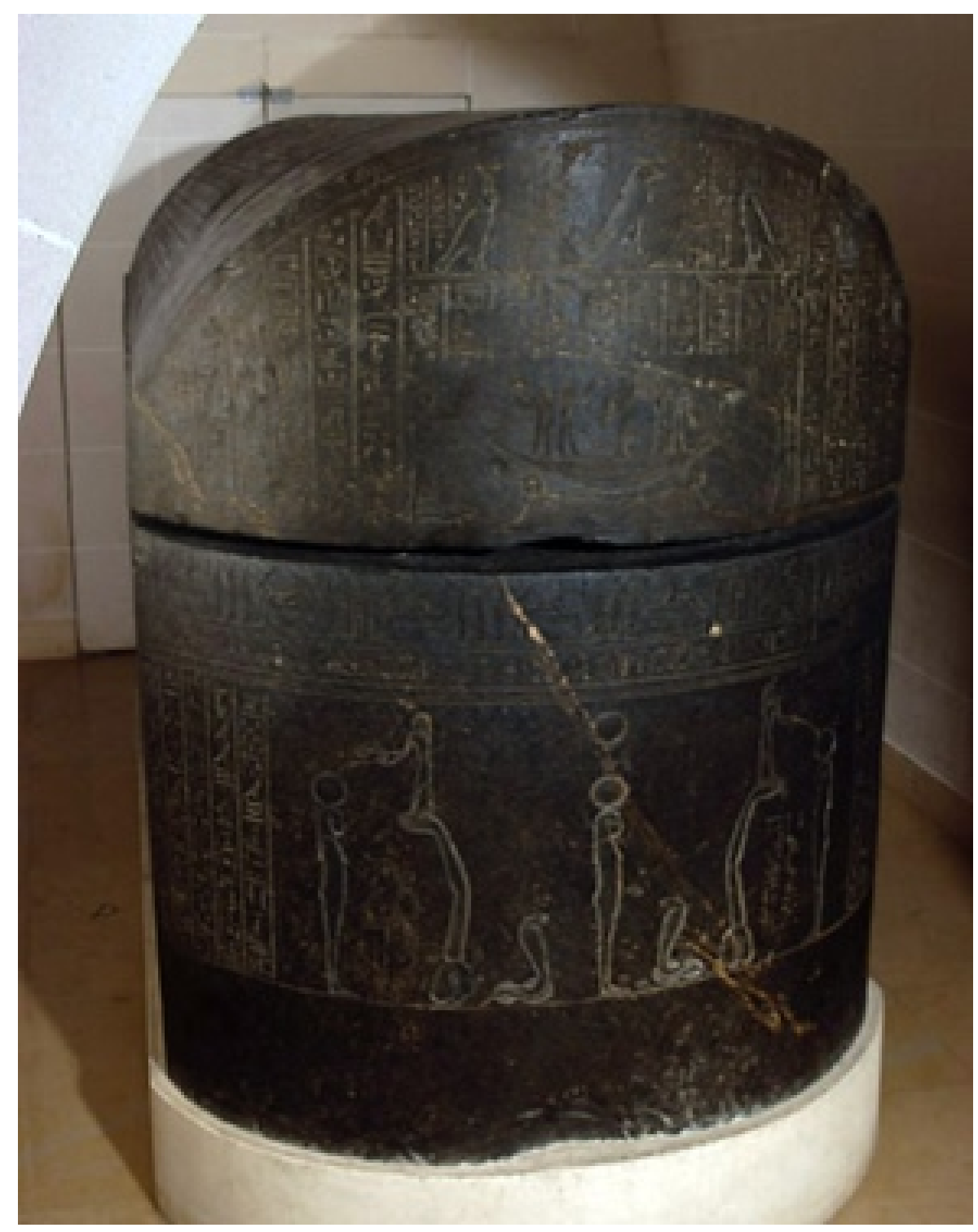

Fig. 21. Sarcophage de Djedhor (D 8), musée du Louvre.

(C) http://cartelfr.louvre.fr/cartelfr/visite? srv $=$ car_not frame\&idNotice $=19048$, consulté le 6 avril 2020. 

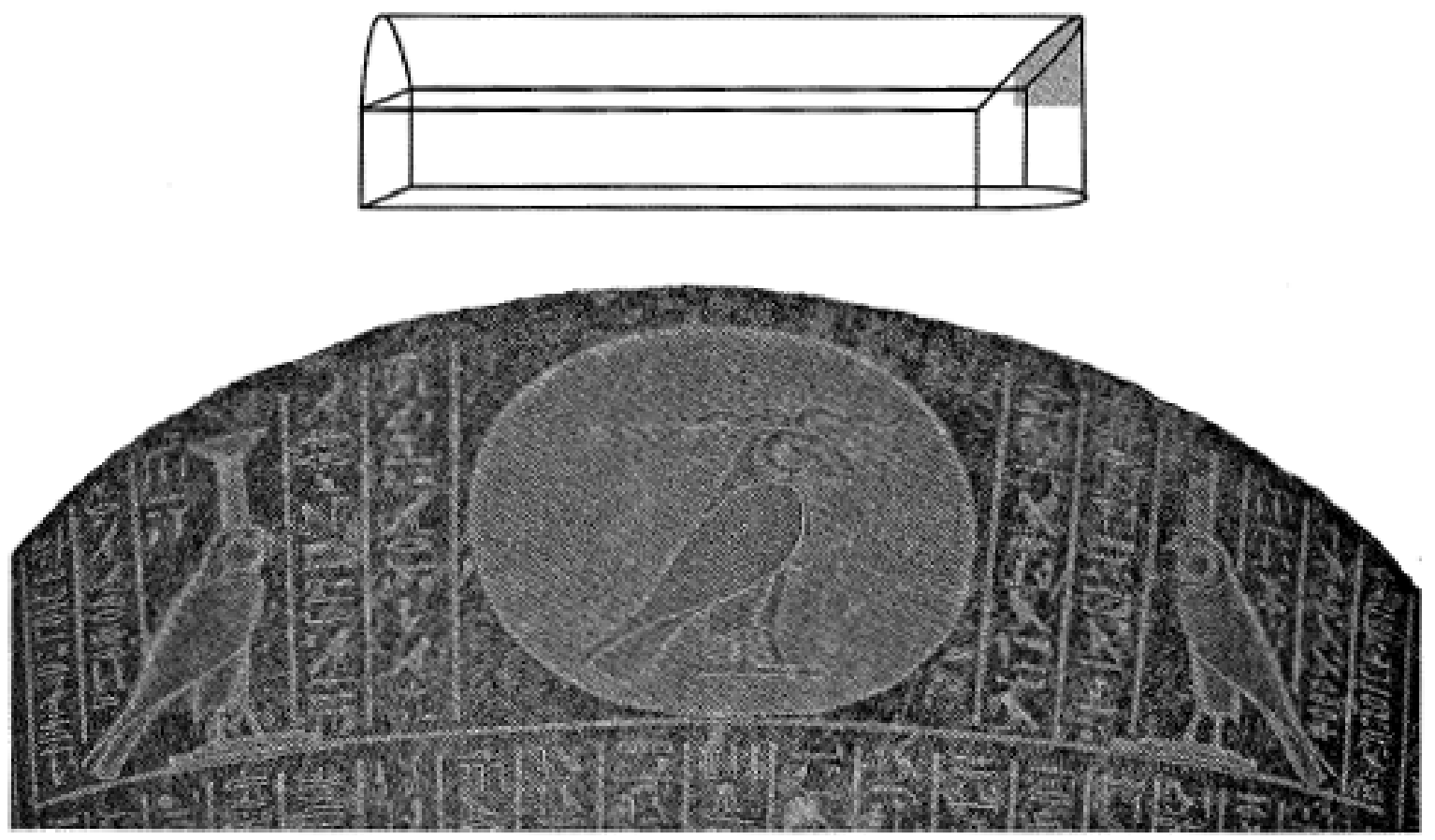

Fig. 22. Détail du couvercle du sarcophage de Tjahorpata (CG 29306). (C MANASSA, 2007, Fig. $280 a$.
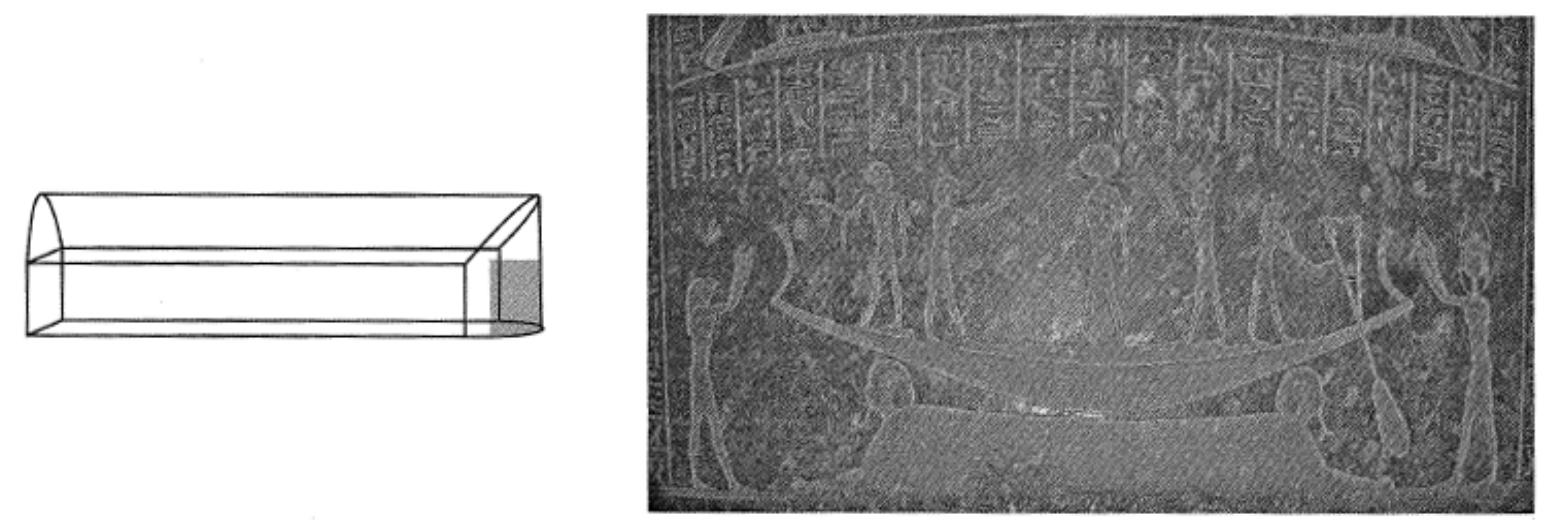

Fig. 23. Détail du couvercle du sarcophage de Tjahorpata (CG 29306). (C) MANASSA, 2007, Fig. $280 b$

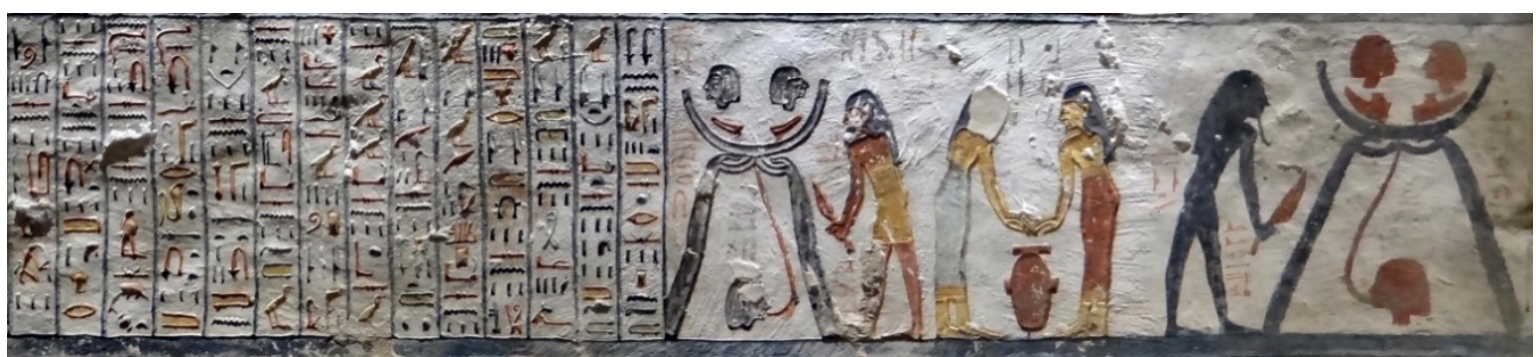

Fig. 24. Scène D 14, détail du mur sud de la chambre funéraire de Ramsès VI. C PLEUGER, 2018. 


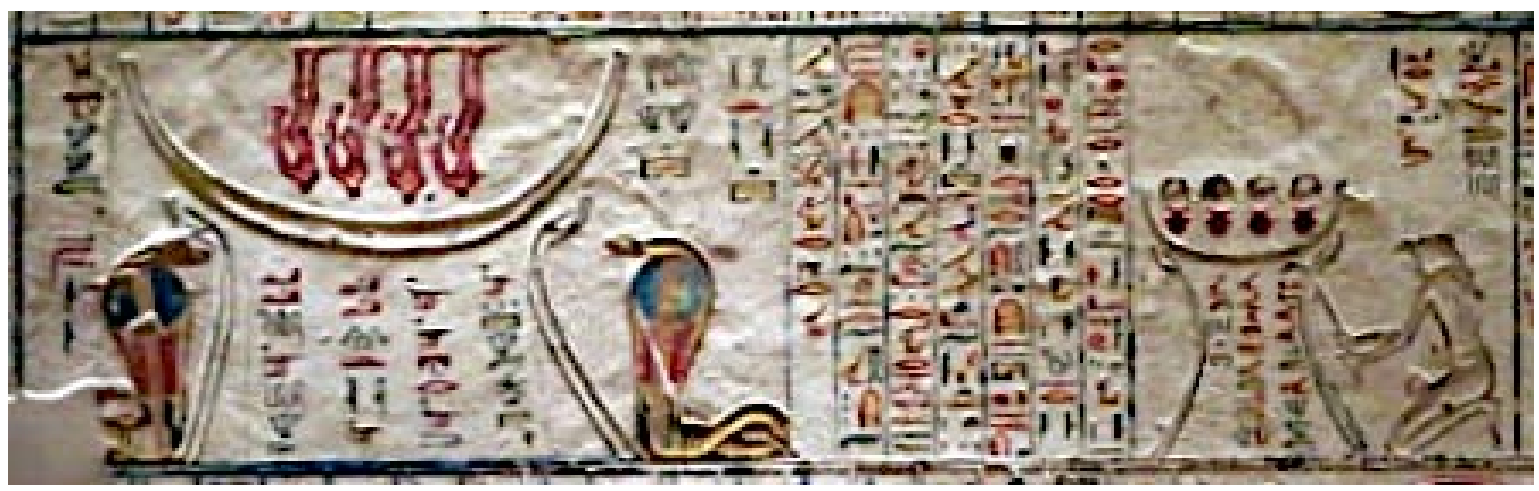

Fig. 25. Détail de la cinquième division du Livre des Cavernes dans la tombe de Ramsès VI. (C) PLEUGER, 2020.

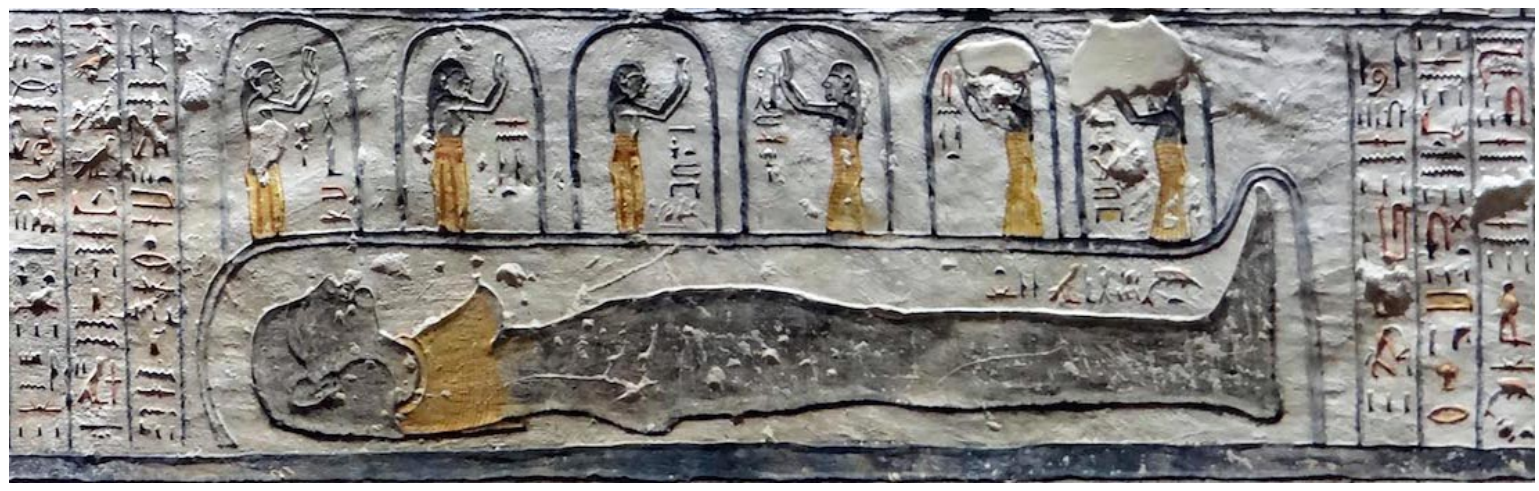

Fig. 26. Scène D 15, détail du mur sud de la chambre funéraire de Ramsès VI. C) PLEUGER, 2018.

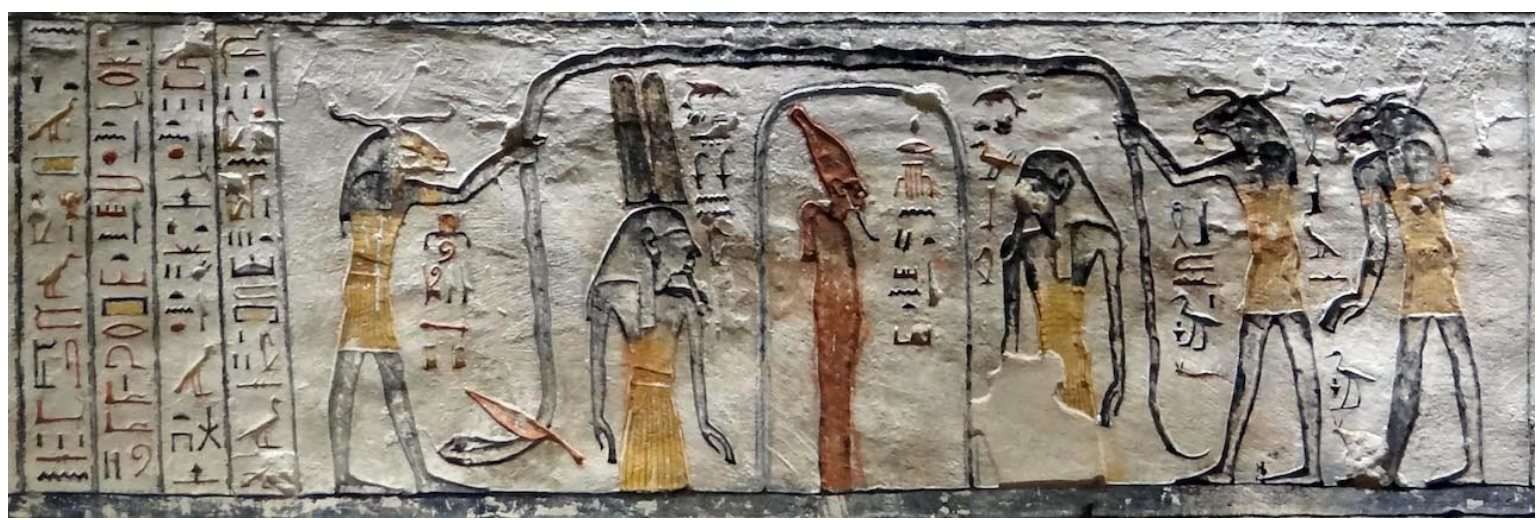

Fig. 27. Scène D 16, détail du mur sud de la chambre funéraire de Ramsès VI. C) PLEUGER, 2018. 


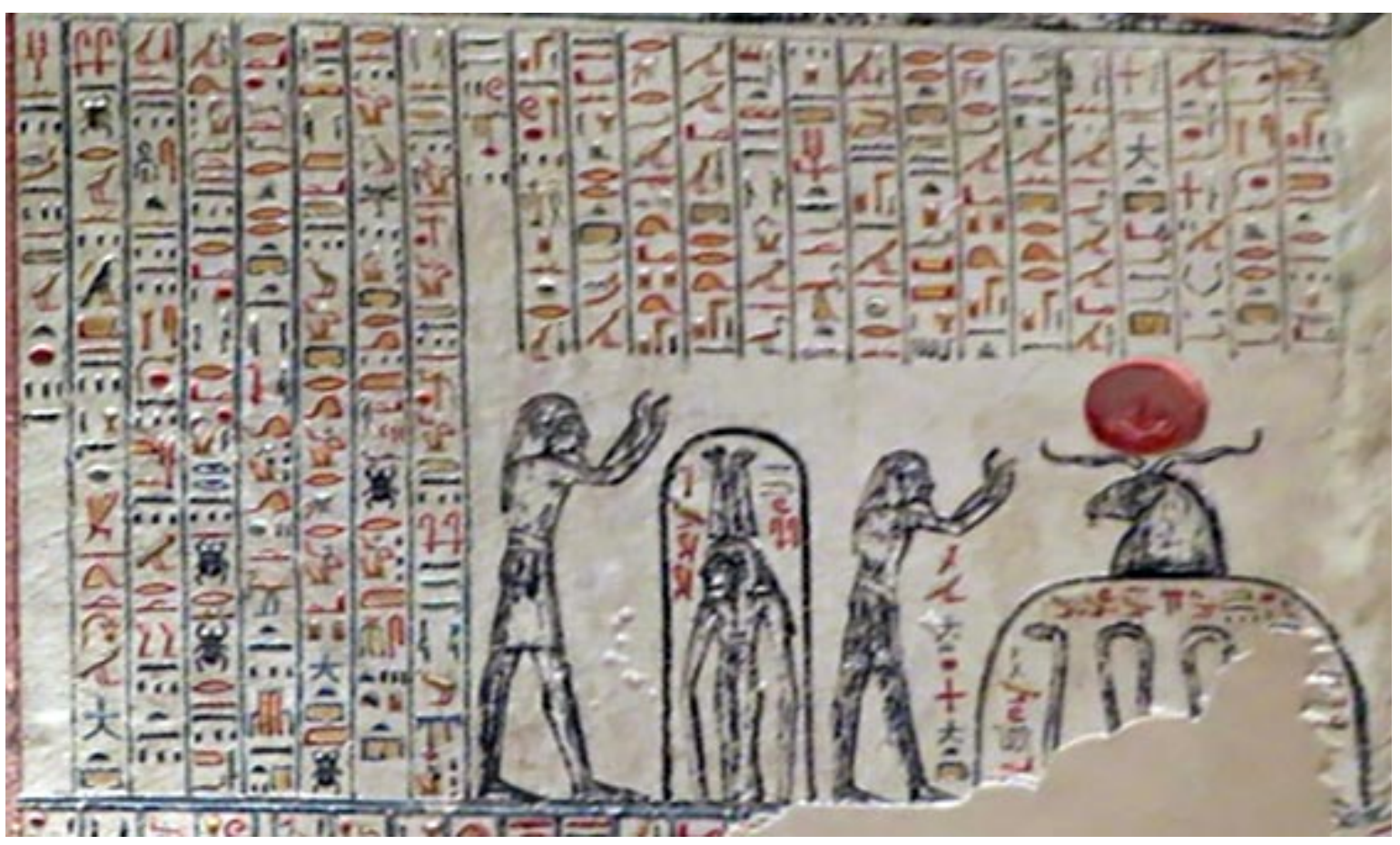

Fig. 28. Détail de la sixième division du Livre des Cavernes dans la tombe de Ramsès VI. (C) PLEUGER, 2020.

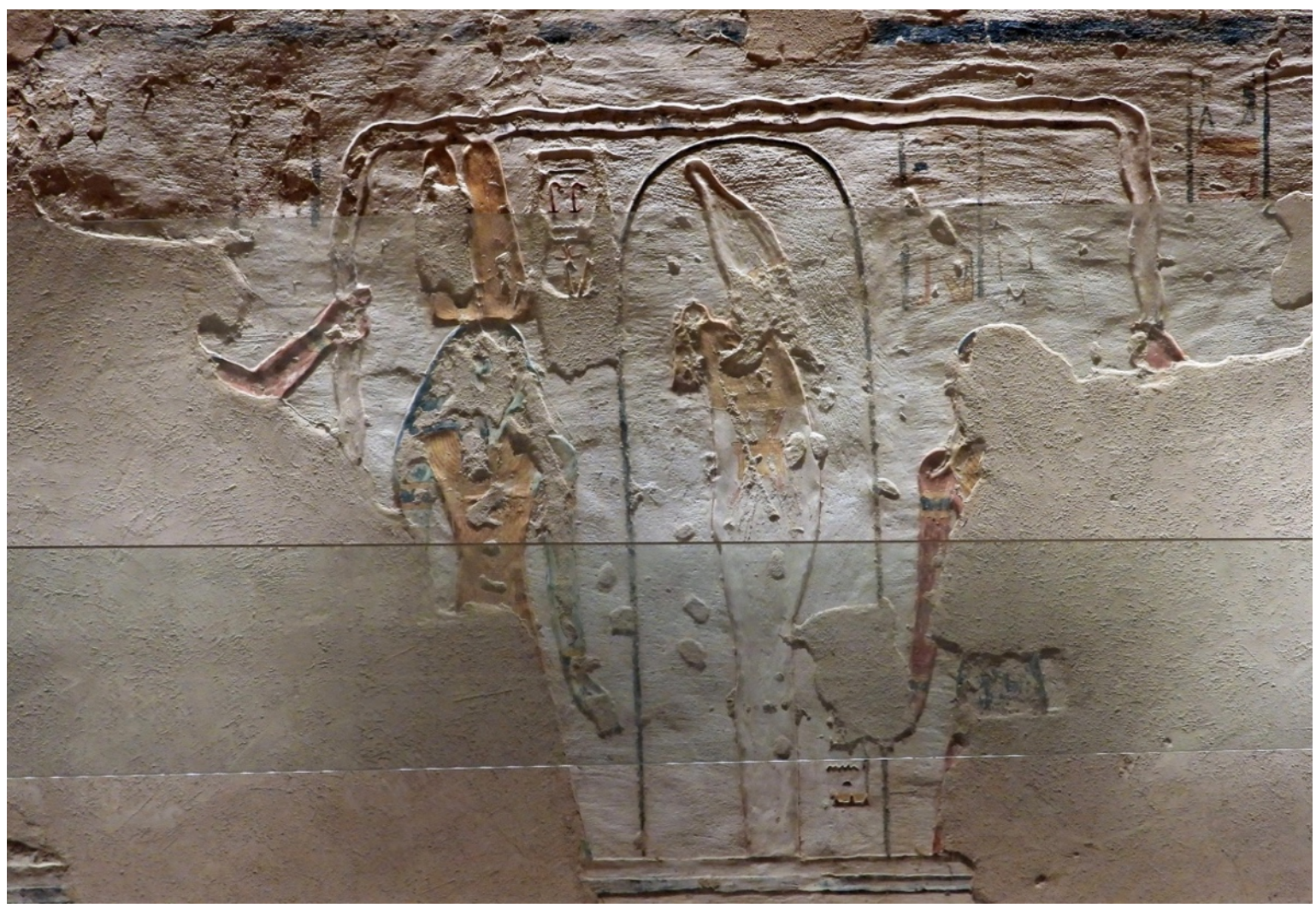

Fig. 29. Scène D 16, détail du mur sud de la chambre funéraire de Ramsès VII. C) BAILLY 2020. 


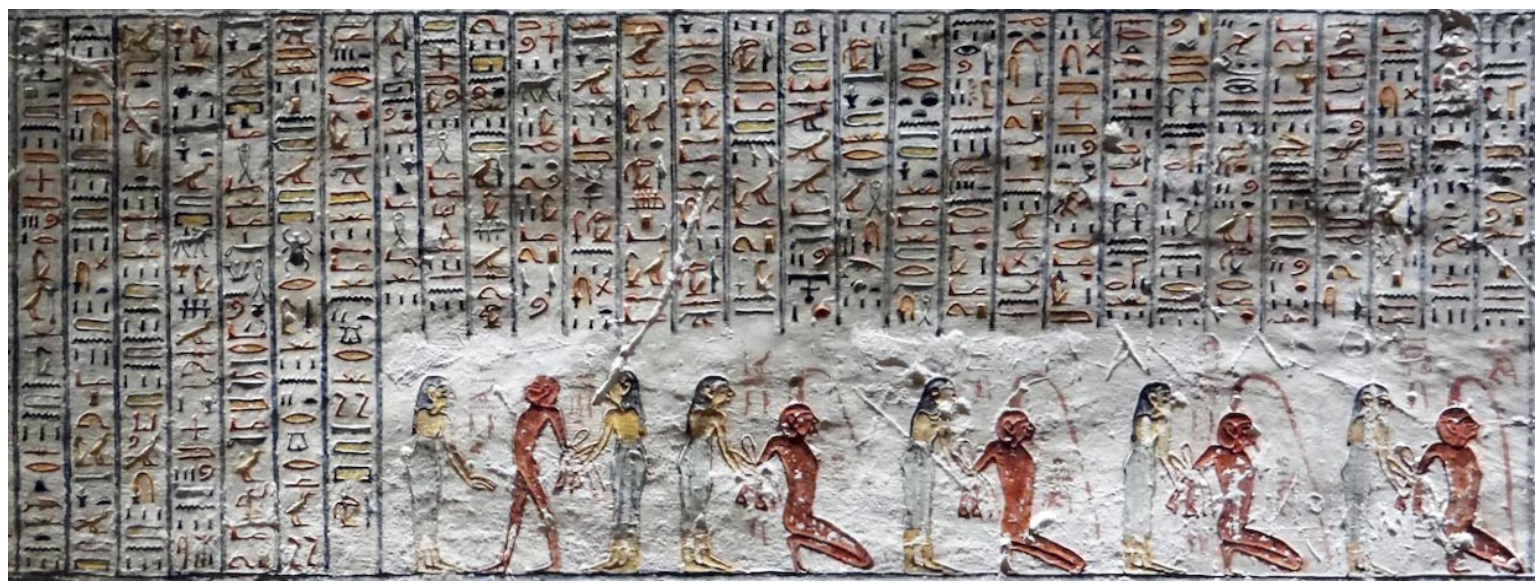

Fig. 30. Scène D 13 détail du mur sud de la chambre funéraire de Ramsès VI. C) PLEUGER, 2018.

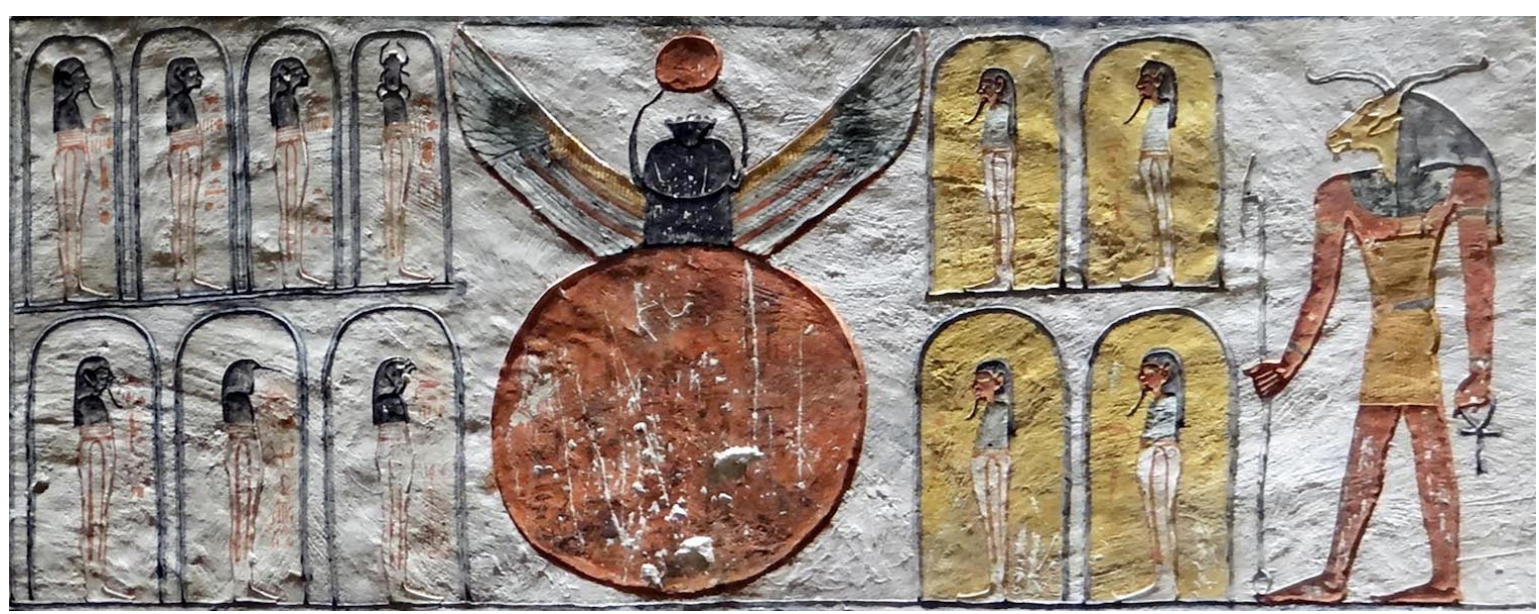

Fig. 31. Scène D 11, détail du mur sud de la chambre funéraire de Ramsès VI. (C) PLEUGER, 2018.

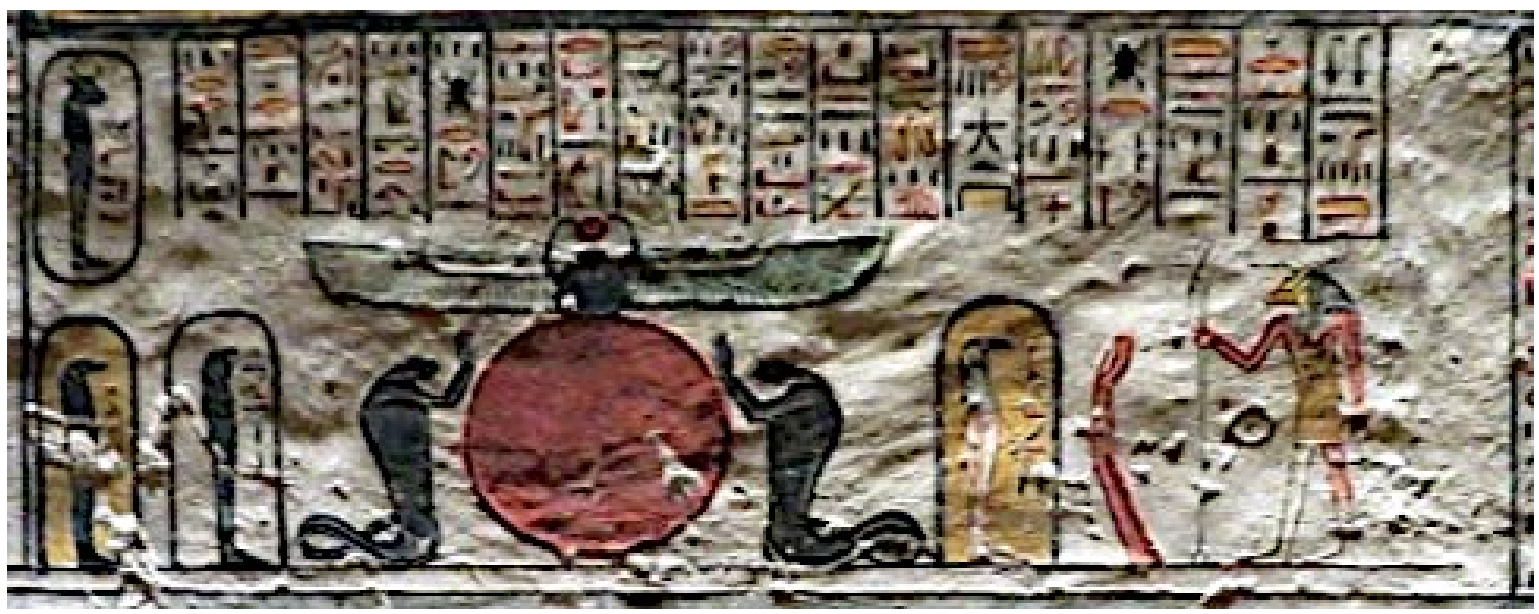

Fig. 32. Scène D 9, détail du mur sud de la chambre funéraire de Ramsès VI. C PLEUGER, 2020. 


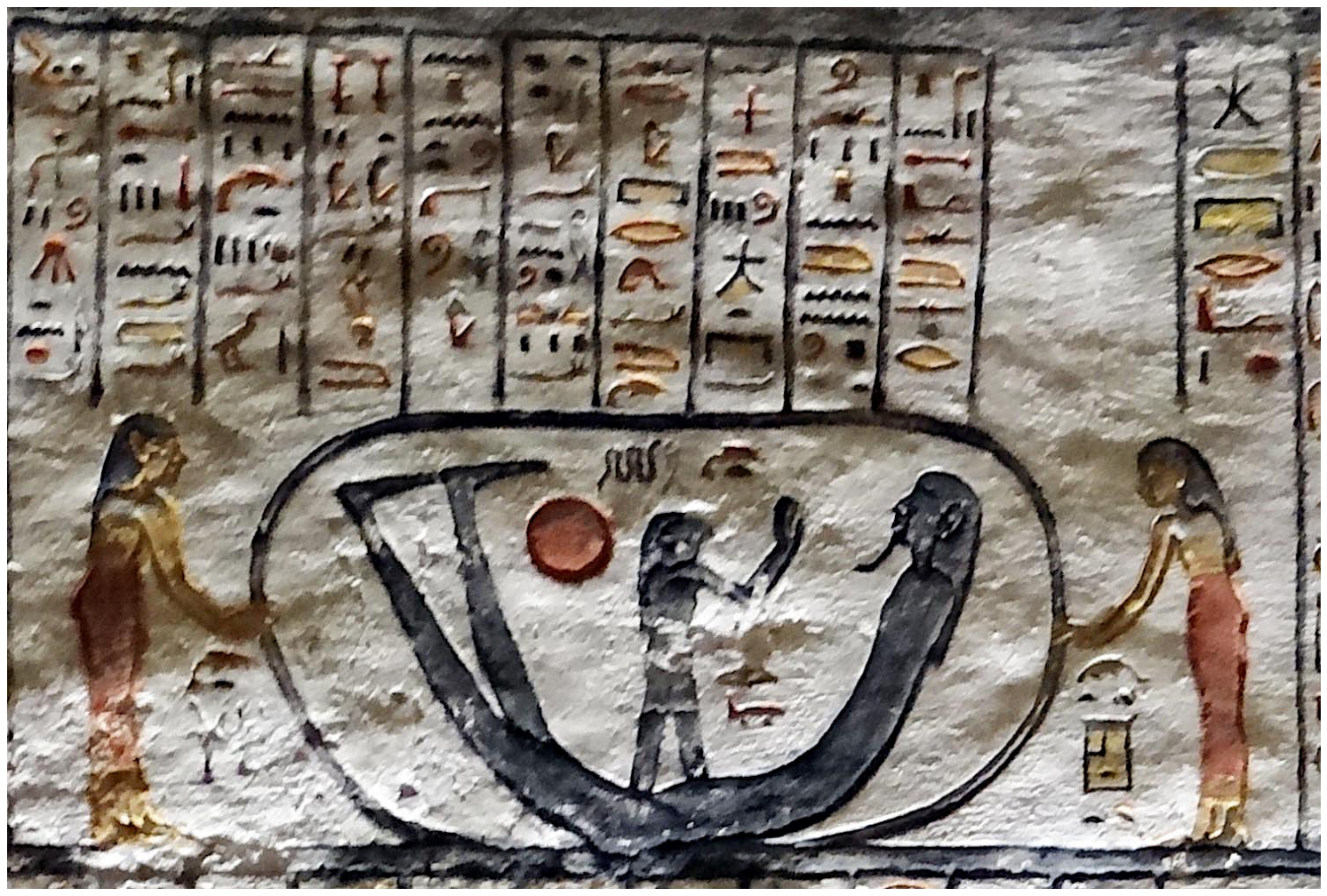

Fig. 33. Scène D 6, détail du mur sud de la chambre funéraire de Ramsès VI. C PLEUGER, 2018.

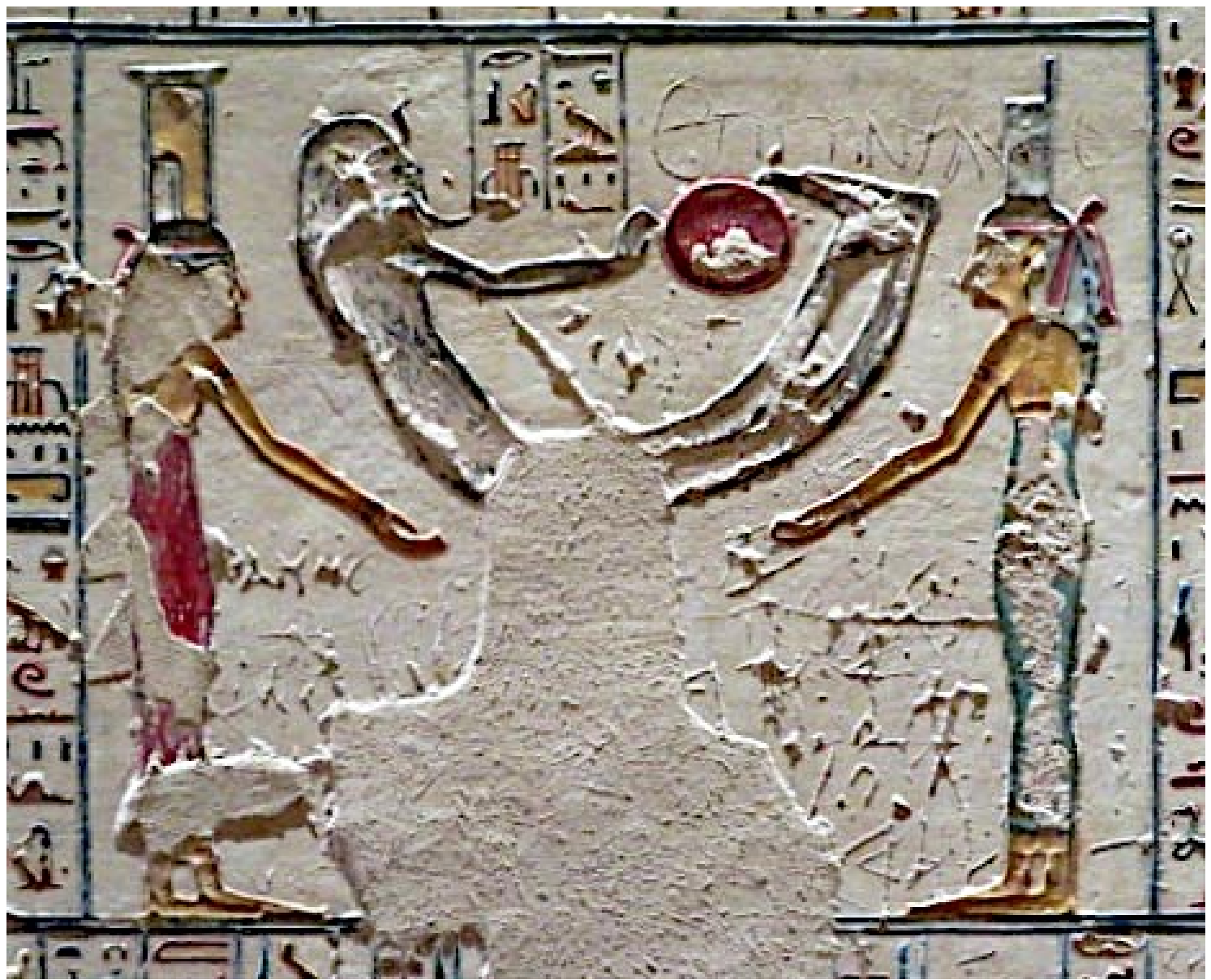

Fig. 34. Détail de la quatrième division du Livre des Cavernes dans la tombe de Ramsès VI.

(C) PLEUGER, 2020. 


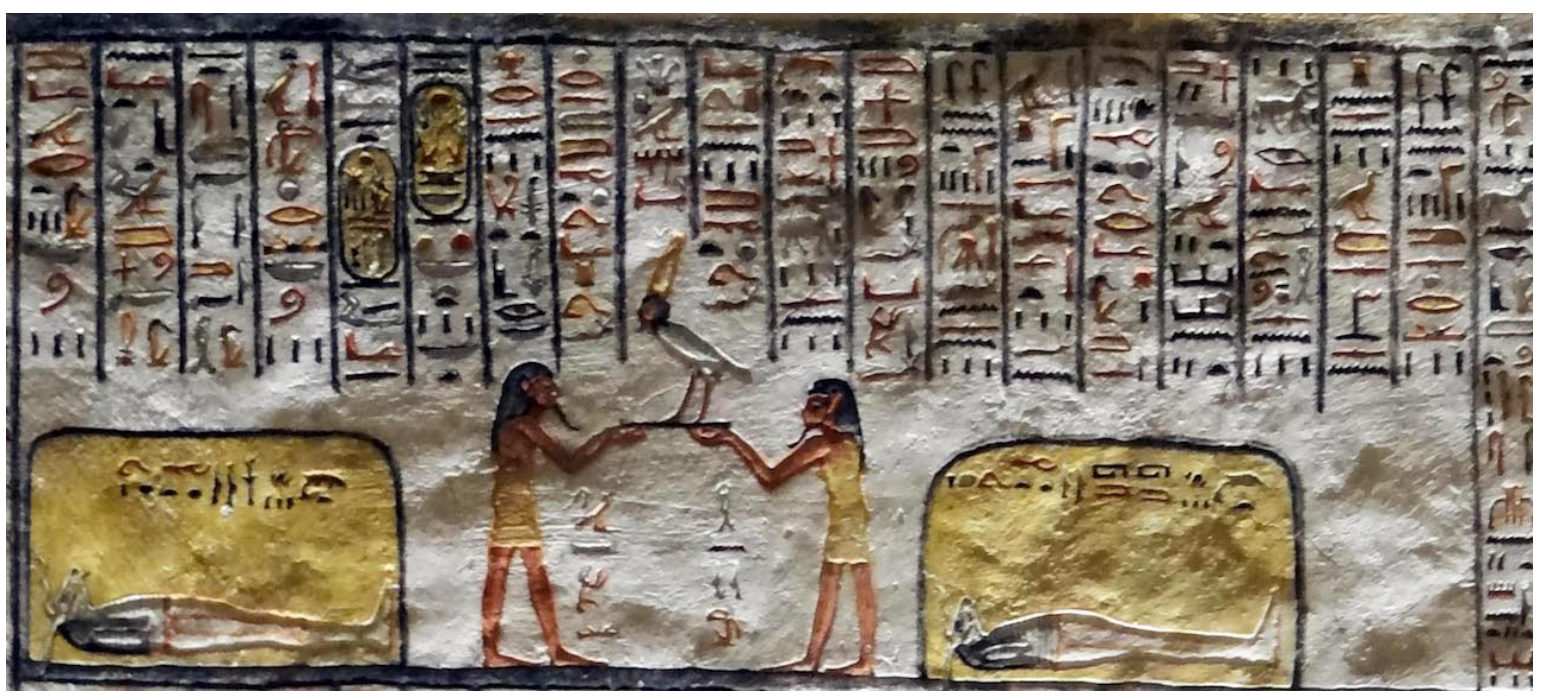

Fig. 35. Scène D 7, détail du mur sud de la chambre funéraire de Ramsès VI. C PLEUGER, 2018.

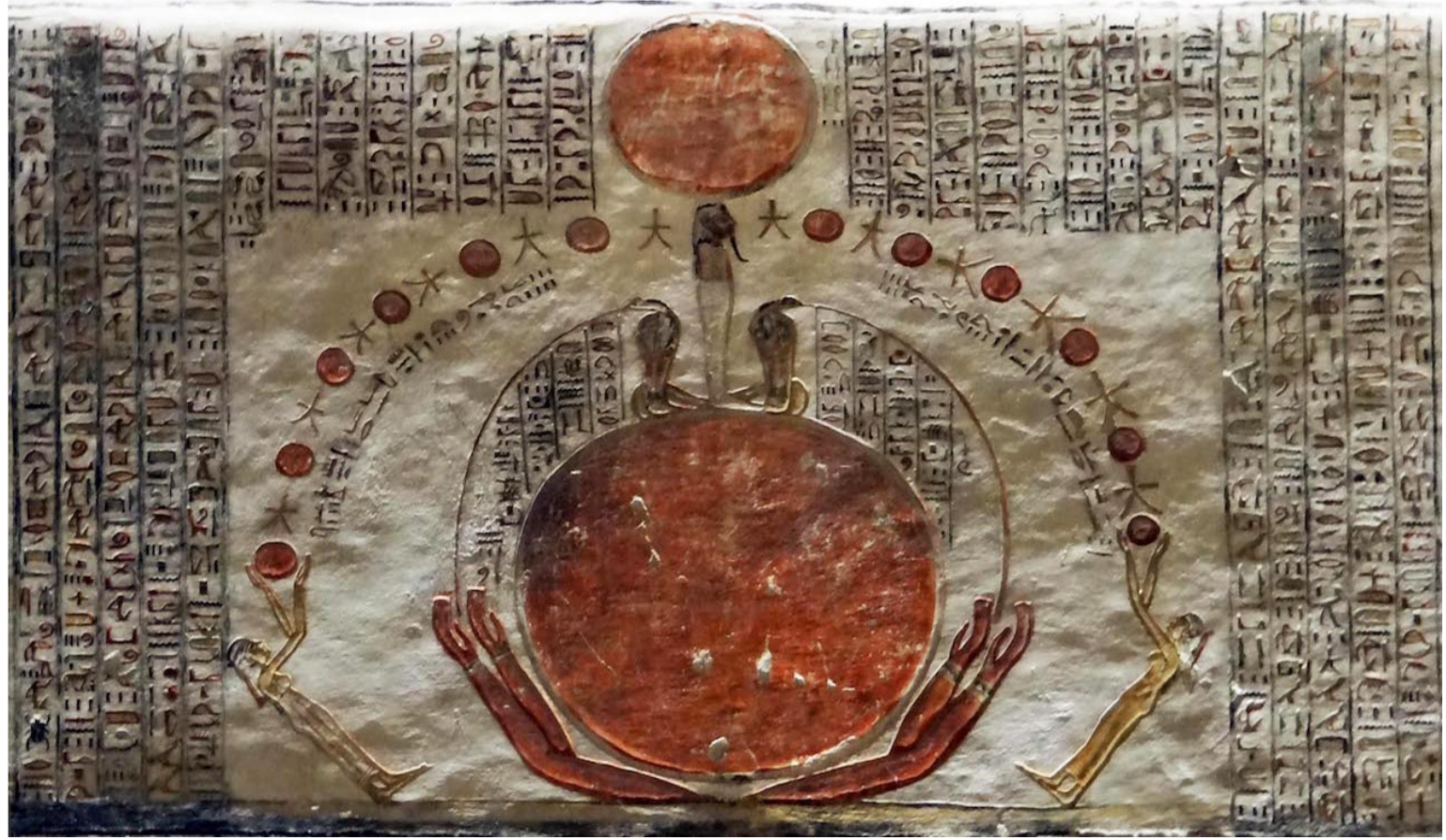

Fig. 36. Scène D 2, détail du mur sud de la chambre funéraire de Ramsès VI. C PLEUGER, 2018. 


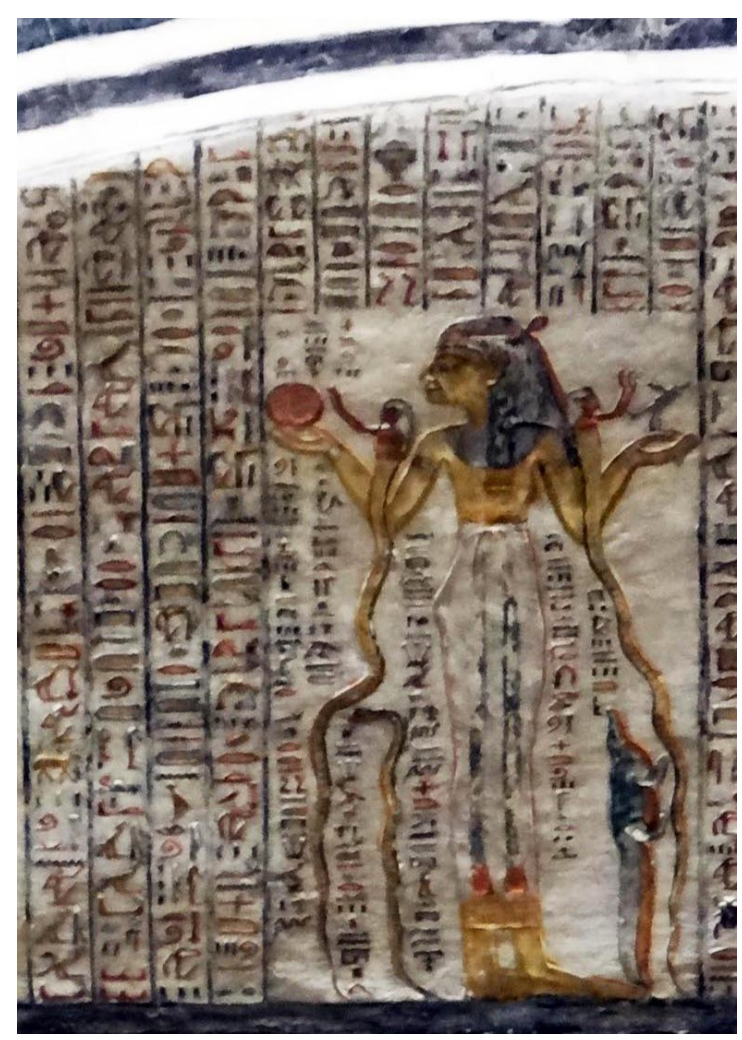

Fig. 37. Scène D 3, détail du mur sud de la chambre funéraire de Ramsès VI. (C PLEUGER, 2018.

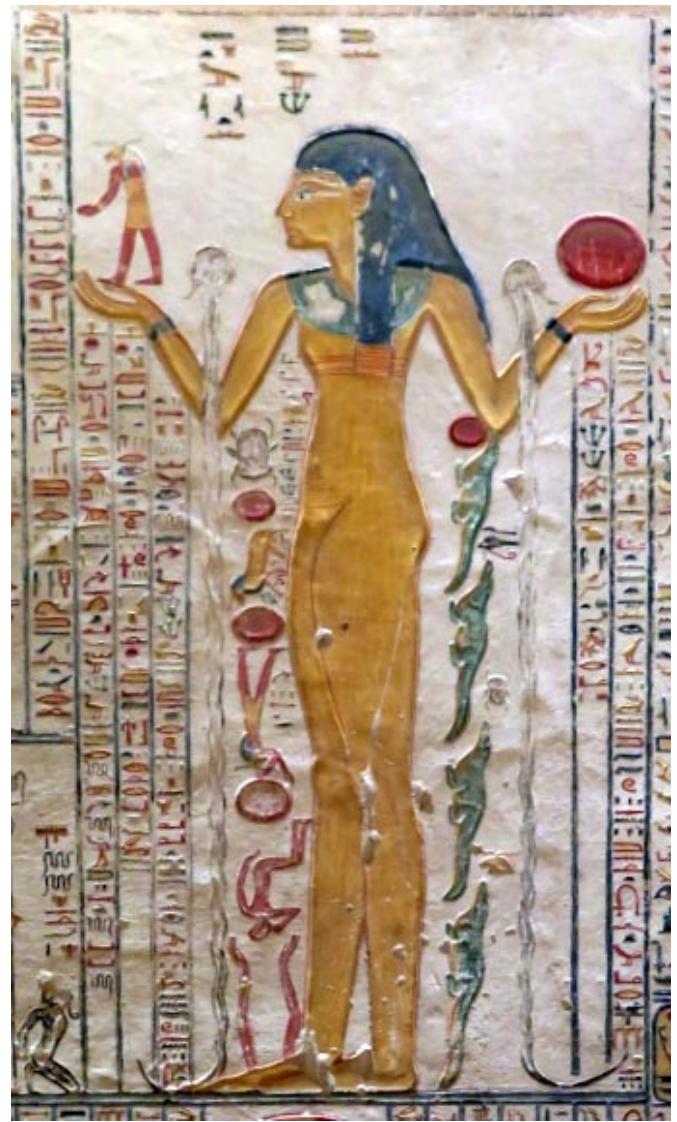

Fig. 38. Détail de la cinquième division du Livre des Cavernes dans la tombe de Ramsès VI (la Mystérieuse). (C) PLEUGER, 2020. 


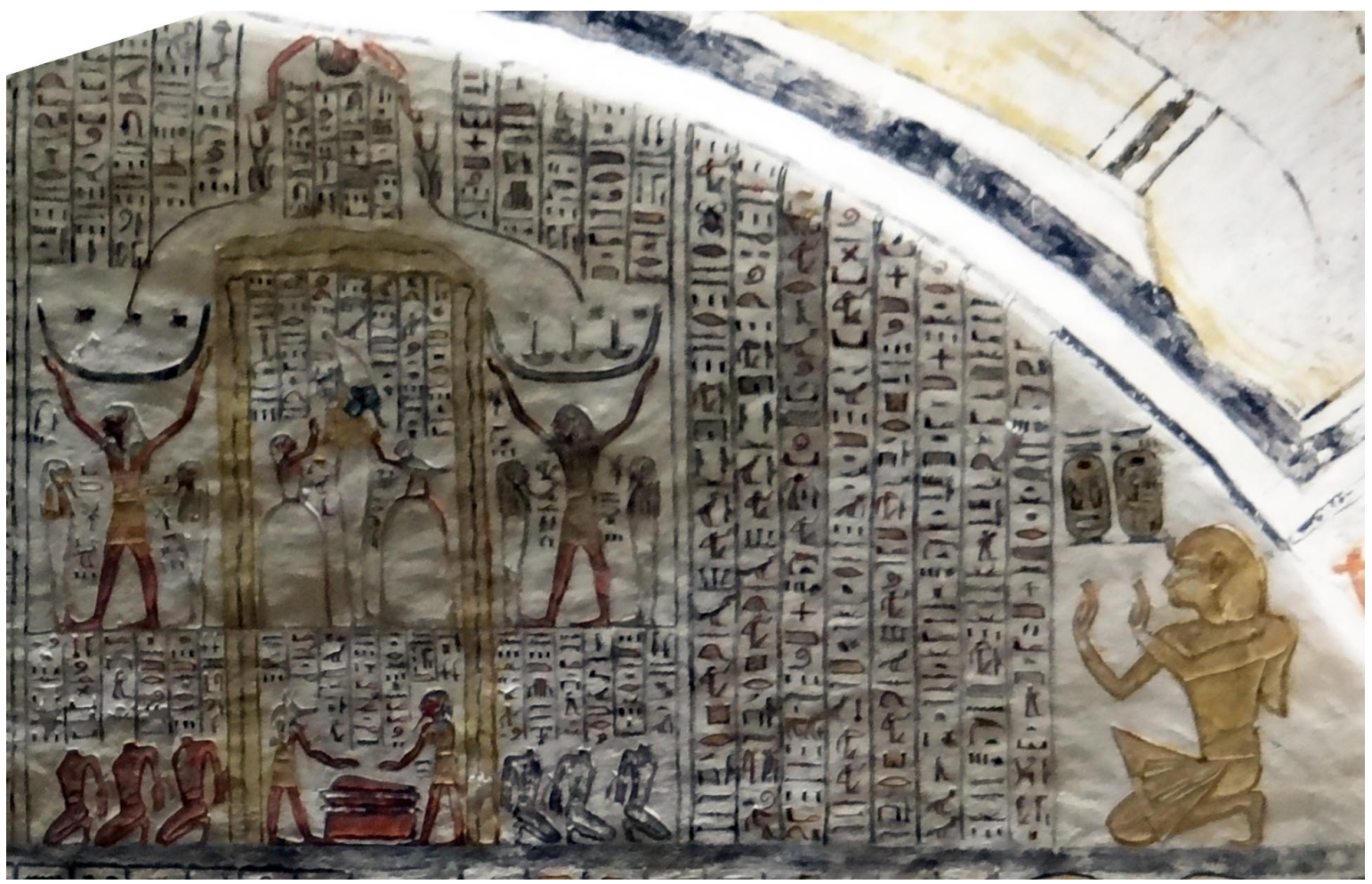

Fig. 39. Scène D 1 détail du mur sud de la chambre funéraire de Ramsès VI. C) PLEUGER, 2020.

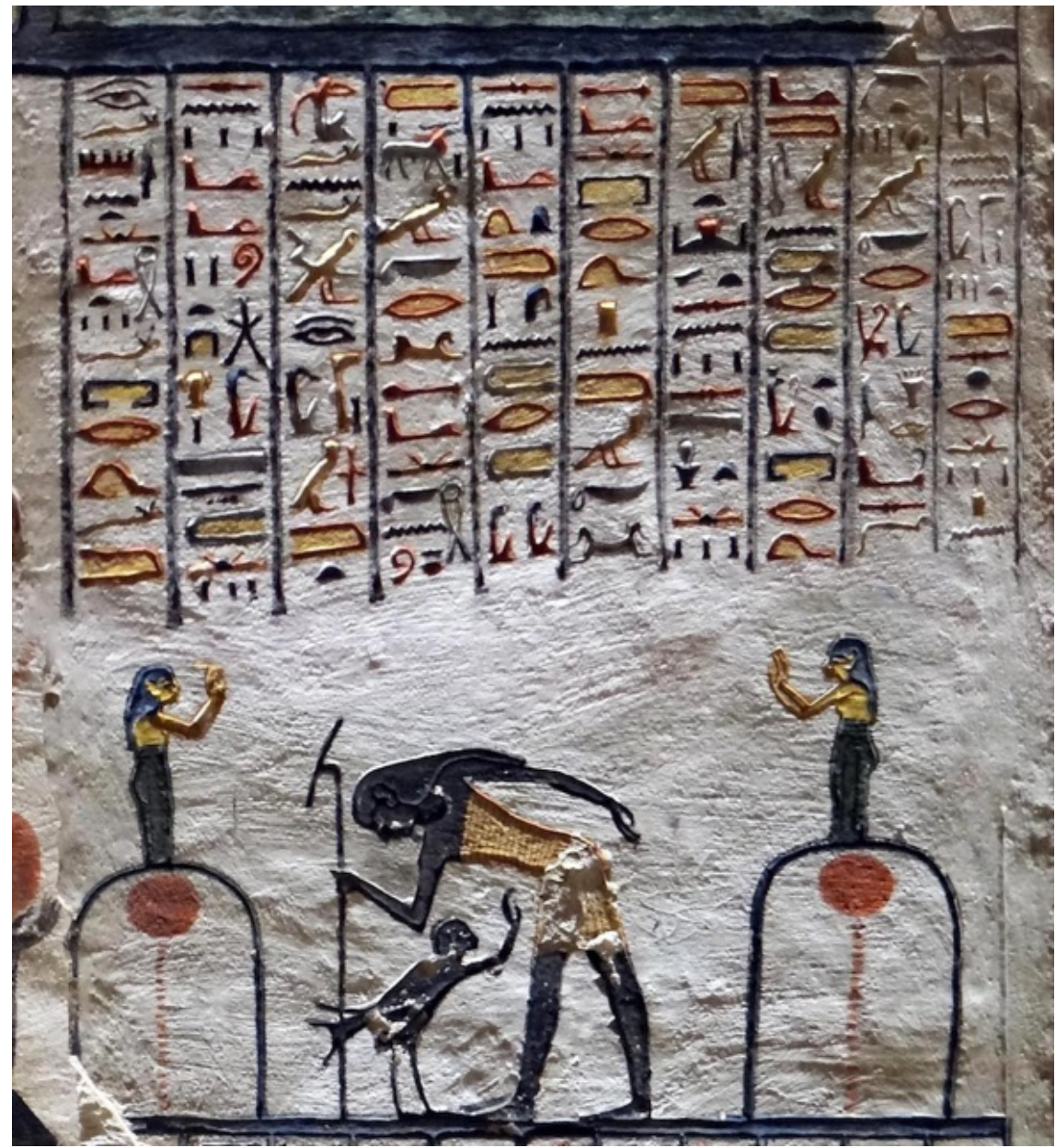

Fig. 40. Scène C 4, détail du mur ouest de la chambre funéraire de Ramsès VI. C PLEUGER, 2018. 


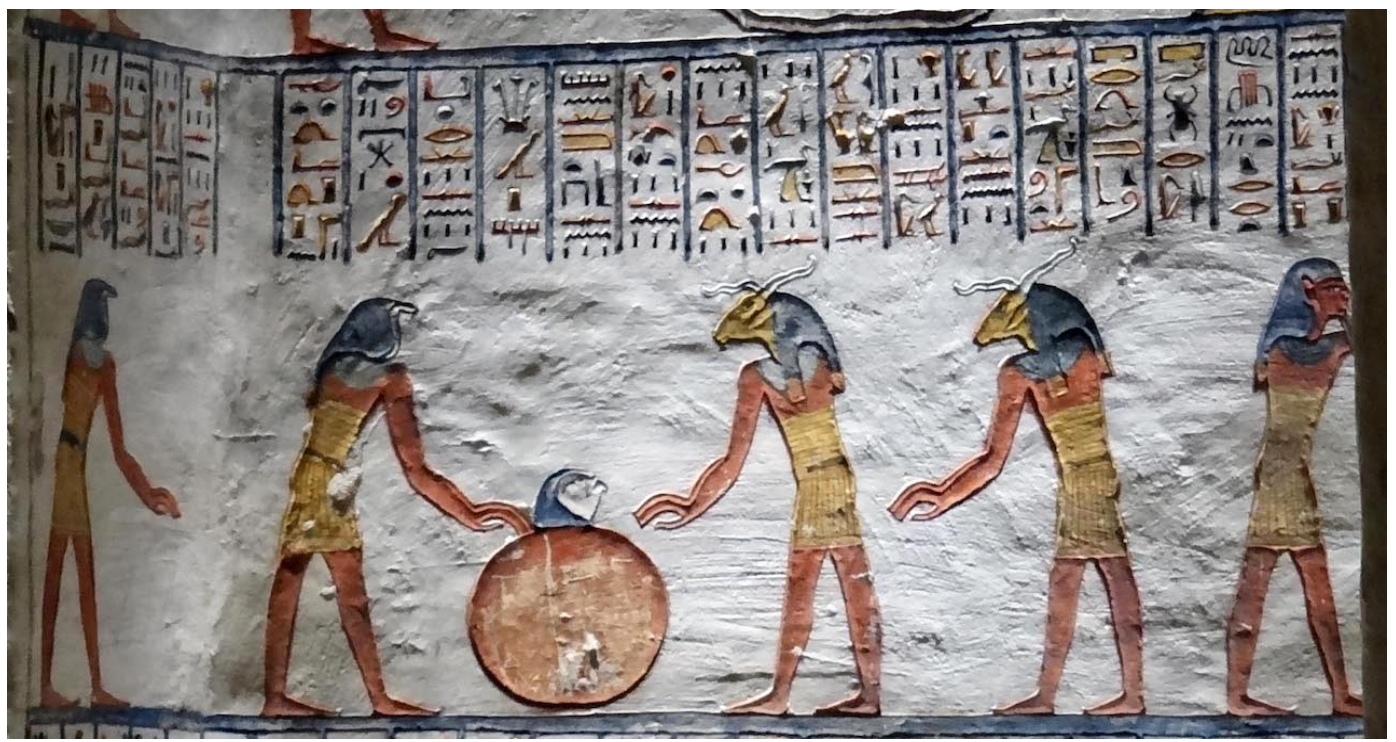

Fig. 41. Scène C 2, détail du mur ouest de la chambre funéraire de Ramsès VI. C) PLEUGER, 2018.

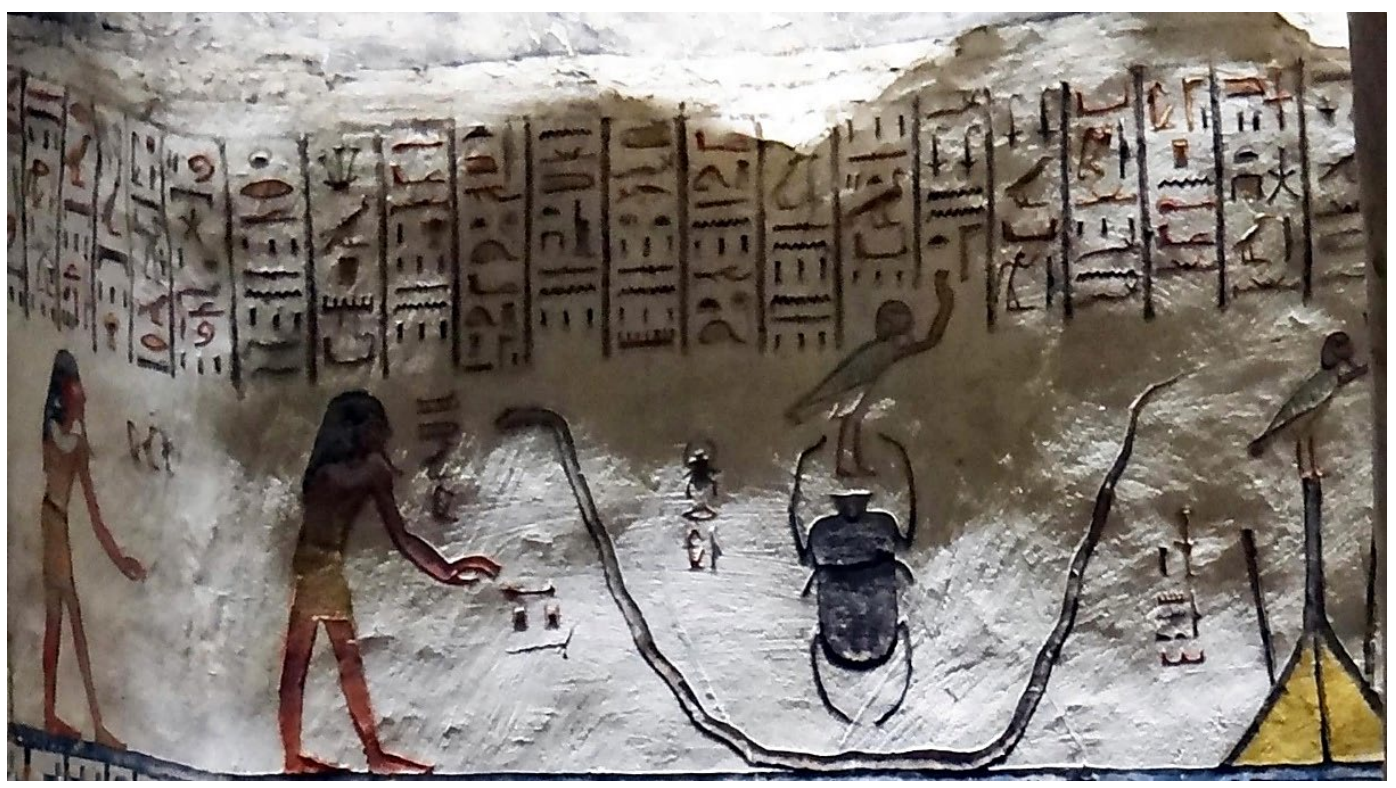

Fig. 42. Scène C 1, détail du mur ouest de la chambre funéraire de Ramsès VI. (C PLEUGER, 2018.

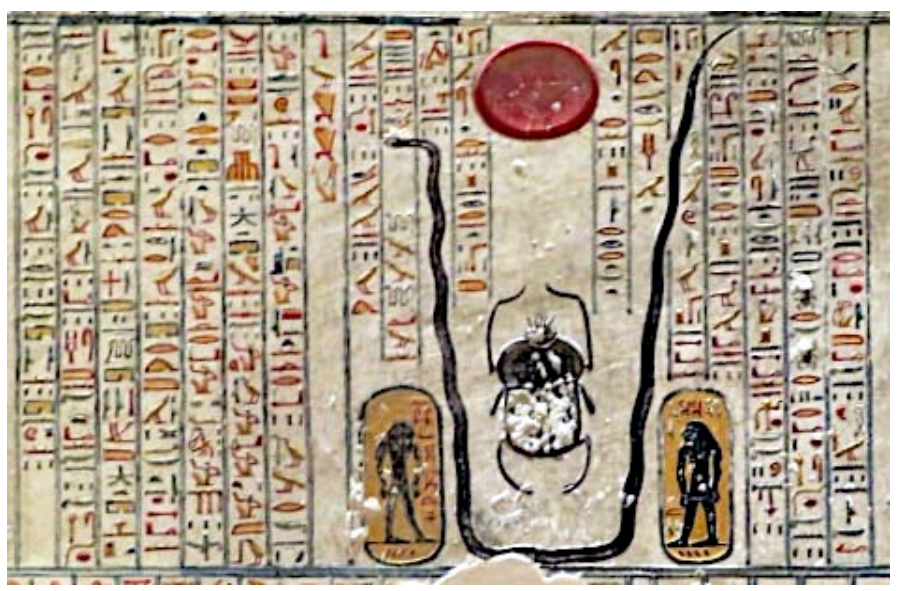

Fig. 43. Détail de la sixième heure du Livre des Cavernes dans la tombe de Ramsès VI. (C) PLEUGER, 2020. 


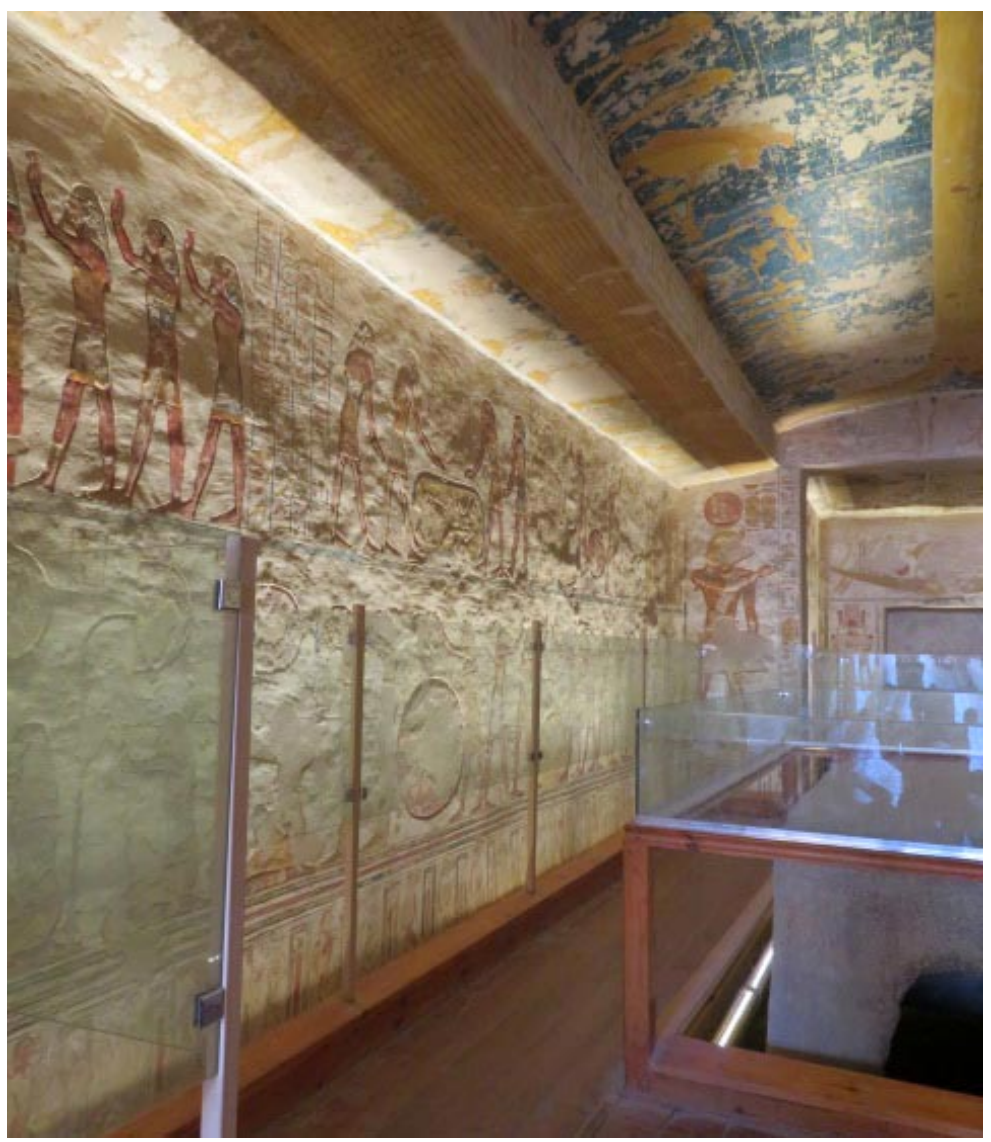

Fig. 44. Mur sud de la chambre funéraire de Ramsès VII. (C PLEUGER, 2018.

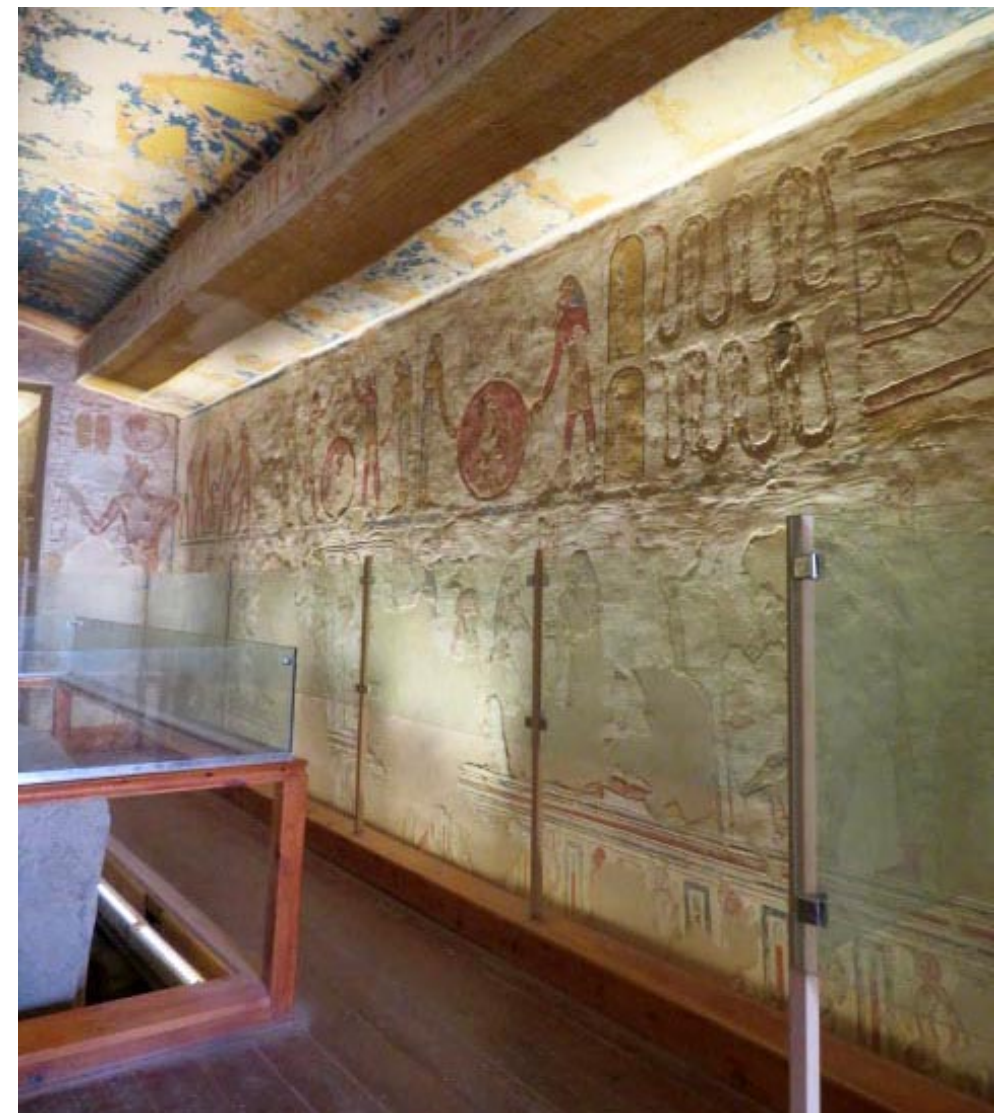

Fig. 45. Mur nord de la chambre funéraire de Ramsès VII. (C PLEUGER, 2018. 


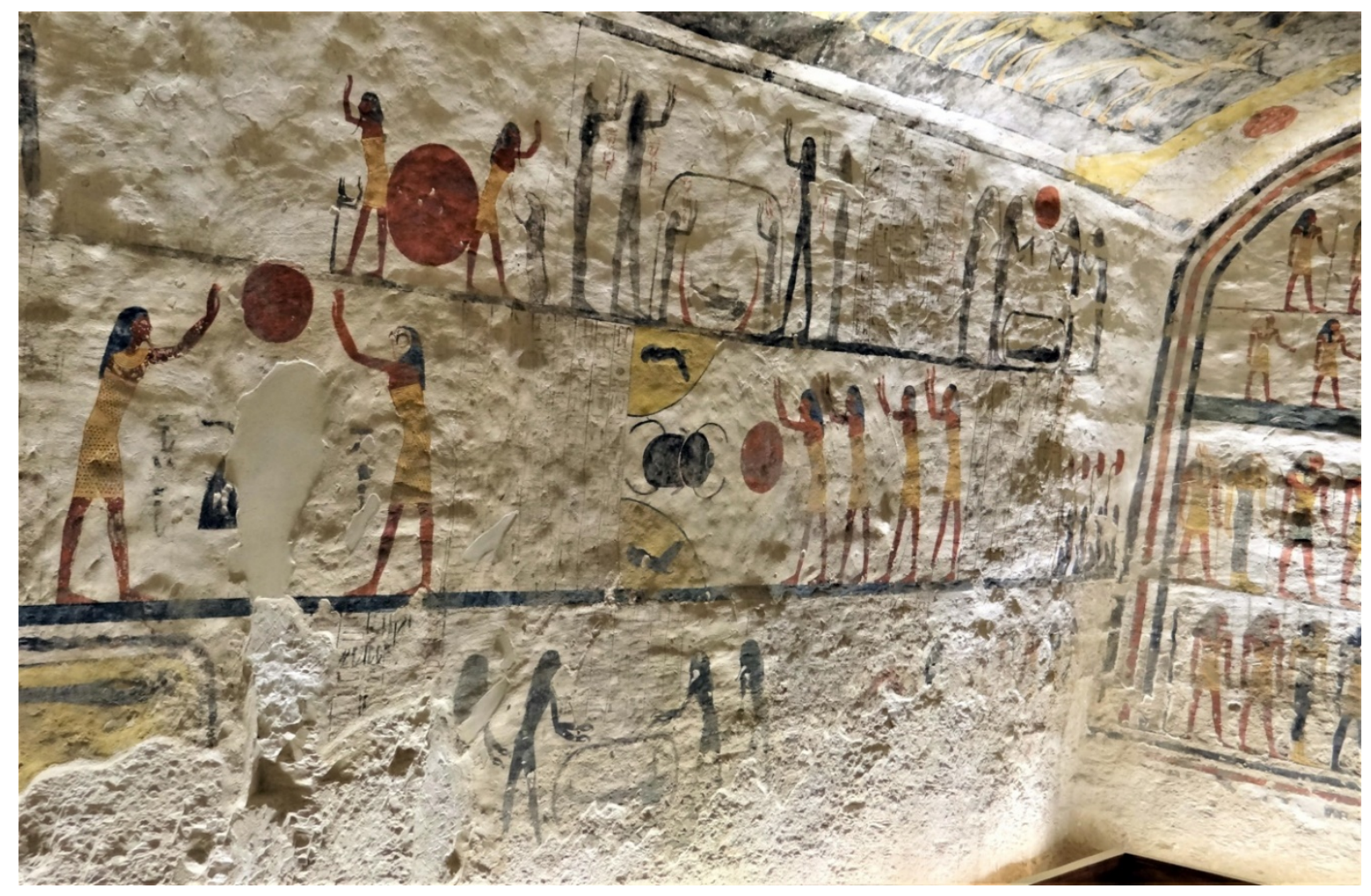

Fig. 46. Mur sud de la chambre funéraire de Ramsès IX. C PLEUGER, 2018.

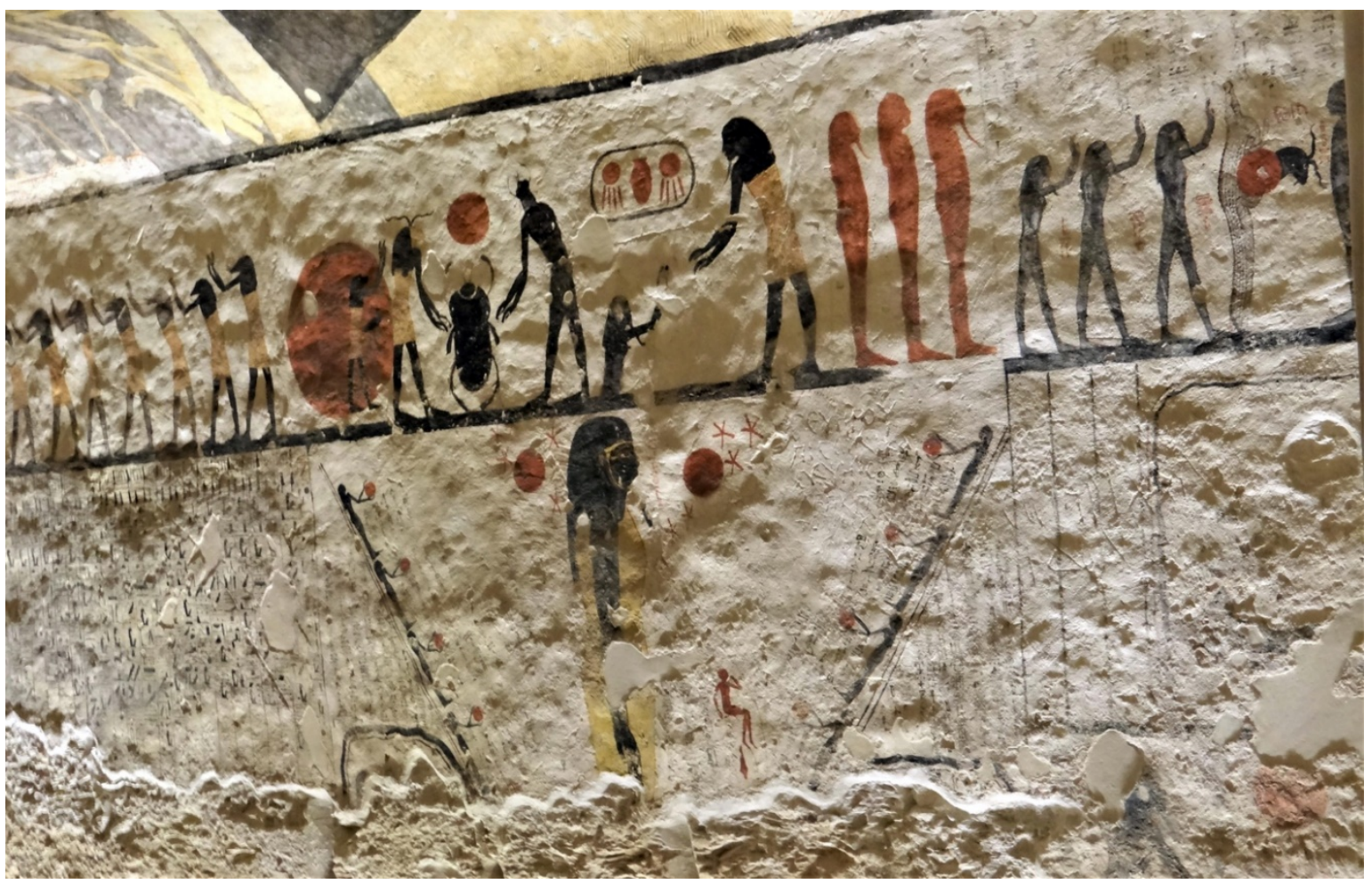

Fig. 47. Mur nord de la chambre funéraire de Ramsès IX. (C PLEUGER, 2018. 


\section{BIBLIOGRAPHIE}

ABITZ F., 1986 : Ramses III. in den Gräbern seiner Söhne (Orbis Biblicus et Orientalis, 72), Fribourg, Göttingen.

—, 1989 : «Baugeschichte und Dekoration des Grabes Ramses' VI» (Orbis Biblicus et Orientalis, 89), Fribourg.

—, 1990 : «Der Bauablauf und die Dekoration des Grabes Ramses’ IX », Studien zur Altägyptischen Kultur, 17, p. 1-40.

—, 1992 : "The Structure of the Decoration in the Tomb of Ramesses IX », dans C.N. REEVES, After Tut'ankhamun. Research and Excavations in the Royal Necropolis at Thebes, Londres, p. 165-185.

—, 1995 : Pharao als Gott in den Unterweltsbüchern des Neuen Reiches (Orbis Biblicus et Orientalis, 146), Fribourg.

AltenmüLler H., 1983 : « Das Grab der Königin Tausret im Tal der Könige von Theben: erster Vorbericht über die Arbeiten des Archäologischen Instituts der Universität Hamburg im Winter 1982-1983 », Studien zur Altägyptischen Kultur, 10, p. 1-24.

—, 1985 : «Das Grab der Königin Twosre (KV14). Bericht über eine archäologische Unternehmung », Göttinger Miszellen, 84, p. 7-17.

_, 1992 : «Bemerkungen zu den neu gefundenen Daten im Grab der Königin Twosre (KV 14) im Tal der Könige von Theben », dans C.N. REEVES (éd.), After Tut'ankhamun. Research and Excavations in the Royal Necropolis at Thebes, Londres, p. 141-164.

—, 2003 : Tauserts Weg zum Königtum. Metamorphosen einer Königin, dans R. GundLACH, U. RoesSler-KoeHler (éd.), Das Königtum der Ramessidenzeit, Akten des 3. Symposions zur ägyptischen Königsideologie in Bonn 7.-9. 6. 2001 (Ägypten und Altes Testament, 36), Wiesbaden, p. 109-128.

Assmann J., 1983 : Sonnenhymnen in thebanischen Gräbern (Theben I), Mayence.

-, 1995: Egyptian solar religion in the New Kingdom: Re, Amun and the crisis of polytheism, Londres.

—, 2001 : Mort et au-delà dans l'Égypte ancienne, Paris.

BARguet P., 1967 : Le Livre des Morts des Anciens Égyptiens (LAPO, 1), Paris.

—, 1976 : « Le Livre des Cavernes et la reconstitution du corps divin », Revue d'Égyptologie, 28 , p. 25-37.

—, 1978 : « Remarques sur quelques scènes de la salle du sarcophage de Ramsès VI », Revue d'Égyptologie, 30, p. 51-56.

BARTA W., 1987 : «Das Erdbuch oder das Buch von der Wiedergeburt aus der Sonnenscheibe », Göttinger Miszellen, 98, p. 7-9.

Brock E. C., 1992 : « The Tomb of Merenptah and its Sarcophagi », dans C.N. ReEves (éd.), After Tut'ankhamun. Research and Excavations in the Royal Necropolis at Thebes, Londres, p. 122-140. 
BuOngarzone R., 1999 : «Una nuova versione del Libro della Terra », Vicino Oriente, 11, p. 43-52.

CAMBEFORT Y., 1987: "Le scarabée dans l'Egypte ancienne. Origine et signification du symbole », Revue de l'histoire des religions, 204, p. 3-46.

CARRIER C., 2009 : Grands livres funéraires de l'Égypte pharaonique (Melchat, 1), Paris.

CARTer H., Gardiner A. H., 1917 : «The Tomb of Ramesses IV and the Turin Plan of a royal Tomb », The Journal of Egyptian Archaeology, 4, p. 130-158.

CAUVILle S., IBRAhim M. A., 2014 : La vallée des rois : itinéraire du visiteur, Louvain.

Corteggiani J.-P., 2007 : L'Égypte ancienne et ses dieux : dictionnaire illustré, Paris.

DARnell J. C., 2004 : The Enigmatic Netherworld Books of the Solar-Osirian Unity : Cryptographic Compositions in the Tombs of Tutankhamun, Ramses VI and Ramses IX (OBO, 198), Fribourg, Göttingen.

EL-SAYED R., 1981 : « Nehaher », Bulletin de l'Institut français d'archéologie orientale, 81.1, p. 119-140.

FAULKNER R. O., 1962 : A concise dictionary of Middle Egyptian, Oxford.

Frankfort H., 1933 : The Cenotaph of Seti I at Abydos (The Egypt Exploration Society, memoir 39), Londres.

Germond P., Livet J., 2001 : Bestiaire égyptien, Paris.

Guilmant F., 1907 : Le tombeau de Ramsès IX (Mémoires publiés par les membres de la mission archéologique française au Caire, XV), Le Caire.

HoRNUng E., 1972 : Die Unterweltsbücher der Ägypter, Stuttgart.

—, 1978 : Zeitliches Jenseits im alten Ägypten (Eranos-Jb 47), Francfort.

—, 1979 : Das Buch von den Pforten des Jenseits nach den Versionen des Neues Reiches, 2 vol., Genève.

—, 1981 : « Zu den Schlusszenen der Unter weltzbücher», Mitteilungen des Deutschen Archäologischen Instituts, 37, p. 217-226.

—, 1984 : « Zum Grab Ramses’ VII », Studien zur Altägyptischen Kultur, 11, p. 419-424.

—, 1990 : Zwei Ramessidische Königsgräber: Ramses IV. und Ramses VII (Theben 11), Mayence.

—, 1999 : The Ancient Egyptian Books of the Afterlife, New York.

—, 2007 : Les textes de l'au-delà dans l'Égypte ancienne, Monaco.

LEITZ C., 1989: «Die obere und die untere Dat», Zeitschrift für ägyptische Sprache und Altertumskunde, 116, p. 41-57.

—, 2002 : Lexikon der ägyptischen Götter und Götterbezeichnungen (Orientalia Lovaniensia Analecta, 110), 8 vol., Louvain.

LEPSIUS C. R., 1897 : Denkmäler aus Aegypten und Aethiopen: Text, Leipzig. 
MANASSA C., 2007: The late Egyptian underworld: sarcophagi and related texts from the Nectanebid period, Wiesbaden.

MAURIC-BARBerio F., 2004a : «Reconstitution du décor de la tombe de Ramsès III (partie inférieure) d'après les manuscrits de Robert Hay », Bulletin de l'Institut français d'archéologie orientale, 104, p. 389-456.

—, 2004b : « La tombe de Ramsès III », Égypte, Afrique \& Orient, 34, p. 15-34.

—, 2010 : « Nouvelles considérations sur le Livre de la Terre dans la tombe de Ramsès VI », Bulletin de l'Institut français d'archéologie orientale, 110, p. 175-220.

OBSOMER C., 2009 : Égyptien hiéroglyphique : grammaire pratique du moyen égyptien (Langues et cultures anciennes, 11), Bruxelles.

PIANKoff A., 1941 : «Le Livre des Quererts [1]. I $^{\text {er }}$ tableau », Bulletin de l'Institut français d'archéologie orientale, 41, p. 1-11.

—, 1942 : « Le Livre des Quererts [2] », Bulletin de l'Institut français d'archéologie orientale, 42 , p. 1-62.

—, 1943 : « Le Livre des Quererts [3]», Bulletin de l'Institut français d'archéologie orientale, 43, p. $1-50$.

—, 1945 : «Le Livre des Quererts (fin) », Bulletin de l'Institut français d'archéologie orientale, 45, p. 1-42.

—, 1946 : «Les grandes compositions de la tombe de Pédéménope », Bulletin de l'Institut français d'archéologie orientale, 46, p. 73-92.

—, 1949 : «Une représentation rare sur l'une des chapelles de Toutânkhamon », The Journal of Egyptian Archaeology, 35, p. 113-116.

_, 1953a : La création du disque solaire (Bibliothèque d'Étude, XIX), Le Caire.

—, 1953b: «Vallée des rois à Thèbes-ouest. La tombe n 1 (Ramsès VII) », Annales du service des antiquités de l'Égypte, 55, p. 145-162.

—, 1954 : The Tomb of Ramesses VI, 2 vols. Egyptian Religious Textes and Representations 1 (Bollingen Series 40), New York.

—, 1958 : «La tombe n¹ (Ramsès VII) », Annales du Service des Antiquités de l'Égypte, 55, p. $145-156$.

—, 1961 : Le Livre des Portes II. Texte (Mémoires publiés par les membres de l'Institut Français d'Archéologie Orientale du Caire, 75), Fasc. 1, Le Caire.

—, 1962 : Le Livre des Portes III. Texte (Mémoires publiés par les membres de l'Institut Français d'Archéologie Orientale du Caire, 90), Le Caire.

Piccione P. A., 1990 : «Mehen, Mysteries, and Ressurection from the Coiled Serpent », Journal of the American Research Center in Egyt, 27, p. 43-53.

Posener G., 1998 : Dictionnaire de la civilisation égyptienne, Paris.

ReEves N., Wilikinson R. H., 2005 : The Complete Valley of the Kings. Tombs and Treasures of Egypt's Greatest Pharaohs, Le Caire. 
Roberson J.A., 2007 : "An Enigmatic Wall from the Cenotaph of Seti I at Abydos », Journal of the American Research Center in Egypt, 43, p. 93-112.

—, 2007 : The Book of the Earth: A Study of Ancient Egyptian Symbol-System and Evolution of New Kingdom Cosmographic Models, UMI.

—, 2012 : The Ancient Egyptian Books of the Earth, Atlanta.

SchlöGl H. A., 1980 : Der Gott Tatenen : Nach Texten und Bildern des Neuen Reiches (Orbis Biblicus et Orientalis, 29), Fribourg, Göttingen.

SCHULER F., 2005 : Le Livre de l'Amdouat, Paris.

SERVAJEAN F., 2007 : Djet et Neheh. Une histoire du temps égyptien, Montpellier.

—, 2017 : «Le monument d'éternité de Nakhtamon à Deir el-Medina. Une tombe monochrome (TT 335) de l'époque de Ramsès II », dans À l'œuvre on reconnaît l'artisan... de pharaon! Un siècle de recherches française à Deir el-Medina (1917-2017), Milan, p. 249-273.

STRICKER B. H., 1989 : De Geboorte van Horus, 5 (Mededelingen en verhandelingen van het vooraziatisch egyptisch genootschap « Ex. Oriente lux », 26), Leyde.

—, 1994 : «The Enemies of Re II. The Textual Tradition », Discussions in Egyptology, 28, p. $95-122$.

TRAUneCKER C., 2009 : «Le palais funéraire de Padiamenopé redécouvert (TT 33)», Égypte, Afrique \& Orient, 51, p. 15-48.

Traunecker C. et Regen I., 2016 : «La tombe du prêtre Padiaménopé (TT 33) : éclairage nouveau », Bulletin de la société française d'égyptologie, 193-194, p. 52-83.

TRAuneCKer C. et RÉgen I., 2018 : «La tombe d'un intellectuel dans la Thèbes des divines adoratrices », dans F. Gombert-Meurice, F. Payraudeau (éd.), Servir les dieux d'Égypte : divines adoratrices, chanteuses et prêtres d'Amon à Thèbes, Paris, p. 60-63.

WiLkInSON R. H., 2003 : The Complete Gods and Goddesses of Ancient Egypt, Le Caire.

VoloKhINE Y., 2014: Le porc en Égypte ancienne: mythes et histoire à l'origine des interdits alimentaires, Liège. 


\section{RÉSUMÉ}

Le Livre de la Terre est une composition funéraire attestée pour la première fois à la $\mathrm{XIX}^{\mathrm{e}}$ dynastie, dans l'Osireion d'Abydos. Il est visible sur les parois des chambres funéraires de plusieurs tombes ramessides de la Vallée des Rois. Identifié et étudié depuis 1946, ce « livre » est composé de textes richement illustrés, dont le sens de lecture et la signification font toujours débat. Aucun exemplaire ne semble être complet, tandis que les textes et légendes des scènes paraissent assez corrompus, ce qui ne facilite pas l'interprétation globale de la composition. L'objectif de cet article est d'éclairer, sur base de l'analyse d'une sélection de scènes et de textes significatifs, le sens de lecture du Livre de la Terre afin de déterminer le rôle de celui-ci au sein de la chambre sépulcrale.

\section{ABSTRACT}

The Book of Earth is a funerary composition first documented during the XIX ${ }^{\text {th }}$ dynasty in the Osireion at Abydos. It is visible on the walls of burial chambers of several Ramessides tombs from the Valley of the Kings. Identified and studied since 1946, the " book » is composed of richly illustrated texts, whose reading direction and the signification are still up for debate. None of the copies seem to be complete, whereas the texts and the scenes captions appear to be relatively corrupted, which does not facilitate the global interpretation of the composition. The purpose of this paper is to determine the reading direction of the Book of the Earth, based on the analysis of a selection of scenes and significant captions, in order to establish its role within the burial chamber. 